\title{
THREE ESSAYS ON ECONOMICS OF HIGHER EDUCATION
}

A Dissertation
presented to
the Faculty of the Graduate School
at the University of Missouri-Columbia
In Partial Fulfillment
of the Requirements for the Degree
Doctor of Philosophy
DIYI LI
Dr. Cory Koedel, Dissertation Supervisor
MAY 2019


The undersigned, appointed by the dean of the Graduate School, have examined the dissertation entitled

\section{THREE ESSAYS ON ECONOMICS OF HIGHER EDUCATION}

presented by Diyi Li, a candidate for the degree of Doctor of Philosophy of Economics, and hereby certify that, in their opinion, it is worthy of acceptance.

Cory Koedel

Peter Mueser

David M. Kaplan

Bradley R. Curs 


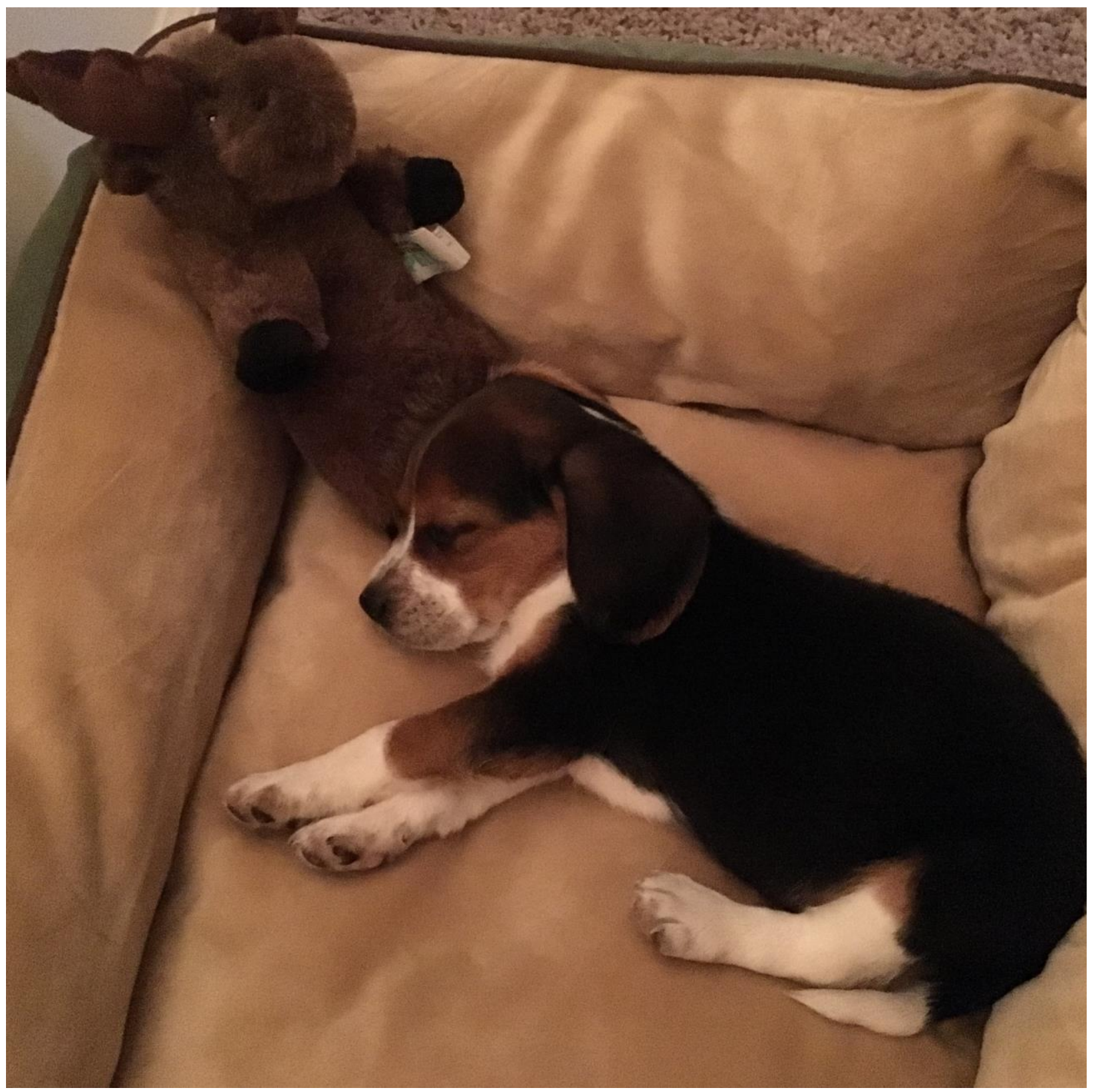

This one is for Donut, for she makes me a better human being. 


\section{ACKNOWLEDGEMENTS}

I would like to sincerely thank my academic advisor, Dr. Cory Koedel, for being the greatest advisor I could ever ask for. I would also like to thank my research supervisor, Dr. Mark Ehlert and my dissertation committee members, Dr. Peter Mueser, Dr. David Kaplan and Dr. Bradley Curs for their support on my dissertation research. 
TABLE OF CONTENTS

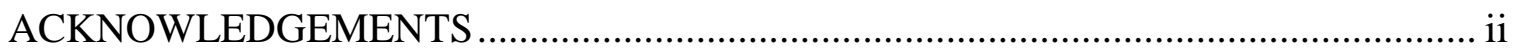

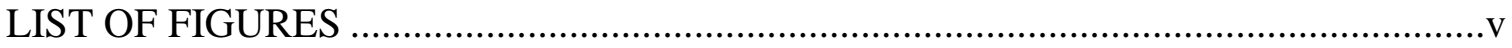

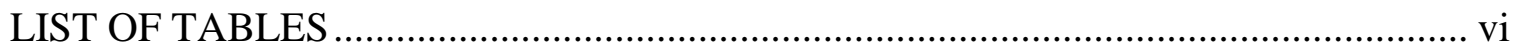

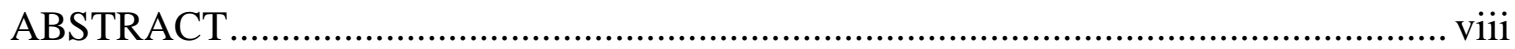

CHAPTER

1. REPRESENTATION AND SALARY GAPS BY RACE/ETHNICITY AND

GENDER AT SELECTIVE PUBLIC UNIVERSITIES .....................................1

Introduction

Data

Racial/Ethnic and Gender Representation among Faculty

Wage Decompositions

Discussion \& Conclusion

2. THE EFFECT OF NON-RESIDENT ENROLLMENT GROWTH ON IN-STATE

COLLEGE STUDENTS

Introduction

Non-Resident Enrollment Growth at MU

Data

Empirical Strategy

Results

Robustness

Extensions

Concluding Remarks

3. CHANGES IN STUDENT DEMAND FOR MAJORS AND FACULTY INVESTMENT

Introduction 
Data

Empirical Analysis and Results

Robustness Tests

Concluding Remarks

APPENDIX

A. SUPPLEMENTARY FIGURES AND TABLES FOR CHAPTER 1 ...............80

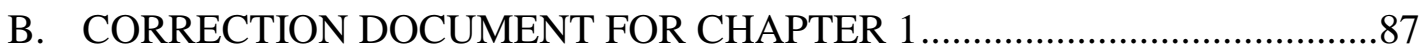

C. SUPPLEMENTARY TABLES FOR CHAPTER 2 .....................................91

D. SUPPLEMENTARY FIGURES AND TABLES FOR CHAPTER 3 .............97

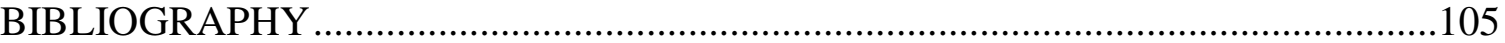

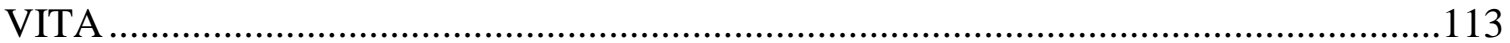




\section{LIST OF FIGURES}

Figure

1.1 Faculty Representation by Field, Split by Assistant and Associate/Full Professors and STEM (biology, chemistry, economics) and non-STEM (educational leadership/policy,

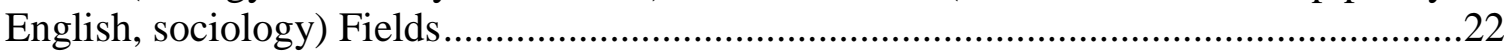

2.1 Freshman Enrollment Trends at MU by Residency Status .....................................55

2.2 Comparison between In-state Freshman Enrollment at MU and Number of High

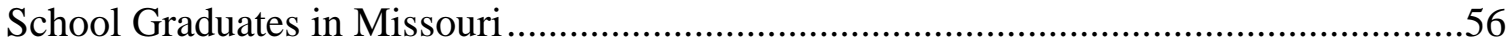

2.3 Pre-entry Qualifications of In-State Freshman Students at MU ...............................57

3.1 Trends of Freshman Enrollment and Bachelor's Degrees Conferred at MU..............75

3.2 Number and Total Annual Salaries of Faculty at MU .........................................76

3.3 Relationships between the Annual Growths in Freshman Enrollment and Faculty

Size, with Faculty Population Weighting ............................................................. 77

3.4 Relationships between the Annual Growths in Freshman Enrollment and Total Salaries of Faculty, with Faculty Population Weighting .............................................78

A.1 Replication of Figure 1.1, Including Non-Tenure-Track Teaching Faculty ...............80

D.1 Relationships between the Annual Growths in Bachelor's Degrees and Faculty Size, with Faculty Population Weighting .....................................................................97

D.2 Relationships between the Annual Growths in Bachelor's Degrees and Total Salaries of Faculty, with Faculty Population Weighting ............................................................98

D.3 Relationships between the Annual Growths in Freshman Enrollment and Faculty

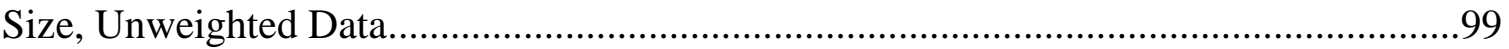

D.4 Relationships between the Annual Growths in Freshman Enrollment and Total Salaries of Faculty, Unweighted Data

D.5 Relationships between the Cumulative Growths in Freshman Enrollment and Faculty Size between Two Periods, with Faculty Population Weighting. 101

D.6 Relationships between the Cumulative Growths in Freshman Enrollment and Total Salaries of Faculty between Two Periods, with Faculty Population Weighting. 102 


\section{LIST OF TABLES}

Table

1.1 Descriptive Statistics for Our Sample

1.2 Comparison of Racial/Ethnic and Gender Representation in Our Data and IPEDS;

Sample Percentages

1.3 Faculty Diversity by Field and U.S. Population Diversity (Percentages)

1.4 Comparison of Race/Ethnicity and Gender Representation by Field in $\mathrm{PhD}$

Production Data from the Survey of Earned Doctorates at Top-50 Universities, and

Among Assistant Professors in Our Data (Percentages).

1.5 Wage Regressions

1.6 Decompositions of Wage Gaps by Race/Ethnicity and Gender .28

2.1 Descriptive Statistics of Each Residency Group ..................................................58

2.2 Validation Tests of Endogenous Student Sorting

2.3 Estimates of the Effects of Non-Resident Enrollment Growth on Third-Year

Outcomes for In-State Students

2.4 Continuous Treatment Differences-in-Differences Model Estimates of the Effects of Out-of-State and Foreign Enrollment Growth on Third-Year Outcomes for In-State Students.

2.5 Robustness Tests for the Main Estimates of the Effects of Non-Resident Enrollment Growth on Third-Year Outcomes for In-State Students

2.6 Continuous Treatment Differences-in-Differences Model Estimates of the Effects of Non-Resident Enrollment Growth on Third-Year Outcomes for In-state Students, by Gender and Race.

2.7 Binned Model Estimates of the Effects of Out-of-State and Foreign Enrollment Growth on Third-Year Outcomes for In-State Students

3.1 Output from Regressions of Faculty Resources on Freshman Enrollment

A.1 Sample of Universities and Departments

A.2 Descriptive Statistics for Our Sample, by Field.....

A.3 Output from a Regression of an Indicator for Missing Wage Data on Observable Faculty Characteristics 
A.4 Replication of Table 1.5, Including Non-Tenure-Track Teaching Faculty

A.5 Extensions of Wage Regressions from Table 1.5 that (A) Include Faculty Rank as Independent Variable Vector (Assistant, Associate, Full), (B) Include All Three Scopus@ Measures of Research Productivity Simultaneously and (C) Include a Vector of Experience Bins in Place of the Linear Experience Control.

A.6 Full Output from the Primary Wage Regression Shown in the Last Column of Table 1.5 .

B.1 Table 1.4 CORRECTED, Comparison of Race/Ethnicity and Gender Representation by Field in PhD Production Data from the Survey of Earned Doctorates at Top-50 Universities, and Among Assistant Professors in Our Data (Percentages)

C.1 Validation Tests, Splitting Non-Resident Enrollment Share into Out-of-State and Foreign Enrollment Share

C.2 Full Output from the First-Stage Regression of the IV Model

C.3 Comparison of Number and Annual Salary of Faculty between Top and Bottom Quartile Majors of Out-of-State Enrollment Growth.

C.4 Full Output from Panel A in Table 2.3

C.5 Estimates of the Effects of Non-Resident Enrollment Growth on Third-Year Outcomes for In-State Students, Using 2008-2014 Subsample

C.6 Continuous Treatment Differences-in-Differences Model Estimates of the Effects of Non-Resident Enrollment Growth on 6-Year Graduation Outcomes for In-State Students, Using 2004-2010 Subsample .96

D.1 Summary Statistics for Regression Analyses.

D.2 Output from Regressions of Faculty Resources on Number of Bachelor's Degrees Conferred 


\begin{abstract}
This dissertation consists of three chapters. In Chapter 1, we use data from the 2015-16 academic year to document faculty representation and wage gaps by race/ethnicity and gender in six fields at 40 selective, public universities. Consistent with widely available information, black, Hispanic, and female professors are underrepresented and white and Asian professors are overrepresented in our data. We show that disadvantaged-minority and female underrepresentation is driven predominantly by underrepresentation in STEM fields. A comparison of senior and junior faculty suggests a trend toward greater diversity in academia along racial/ethnic and gender lines, especially in STEM fields, because younger faculty are more diverse. However, black faculty are an exception; there is little indication that their representation is improving among young faculty. We decompose racial/ethnic and gender wage gaps and show that three observed factors account for most or all of the gaps: academic field, experience, and research productivity. We find no evidence of wage premiums for individuals who improve racial/ethnic and gender diversity, although for black faculty we cannot rule out a modest premium.

In Chapter 2, I use student-level administrative data from a state flagship university to study the effect of changes in non-resident enrollment on in-state student outcomes. I leverage within-major and cross-time variation in non-resident enrollment using a differences-in-differences framework. I find no evidence of negative effects of nonresident enrollment growth on third-year persistence or performance outcomes for in-state students. Moreover, there is no effect heterogeneity by in-state student gender or race. There is some evidence of effect heterogeneity when I split total non-resident enrollment
\end{abstract}


into (a) out-of-state domestic enrollment and (b) foreign enrollment. Specifically, the results reveal no adverse effects of out-of-state domestic enrollment growth on in-state students for any outcome measure. However, although it is modest in magnitude, there is some evidence that increasing foreign enrollment has negative effects on the postsecondary persistence of in-state students.

In Chapter 3, I construct an 11-year data panel of academic departments at a state flagship university to study the relationship between changes in student demand for majors and investment in faculty resources. Larger numbers of freshmen declaring a major, and large numbers of bachelor's degrees conferred, are both associated with more faculty and more salary expenditures on faculty. However, using various specifications of growth, I find no evidence that growth in student demand for majors is associated with growth in faculty, or faculty salary expenditures. 


\section{Chapter 1}

\section{Representation and Salary Gaps by Race/Ethnicity and Gender at Selective Public Universities}

\subsection{Introduction}

Recent unrest at college campuses across the United States has put renewed focus on the issue of faculty diversity. Student organizations at numerous universities have issued demands of administrators that call for a more explicit focus on recruiting disadvantaged minority and female faculty. For example, The Legion of Black Collegians at the University of Missouri has demanded an increase in the percentage of black faculty and staff campus-wide to 10 percent by 2017-18. Similarly-spirited demands have been made by groups at many universities, including “Who's Teaching Us?” at Stanford University, "Liberate MSU" at Michigan State University, and "The Irate 8" at the University of Cincinnati, among others.

Although it is straightforward to obtain aggregate data on faculty representation at universities (e.g., from a source like the Integrated Postsecondary Education Data System), contemporary policy discussions would benefit from more detailed information. For example, it would be useful to know how faculty diversity compares across fields, and whether universities are behaving in a way consistent with placing independent value on a faculty member's contribution to workforce diversity. To inform these questions, we use new data to examine racial/ethnic and gender diversity, and wage gaps, at 40 selective public universities. Our data cover faculty in six academic departments that we selected to be inclusive of STEM and non-STEM fields - biology, chemistry, economics, educational 
leadership and policy, English, and sociology - and are taken from the 2015-16 academic

year.

Our analysis of faculty representation overall reveals anticipated results: black, Hispanic, and female faculty are underrepresented relative to their U.S. population shares; while Asian, white, and male faculty are overrepresented. ${ }^{1}$ When we break our results out by field, the underrepresentation of black, Hispanic, and female faculty is shown to be driven predominantly by underrepresentation in STEM fields (biology, chemistry, and economics). ${ }^{2}$ In non-STEM fields (educational leadership and policy, English, and sociology) the degree of underrepresentation of black, Hispanic and female faculty declines substantially, and in some cases these groups are not underrepresented at all. ${ }^{3}$ Patterns of race/ethnicity and gender representation by field in our faculty data generally align with analogous representation patterns in field-specific $\mathrm{PhD}$ production data.

\footnotetext{
${ }^{1}$ We identify faculty as "black" rather than "African American" throughout our study in acknowledgment of black faculty from other countries who may be included in our data.

${ }^{2}$ We classify economics as a STEM field, as in Nelson and Brammer (2010). Although the classification of economics may not seem as obvious as the other fields, economics is a mathematically-oriented field and empirically it has more in common with STEM than non-STEM fields in terms of student and faculty composition. For example, Arcidiacono and Koedel (2014) find that incoming economics majors are similar to other STEM entrants in terms of pre-entry qualifications. In addition, Butcher, McEwan, and Weerapana (2014) and Koedel (2011) document that the grade distributions in economics courses align with grade distributions in other STEM fields and differ from grade distributions in non-STEM fields. Data from the 2016 Science and Engineering Indicators report published by the National Science Foundation (National Science Board, 2016) also show that enrollment patterns in economics share key features with other STEM fields that are not shared by non-STEM fields, most notably a sharp increase in foreignstudent enrollment and a decline in the proportion of bachelor's degrees awarded to women (see Chapter 2 in particular). Ceci et al. (2014) also illustrate the similarity of economics with other STEM fields. ${ }^{3}$ We were surprised that a direct comparison of faculty representation in STEM and non-STEM fields is unavailable in the modern academic literature. The most recent comparable information we found is from Glover, Parsad, and Zimbler (2002), who document faculty representation across departments using survey data from the 1999 National Study of Postsecondary Faculty (NSOPF). Several other studies provide related information but do not directly compare STEM/non-STEM faculty representation. For example, Nelson and Brammer (2010) document STEM representation in the top-100 departments in 15 STEM disciplines, but do not collect non-STEM data. Freeman (1977) documents the within-race shares of black and white faculty across fields, but not cross-race shares within fields (Freeman's data are also over 40 years old).
} 
We also examine faculty representation by rank. Comparing assistant professors to their senior colleagues provides insight into the future of faculty diversity. Our findings suggest that a more diverse workforce is building in higher education. Assistant professors are less likely to be white and more likely to be Asian and Hispanic, and less likely to be male, than associate and full professors. Evidence of increasing diversity among junior faculty is apparent in all of the fields we study, and particularly in STEM (also see Nelson and Brammer, 2010). The exception is for black faculty - while the representation of black faculty in non-STEM fields is improving modestly, in STEM fields black faculty are just as underrepresented among junior faculty as they are among senior faculty.

Finally, we document and decompose faculty wage gaps by race/ethnicity and gender. Unconditionally, black and Hispanic faculty have significantly lower annual earnings than white faculty, and to a lesser extent Asian faculty. Our decompositions indicate that three observable factors can entirely explain racial/ethnic wage gaps: academic field, work experience, and research productivity. These same three factors account for a large fraction of the gender wage gap as well; however, unlike with the racial/ethnic gaps, they do not fully explain wage differences by gender.

In a concluding section we briefly discuss the policy implications of our study. A simple takeaway is that STEM and non-STEM fields exhibit very different diversity conditions, which merits consideration in the design of policies to increase faculty diversity. Our wage decompositions identify the key factors that account for differences in faculty wages across racial/ethnic and gender groups, which can be used to guide policies aimed at mitigating these differences. Finally, our analysis of wages give no indication of a wage premium for faculty who contribute to workforce diversity. This result is 
inconsistent with a model in which a faculty member's contribution to diversity is valued as an independent contributor to productivity, although it could also reflect a lack of wage flexibility along race and gender lines afforded to universities even in the presence of an explicit valuation on diversity.

\subsection{Data}

Our sample consists of faculty from 40 selective public universities ranked highly by the 2016 U.S. News and World Report, as listed in Appendix A. ${ }^{4}$ We collected data from faculty rosters as published on department websites at the sampled universities during the 2015-16 academic year. The data were collected manually, and as such it was not feasible to include all faculty at all 40 universities. Instead, we used a sampling strategy focusing on faculty in the six above-described academic departments. We selected three of the six departments at random at each university, and for each selected department we collected data from every faculty member listed on the department website whose position involved at least some teaching. ${ }^{5}$ We focus our primary analysis on tenure-track faculty, but show

\footnotetext{
${ }^{4}$ Our initial objective was to include the 40 highest-ranked public universities in the U.S. News rankings, but we excluded seven universities in the top- 40 because wage data were not readily available or were available but difficult to interpret. As an example of the latter, during our data collection timeframe the state of Alabama reported wages on a paycheck-by-paycheck basis and it was not straightforward to aggregate the information. We also skipped two University of California schools (UC Davis and UC Santa Cruz) to minimize the overrepresentation of California universities in our data, which are disproportionately highly ranked. To confirm that our findings are not sensitive to which universities are in the sample, in results omitted for brevity we perform a sensitivity exercise where we randomly drop four universities from the sample (10 percent of universities) and replicate our analysis. We do this five times and across the five iterations our findings are qualitatively similar to what we report below. Thus, we conclude that small-to-moderate fluctuations in the list of universities included in our study do not influence the findings.

${ }^{5}$ More specifically, we assigned a random number to each department and pulled data from the three departments within each university that had the highest numbers. One issue that came up is that universities sometimes house multiple biology-related departments. For example, the University of California-Santa Barbara has departments of ecology, evolution and marine biology; and molecular, cellular and developmental biology. When "biology" was a randomly selected department at such universities, we collected data from faculty in all departments that confer the undergraduate biology degree (in the UCSanta Barbara example, both departments confer the degree).
} 
results that include non-tenure-track teaching faculty in Appendix B. Appendix A documents the departments at each university that are included in our analytic sample.

Our use of data from all listed faculty members in each university-by-department cell we sampled offers an important advantage over survey-based studies, where individual respondents may choose not to participate. Of direct relevance to our research questions, Bollinger et al. (2014) show that survey response rates can differ by race; and moreover, correlate differentially with earnings outcomes for men and women. This type of selfselection into survey participation raises questions about the ability of survey data to inform the questions we pursue. The most widely used data to study faculty wages in previous research comes from the National Study of Postsecondary Faculty (NSOPF) administered by the National Center for Education Statistics (NCES), which was discontinued in 200304. The 2003-04 NSOPF faculty survey had a response rate of 76 percent.

For each sampled university-by-department cell, we collected data on faculty demographics, qualifications, salaries, and measures of research productivity. Table 1.1 provides descriptive statistics for our dataset of tenure-track faculty (Appendix Table B.1 further breaks out the descriptive statistics by field). Note that although we evenly sampled departments across universities (subject to random sampling variability - see Appendix A), faculty in our data are disproportionately in STEM fields. This is because academic departments in these fields tend to be larger.

Wage data for faculty at most public universities are published by government agencies and freely accessible. Our aim was to collect data on base pay for faculty in each state. While in many states base pay is clearly labeled in agency reports, this is not always the case. Thus, in some states it may be that the earnings data include some supplemental 
salary. Although our sense is that this is rare, it is a source of measurement error in the wage data. That said, empirically we do not anticipate this causing a significant problem because we use wages as the dependent variable in our analysis of earnings and in addition, our wage regressions include university fixed effects that will net out wage-reporting differences across states on average. Moreover, despite this potential limitation, our wage data offer a number of benefits over survey data - which have been commonly used in previous, similar research to obtain faculty wage information - including (a) what is likely to be a significant reduction in measurement error owing to mistakes in self-reporting and (b) our ability to mitigate the potential for selective responses correlated with earnings (Bollinger et al., 2014) by pulling data from all faculty in sampled departments.

Of all tenure-track faculty included on the rosters we sample, wage data were available for 94 percent. The primary reason for missing wage data - and in fact the only reason we can identify given the comprehensive nature of wage reporting for public employees - is that the faculty member is new to the university or was on leave and did not draw a salary during the previous year. This generates missing data because wage data are posted by government agencies with a lag. Consistent with this explanation, in Appendix Table A.3 we show that being a young professor is by far the strongest predictor of missing wage data. ${ }^{6}$

The qualification data we collected include the faculty member's rank, years of experience, and the prestige of the $\mathrm{PhD}$ granting institution. Ideally, and for most faculty,

\footnotetext{
${ }^{6}$ Appendix Table A.3 reports results from a regression of an indicator variable for missing wages on faculty characteristics. The regression results reveal several differences between faculty with and without wage data, which derive primarily from the seniority difference. The one non-seniority related difference is that English professors are marginally less likely to have wage data, but this difference pales in comparison to the seniority-driven differences.
} 
we measure experience from the year the $\mathrm{PhD}$ was obtained as reported on faculty websites or CVs. In cases where a faculty member's profile does not indicate the year of the $\mathrm{PhD}$, we measure experience by the time since the first registered publication, either on the faculty member's website (first choice) or Scopus $($ ) (second choice). Between these various sources, we obtain experience measures for 98 percent of our sample. ${ }^{7}$ The $\mathrm{PhD}$ granting institution is taken from each faculty member's profile and is available for 94 percent of faculty. We divide $\mathrm{PhD}$-granting institutions into four groups based on their ranking in U.S. News and World Report, inclusive of private universities, as shown in Table 1.1.

We collected research-productivity data from Scopus $@$ including the number of publications, number of citations, and h-index for each faculty member. For each metric, we create standardized measures of productivity within fields as follows:

$\tilde{P}_{i j}=\frac{P_{i j}-\bar{P}_{j}}{\sigma_{j}}$

where $\tilde{P}_{i j}$ is the standardized measure for faculty member $i$ in field $j, P_{i j}$ is the raw measure, and $\bar{P}_{j}$ and $\sigma_{j}$ are the sample average and standard deviation in field $j$, respectively. The standardization allows for different distributions of productivity metrics across fields. While all of our metrics are imperfect measures of research productivity (Perry and Reny, 2016), below we show that they explain a substantial fraction of faculty

\footnotetext{
${ }^{7}$ We use experience as a control variable in wage regressions below. A concern is that for faculty who do not list the year of the $\mathrm{PhD}$, our approximation of experience based on the first publication likely introduces measurement error into the experience variable. In a robustness test omitted for brevity, we confirm that our findings are qualitatively insensitive to restricting the sample for the wage regressions to the 77 percent of faculty who list the year of the $\mathrm{PhD}$ on their website or $\mathrm{CV}$, indicating that measurement error generated by our imperfect experience proxies does not unduly influence our results.
} 
wages and of racial/ethnic and gender wage gaps. Of the three measures, the h-index is the strongest single predictor of wages.

The most important elements in our dataset are the demographic measures - i.e., the racial/ethnic and gender designations. While such measures are straightforward to obtain in respondent-driven datasets given their self-reported nature, obtaining these designations in our case is more complicated. In short, we relied on visual inspections of faculty pictures (found on faculty websites and elsewhere on the internet as available), origins of names, and in some cases biographical details (e.g., the country of the undergraduate institution listed on the $\mathrm{CV}$ ) to assign racial/ethnic and gender designations to faculty. We group faculty into one of five possible race/ethnicity categories: black, Asian, Hispanic, white, and other/unknown. We use three gender groups: male, female, and unknown.

We could speculatively debate the conceptual merits of our approach to collecting race/ethnicity and gender designations in some detail. One notable point is that unlike datasets that rely on respondents' own input, our designations are best described as race/ethnicity and gender "appearance measures." This approach has both benefits and costs given our research objectives. Rather than delving into an extended conceptual discussion, we evaluate our data empirically. ${ }^{8}$ Specifically, we ask how well the racial/ethnic and gender shares in our data compare to related available numbers.

\footnotetext{
${ }^{8}$ The conceptual discussion is important but beyond the scope of the present article. Briefly, the issue is that given the nature of our measures, there will surely be instances where we have identified someone as one race/ethnicity but they would self-identify differently. This brings up the sensitive topic of perceived versus self-identified race, which has a long history in the United States and elsewhere, and remains policy relevant contemporarily. For example, the Brazilian government recently set up controversial boards charged with externally determining an individual's race in affirmative action cases, rather than relying on self-reported race (Garcia-Navarro, 2016). For the purposes of our study, the key empirical point is that our appearance measures line up well with self-identified measures from other sources (namely IPEDS; see below).
} 
Table 1.2 compares the race/ethnicity and gender shares in our data with data from the Integrated Postsecondary Education Data System (IPEDS) from 2014 (i.e., the most recently available data from IPEDS). IPEDS data can be used to measure faculty diversity at universities but the data are not broken out by field. We compare the race/ethnicity and gender shares in our full sample to the full IPEDS sample of Research-I universities, and to IPEDS data from the same 40 institutions we study. Overall, the race/ethnicity and gender shares in our data are a close match to the IPEDS shares, particularly when one recognizes that we sample a small and selected fraction of the academic departments upon which the IPEDS numbers are based. ${ }^{9}$

While the comparisons in Table 1.2 are of some comfort and suggest that our data are broadly consistent with related data from other sources, surely there are some inaccuracies. To quantify the scope for errors in our data, we examine the inter-rater reliability of faculty designations by using two different raters to code race/ethnicity and gender designations for 400 faculty in our dataset. This exercise yields high inter-rater reliabilities. For the racial/ethnic designations inter-rater reliability is 95.5 percent; for the gender designations it is 99.75 percent (i.e., 1 inconsistency in 400).

\subsection{Racial/Ethnic and Gender Representation Among Faculty}

Table 1.3 shows field-specific race/ethnicity and gender representation in our data. We also show population shares using data from the 2010 Census as one point of

\footnotetext{
${ }^{9}$ The shares of underrepresented minorities in biology, chemistry, and economics in our data also align closely with shares reported for the same fields by Nelson and Brammer (2010) (Nelson and Brammer do not study non-STEM fields). However, we hesitate to draw too strong of inference from this comparison because their sample includes selective private universities and is therefore less comparable to our publicuniversity sample.
} 
comparison for the faculty representation numbers. Another useful comparison is to the pool of qualified workers, which we address below in Table 1.4.

Starting with Table 1.3, our data highlight a stark contrast dividing the STEM fields - biology, chemistry, and economics - and non-STEM fields - educational leadership and policy, English, and sociology. Black and Hispanic representation in STEM ranges from 0.7-2.9 and 2.5-5.1 percent across fields, respectively; versus 8.8-15.1 and 4.2-7.8 percent across non-STEM fields. Particularly for black faculty, the representation differences between STEM and non-STEM fields are large. Gender representation follows a similar pattern - female representation ranges from 18.1-31.1 percent in STEM fields and 47.153.2 in non-STEM fields.

In Figure 1.1, we provide complementary information to Table 1.3 by documenting differences in representation in STEM and non-STEM fields between assistant and associate/full professors. The rank separation is of interest for two reasons. First, representation at the assistant-professor level can be viewed as a leading indicator of faculty diversity in the future. ${ }^{10}$ The comparison reveals that representation of Asian, Hispanic and female faculty among assistant professors is significantly higher than among associate/full professors, particularly in STEM fields. However, for black faculty, while there is a modest increase in representation in non-STEM fields, there is no indication of diversity progress in STEM in the assistant professor data.

The second benefit of focusing on assistant professors is that it allows us to connect representation among young faculty to recent $\mathrm{PhD}$ production rates by field, as indicated

\footnotetext{
${ }^{10}$ A potential caveat is that differential persistence across ranks, by group, may dull projected diversity changes. Available evidence suggests differential persistence among modern young faculty will be limited (e.g., see Ceci et al., 2014; Ginther et al., 2010; Ginther and Kahn, forthcoming). An exception is that there remain substantial promotion gaps by gender in economics (Ceci et al., 2014).
} 
by the Survey of Earned Doctorates (SED) from the National Center for Science and Engineering Statistics (NCSES). The SED is a national survey of recent doctoral recipients. In Table 1.4, we show PhD production rates by race/ethnicity, gender, and field for U.S. citizens and permanent residents from the SED, which we compare to racial/ethnic and gender shares among assistant professors in our data. ${ }^{11}$ Because the selective public universities in our sample are likely to draw primary from selective programs for new hires, we limit the SED production data to include only universities in the top-50 of the U.S. News rankings, inclusive of private universities. The SED data are taken from the 2013-14 academic year; $\mathrm{PhD}$ production rates in 2013-14 should be highly relevant for assistant professors in 2015-2016. ${ }^{12}$

The patterns in the SED data broadly reflect patterns in our assistant professor data. This points toward the $\mathrm{PhD}$ pipeline as a key source of racial/ethnic and gender imbalance among faculty (also see Ginther et al., 2010), but there are some points of divergence. For instance, even conditional on $\mathrm{PhD}$ production rates, black faculty are consistently underrepresented as assistant professors in STEM fields at the selective universities we study. Alternatively, they are overrepresented among assistant professors relative to their $\mathrm{PhD}$ production rates in all three non-STEM fields (albeit only marginally in educational leadership and policy). The picture for Hispanic faculty is mixed and while there is variability across fields, no indication of systematic over- or under-representation among assistant professors relative to $\mathrm{PhD}$ degree production is apparent. Asian faculty are

\footnotetext{
${ }^{11}$ Field-level $\mathrm{PhD}$ production shares in the SED are only reported for U.S. citizens and permanent residents. We thank Mark Fiegener for assistance with the SED data.

${ }^{12}$ In results omitted for brevity we also collected data on $\mathrm{PhD}$-production shares overall (i.e., where we do not condition on the selectivity of the $\mathrm{PhD}$-granting institution). A comparison to these broader production rates yields qualitatively similar insights, although $\mathrm{PhD}$ production at less-selective institutions is somewhat more diverse.
} 
significantly overrepresented as assistant professors relative to domestic degree-production rates in all fields except in sociology. Some of the overrepresentation of Asians among junior faculty is surely driven by in-migration of students from other countries into domestic PhD programs, which is not accounted for in the SED numbers (as noted above, the SED only reports $\mathrm{PhD}$ production rates by field for U.S. citizens and permanent residents). White faculty are overrepresented relative to $\mathrm{PhD}$ production in biology, and to a lesser extent educational leadership and policy; but underrepresented in all other fields, most notably in economics. In terms of gender, representation among assistant professors relative to $\mathrm{PhD}$ production rates varies somewhat across fields but is generally fairly even, and no consistent gender gaps emerge along STEM/non-STEM lines. [This text is unmodified from the published version of our article in Educational Researcher, but as noted in a subsequent correction, there was a consequential error in the reported gender shares from our data in the published version of Table 1.4. We have not changed the text in this document so that it matches the published version, but note that our inference regarding gender disparities relative to $\mathrm{PhD}$ production rates is not accurate based on the corrected version of Table 1.4: female representation among assistant professors in our data is meaningfully below female representation among PhDs in STEM fields (but not in non-STEM fields). Please see our correction document (Appendix B) for details.]

\subsection{Wage Decompositions}

In this section we decompose racial/ethnic and gender wage gaps into their observed components using the method of Gelbach (2016). The foundation of our decompositions is the following linear regression model:

$Y_{i j k}=\beta_{0}+\boldsymbol{X}_{i j k} \boldsymbol{\beta}_{\mathbf{1}}+\boldsymbol{R}_{\boldsymbol{i}} \boldsymbol{\beta}_{\mathbf{2}}+\boldsymbol{G}_{\boldsymbol{i}} \boldsymbol{\beta}_{\mathbf{3}}+\delta_{j}+\theta_{k}+\varepsilon_{i j k}$ 
In Equation (1.2), $Y_{i j k}$ is the annual salary for faculty member $i$ at university $j$ in field $k$, in dollars. ${ }^{13} \boldsymbol{X}_{\boldsymbol{i j k}}$ is a vector of faculty qualifications and measures of research productivity, $\boldsymbol{R}_{\boldsymbol{i}}$ a vector of indicators for the racial/ethnic designation of faculty member $i$ where white faculty are the omitted group, $\boldsymbol{G}_{\boldsymbol{i}}$ a vector of indicators for gender designation where males are omitted (i.e., there are indicators for whether the faculty member is female and whether gender is unknown), $\delta_{j}$ a university fixed effect, $\theta_{k}$ a field fixed effect, and $\varepsilon_{i j k}$ an idiosyncratic error term. We cluster our standard errors at the university level.

The $X$-vector includes years of experience, Scopus $\bigodot$ measures of research productivity, and indicators for the prestige of the $\mathrm{PhD}$-granting institution. Recall from Section 1.2 that the experience information comes from several different sources; our regressions also include indicator variables to identify the source of the experience data. ${ }^{14}$ Of the three normalized productivity measures from Scopus@, we include just the h-index in our preferred wage models, as it is the most predictive over wages. We interact the normalized h-index with field indicators to allow for differential returns to productivity across disciplines. In Appendix Table A.5 we confirm that our wage-gap findings are qualitatively unaffected if we include all three Scopus@ measures simultaneously in the model. Finally, for the prestige of the Phd-granting institution, we use the categories shown in Table 1.1 to divide universities. We also include missing-data indicators as appropriate in cases where some data elements are unavailable for individual faculty. ${ }^{15}$

\footnotetext{
${ }^{13}$ In our preferred models we use raw wages as the dependent variable but none of our findings are qualitatively sensitive to using the natural log of wages.

${ }^{14}$ In our main specification experience enters linearly. In Appendix Table A.5 we verify that our findings are qualitatively robust to including experience in a more flexible manner.

${ }^{15}$ We exclude faculty rank from the $X$-vector in Equation (1.2), although as a practical matter including rank does not substantively affect our findings (see Appendix Table A.5).
} 
Table 1.5 shows racial/ethnic and gender wage differences estimated from progressively detailed models. Column (1) reports unconditional wage gaps from a model that excludes the $X$-vector and university and field fixed effects. Column (2) adds university fixed effects, column (3) adds field fixed effects, column (4) adds the prestige of the PhD-granting institution, column (5) adds experience, and column (6) adds the normalized h-index interacted with field, which fills out the full model as shown in Equation (1.2). We include individuals with unknown race/ethnicity and gender for completeness in the models; however, as indicated by Table 1.1, they account for a very small fraction of our sample (less than 0.5 percent) and thus strong inference is not warranted. The coefficients for the control variables are omitted from Table 1.5 for brevity but provided for interested readers in Appendix Table A.6.

Column (1) of Table 1.5 shows that unconditional wage gaps favor white faculty and men, who are the omitted groups. In the racial/ethnic comparisons, black and Hispanic faculty have significantly lower wages than white faculty, on the order of roughly $\$ 10$ 15,000 annually, or $8-12$ percent of the average wage $(\$ 120,195$; see Table 1.1$)$. The unconditional gender gap is larger, at just over $\$ 23,000$. The table shows that racial/ethnic and gender gaps moderate as more information is included in the model. In the final column the racial/ethnic gaps disappear. In fact, they nominally favor black and Hispanic faculty relative to white faculty, although the differences are not statistically significant. The gender gap attenuates significantly after including available controls, but remains statistically significant at about $\$ 4,000$. These results are consistent with previous, related evidence. $^{16}$

\footnotetext{
${ }^{16}$ Our finding for current faculty that racial/ethnic wage gaps can be explained by observed factors is generally in line with previous findings using older data in Porter, Toutkoushian, and Moore (2008) and
} 
Next, in order to understand the factors that drive observed wage gaps, we decompose the gaps into the following components: (1) differences in universities, (2) differences in fields, (3) differences in experience, (4) differences in the prestige of the $\mathrm{PhD}$ granting institution, and (5) differences in research productivity. It may be tempting to read across the columns in Table 1.5 to assess the relative importance of these factors. However, this can be misleading because the order by which the variables are added can affect their implied explanatory significance. Gelbach (2016) shows that a number of previous high-profile studies have inaccurately estimated component weights in various decomposition exercises by relying on sequence-dependent methods. The sequenceinvariant method developed by Gelbach (2016) and used in our study solves this problem.

The key feature of Gelbach's approach that makes it order invariant is that the parameter estimates upon which the decomposition is based come only from of the full specification. Intermediary specifications are ignored. We illustrate following Gelbach's notation. Suppose we have an $n x l$ outcome vector, $\mathbf{Y}$, and two $n x k$ matrices of independent variables, $\mathbf{X}_{\mathbf{1}}$ and $\mathbf{X}_{\mathbf{2}}$, where $\mathbf{X}_{\mathbf{1}}$ includes the group indicator variables (i.e., indicators for the groups between which we want to decompose outcomes) and the constant and $\mathbf{X}_{\mathbf{2}}$ includes other covariates. Define $\widehat{\boldsymbol{\beta}}_{\mathbf{1}}^{\text {base }}$ as the estimated coefficients on $\mathbf{X}_{\mathbf{1}}$ in a baseline specification that excludes the covariates in $\mathbf{X}_{\mathbf{2}}$, and $\widehat{\boldsymbol{\beta}}_{\mathbf{1}}^{\text {full }}$ and $\widehat{\boldsymbol{\beta}}_{\mathbf{2}}$ the estimated coefficients on $\mathbf{X}_{\mathbf{1}}$ and $\mathbf{X}_{\mathbf{2}}$ in the full specification. Gelbach notes that the difference between $\widehat{\boldsymbol{\beta}}_{\mathbf{1}}^{\text {base }}$ and $\widehat{\boldsymbol{\beta}}_{\mathbf{1}}^{\text {full }}$ is algebraically identical to the following sample omitted variables bias formula: ${ }^{17}$

Toutkoushian, Bellas, and Moore (2007). Similarly, Ginther and Hayes (2003), Porter, Toutkoushian, and Moore, (2008), and Toutkoushian, Bellas, and Moore (2007) find unexplained gender gaps even after conditioning on observable factors.

${ }^{17} \widehat{\boldsymbol{\beta}}_{1}^{\text {base }}$ and $\widehat{\boldsymbol{\beta}}_{1}^{\text {full }}$ in our application are as reported in column (1) and column (6) of Table 1.5 , respectively. 
$\widehat{\boldsymbol{\beta}}_{1}^{\text {base }}=\widehat{\boldsymbol{\beta}}_{1}^{\text {full }}+\left(\mathbf{X}_{1}^{\prime} \mathbf{X}_{1}\right)^{-1} \mathbf{X}_{1}^{\prime} \mathbf{X}_{2} \widehat{\boldsymbol{\beta}}_{2}$

Thus, decomposing this formula is equivalent to decomposing the differences between the restricted- and full-model coefficients of interest:

$\widehat{\boldsymbol{\delta}} \equiv \widehat{\boldsymbol{\beta}}_{1}^{\text {base }}-\widehat{\boldsymbol{\beta}}_{1}^{\text {full }}=\left(\mathbf{X}_{1}^{\prime} \mathbf{X}_{1}\right)^{-1} \mathbf{X}_{1}^{\prime} \mathbf{X}_{\mathbf{2}} \widehat{\boldsymbol{\beta}}_{2}$

Defining $\mathbf{X}_{\mathbf{2}}$ as the column of observations of the $k^{\text {th }}$ covariate in $\mathbf{X}_{\mathbf{2}}$, Equation (1.4) indicates that the portion of sample omitted variable bias $\left(\widehat{\boldsymbol{\delta}}_{\mathbf{k}}\right)$ due to $\mathbf{X}_{\mathbf{2 k}}$ consists of two components: a) $\widehat{\boldsymbol{\Gamma}_{\mathbf{k}}}=\left(\mathbf{X}_{\mathbf{1}}^{\prime} \mathbf{X}_{\mathbf{1}}\right)^{-1} \mathbf{X}_{\mathbf{1}}^{\prime} \mathbf{X}_{\mathbf{2} \mathbf{k}}$, which is the estimated OLS coefficient from a regression of $\mathbf{X}_{\mathbf{2 k}}$ on $\mathbf{X}_{\mathbf{1}}$; and b) $\hat{\beta}_{2 k}$, which is the estimated coefficient on $\mathbf{X}_{\mathbf{2 k}}$ from the original, full specification. As a specific example consider our interest in how experience explains the gender wage gap among faculty. Intuitively, Equation (1.4) tells us that the explanatory power of experience depends on two factors: whether average experience differs by gender and whether years of experience conditionally influences salary.

We decompose racial/ethnic and gender wage gaps into five covariate groups: university, field, experience, prestige of the $\mathrm{PhD}$-granting institution, and research productivity. When the number of covariates is large as in our study, Gelbach proposes a way to simplify the computation process. First note that for covariate group $g$, the explained wage gap is $\widehat{\boldsymbol{\delta}}^{\mathbf{g}}=\sum_{\mathrm{k} \in \text { group g }} \widehat{\boldsymbol{\delta}}_{\mathbf{k}}$. Defining a "heterogeneity variable" for each individual, $\widehat{H}_{k(i)}=X_{2 k(i)}^{\prime} \hat{\beta}_{2 k}$, which reflects the estimated share of individual $i$ 's outcome attributable to the $k^{\text {th }}$ covariate, and summing over the covariates in group $g$ (note that $\left(\mathbf{X}_{\mathbf{1}}^{\prime} \mathbf{X}_{\mathbf{1}}\right)^{-1} \mathbf{X}_{\mathbf{1}}^{\prime}$ does not vary with the index $k$ ), yields:

$$
\begin{aligned}
\widehat{\boldsymbol{\delta}}^{\mathbf{g}} & =\sum_{\mathrm{k} \in \text { group g }} \widehat{\boldsymbol{\delta}}_{\mathbf{k}} \\
& =\left(\mathbf{X}_{\mathbf{1}}^{\prime} \mathbf{X}_{\mathbf{1}}\right)^{-1} \mathbf{X}_{\mathbf{1}}^{\prime} \sum_{\mathrm{k} \in \text { group g }} \widehat{\mathbf{H}}_{\mathbf{k}}
\end{aligned}
$$


The values in Equation (1.5), which capture the explanatory power for each group of covariates, $g$, can be recovered by applying the following procedure as outlined by Gelbach (2016, pp. 523):

1. Estimate the full model (in our application, this is the model shown in the last column of Table 1.5).

2. For each faculty observation $i$, sum the contributions of the decomposition covariates $\widehat{H}_{k(i)}=X_{2 k(i)}^{\prime} \hat{\beta}_{2 k}$ for each group of covariates to get $\widehat{H}_{g(i)}=$ $\sum_{\mathrm{k} \in \text { group g }} \widehat{H}_{k(i)}$. This step creates the set of "heterogeneity variables" for each faculty member indicating the estimated share of wages attributable to each group of covariates.

3. In auxiliary OLS regressions, regress the heterogeneity variables $\widehat{H}_{g(i)}$ from step 2 on the variables of interest $\mathbf{X}_{\mathbf{1}}$ (the race and gender indicators); these OLS estimates are as expressed by Equation (1.5). ${ }^{18}$

Table 1.6 shows results for our decompositions of wage gaps for black, Asian, and Hispanic faculty relative to white faculty; and for women relative to men. ${ }^{19}$ Negative numbers in the table correspond to factors that exacerbate the gaps, positive numbers indicate factors that shrink them. At the bottom of Table 1.6 we show the percentage of each unconditional wage gap explained by the observable factors in our dataset. Values in excess of 100 percent reflect cases where the direction of the gap changes going from

\footnotetext{
${ }^{18}$ The preceding paragraphs briefly summarize material in Gelbach (2016) - additional details can be found in his paper. Gelbach (2016) also shows that this method nests the Oaxaca-Blinder decomposition, which under some assumptions can lead to additional insights about sources of unequal outcomes across groups. Also see Toutkoushian and Hoffman (2002) for more information about decomposition methods.

${ }^{19}$ We do not decompose wage gaps for the groups with unknown race/ethnicity or gender because our sample sizes are too small for these groups to be informative (see Table 1.1).
} 
column (1) to column (6) of Table $1.5 .{ }^{20}$ Values below 100 percent indicate that the observable factors in our data are insufficient to fully explain the wage difference.

The decompositions identify three factors that primarily explain observed wage gaps by race/ethnicity and gender: (1) academic field, (2) experience, and (3) research productivity. Although there is some variability in the importance of these factors across the gaps we consider, all three are generally important. ${ }^{21}$ To elaborate briefly, field differences account for a substantial portion of the higher wages of white relative to black faculty, and men relative to women, but do not explain the wage gap between Hispanics and whites. For the Asian-white gap, field differences contribute positively because Asians tend to be concentrated in higher-paying fields than other faculty, including whites. Consistent with data from other occupations, we find significant wage returns to experience for faculty (see Appendix Table A.6), and Table 1.6 shows that a substantial share of each wage gap we consider can be explained by the fact that white and male faculty are more experienced than other groups, as illustrated by Figure 1.1. Figure 1.1 also implies a reduced role of experience in explaining wage gaps in the future. Finally, research productivity is a consistently important factor in explaining wage gaps by race/ethnicity and gender, accounting for at least 30 percent of the total gap in each comparison we consider.

Tables 1.5 and 1.6 show that the racial/ethnic wage gaps are fully explained by the observable components in our data. On the one hand, this result is consistent with a lack of

\footnotetext{
${ }^{20}$ That is, where the unconditional gap starts out negative but conditional on observable factors becomes positive (regardless of statistical significance).

${ }^{21}$ Note that differences in the prestige of the PhD-granting institution do not explain faculty wage differences in our data (Appendix Table A.6), but this is surely driven by the fact that we condition on university of employment. If more prestigious universities place their PhD students at higher paying universities on average, this type of effect will not be reflected in our estimates.
} 
systematic bias toward specific racial/ethnic groups in hiring and wage negotiations. On the other, it is also consistent with universities placing little value on the diversity contributions of faculty per se, at least as measured by wages, although a caveat to this interpretation is that universities may be limited in how much wage flexibility they have. ${ }^{22}$ It also bears mentioning that our models do not account for teaching or service contributions. Previous research on whether minorities and women are burdened by more service requirements and/or invest more time in teaching is mixed. While some studies find that these groups take on more service and invest more in teaching (Guarino and Borden, forthcoming; Menges and Exum, 1983), others find that they do not (Olsen, Maple, and Stage, 1995; Porter, 2007).

\subsection{Discussion \& Conclusion}

We use recent data from the 2015-16 academic year to examine faculty representation and wage gaps at 40 selective public universities. Our study focuses on six academic departments: biology, chemistry, economics, educational leadership and policy, English, and sociology. We show that the underrepresentation of black, Hispanic and female professors among faculty in these departments overall is driven predominantly by a lack of diversity in STEM fields. Non-STEM fields are much more diverse. Younger cohorts of faculty are more diverse than their senior colleagues in most respects, which projects for improved faculty diversity in the future. The trend toward diversity is particularly apparent in STEM fields. However, black faculty are an exception - younger

\footnotetext{
${ }^{22}$ Given that universities may be constrained in their ability to manipulate wages to reflect diversity preferences, we also examined whether faculty who improve diversity receive their $\mathrm{PhDs}$ from less selective institutions than white men in our sample. With wage constraints, one way that universities could promote (and thus show that they value) diversity would be to recruit/accept faculty that improve diversity from less-selective $\mathrm{PhD}$ programs. However, conditional on being a faculty member at one of the institutions in our sample, we do not observe systematic differences in the prestige of the $\mathrm{PhD}$-granting institution across race or gender groups (results omitted for brevity).
} 
cohorts in STEM fields do not include more black faculty than older cohorts at the universities we study.

Our wage decompositions identify three observed factors that explain racial/ethnic wage gaps in their entirety, and most of the gender wage gap: (1) academic field, (2) experience, and (3) research productivity. These factors should be of focal consideration in policy efforts to ameliorate racial/ethnic and gender wage differences among faculty. We do not find any evidence of wage premiums associated with diversity per se, although for black faculty we cannot rule out a modest premium.

We conclude by briefly addressing the policy implication of our finding that diversity is particularly lacking in STEM fields. If a rationale for policies to improve faculty diversity is to provide role models for underrepresented students, and if it is presumed that students will gravitate toward such role models, the current diversity imbalance in higher education implies that students from underrepresented groups may be nudged toward lower paying, non-STEM fields. ${ }^{23}$ This would serve to perpetuate an already-existing imbalance in the workforce, both in academia and the broader labor market (e.g., also see Bayard et al., 1999; Carnavale et al., 2016). If an aim of diversifying the faculty is to promote better long-term outcomes for underrepresented students, targeted efforts to increase diversity in STEM fields may need to be an explicit objective. However,

\footnotetext{
${ }^{23}$ There is a large literature showing that racial congruence between students and faculty can influence student outcomes. Fairlie, Hoffman, and Oreopoulos (2014) show that racial congruence improves persistence and performance outcomes for underrepresented minority students at the community college level. There is also a large body of research showing that racial congruence is important for student outcomes at the K-12 level (Dee, 2004; Gershenson, Holt, and Papageorge, 2016; Grissom, Rodriguez, and Kern, 2017), and that a more diverse workforce can offer broader benefits (Cherng and Halpin, 2016). On the topic of gender congruence research is somewhat mixed, but on the whole indicates that gender congruence matters (e.g., see Bettinger and Long, 2005; Carrell, Page, and West, 2010; Ellis and Gershenson, 2016; Robst, Keil, and Russo, 1998). See Grissom, Kern, and Rodriguez (2015) for a general discussion of the value of improving workforce diversity in the education sector.
} 
STEM specific considerations do not seem to be prominent in current policy discussions on faculty diversity. ${ }^{24}$

${ }^{24}$ Diversity-related demands of numerous student groups at universities are posted online at http://www.thedemands.org/. In reviewing the lists of demands as of October 2016, we found only 2/80 lists (Beloit College, University of Puget Sound) that explicitly reference faculty diversity in STEM. 
Figure 1.1. Faculty Representation by Field, Split by Assistant and Associate/Full Professors and STEM (biology, chemistry, economics) and non-STEM (educational leadership/policy, English, sociology) Fields.

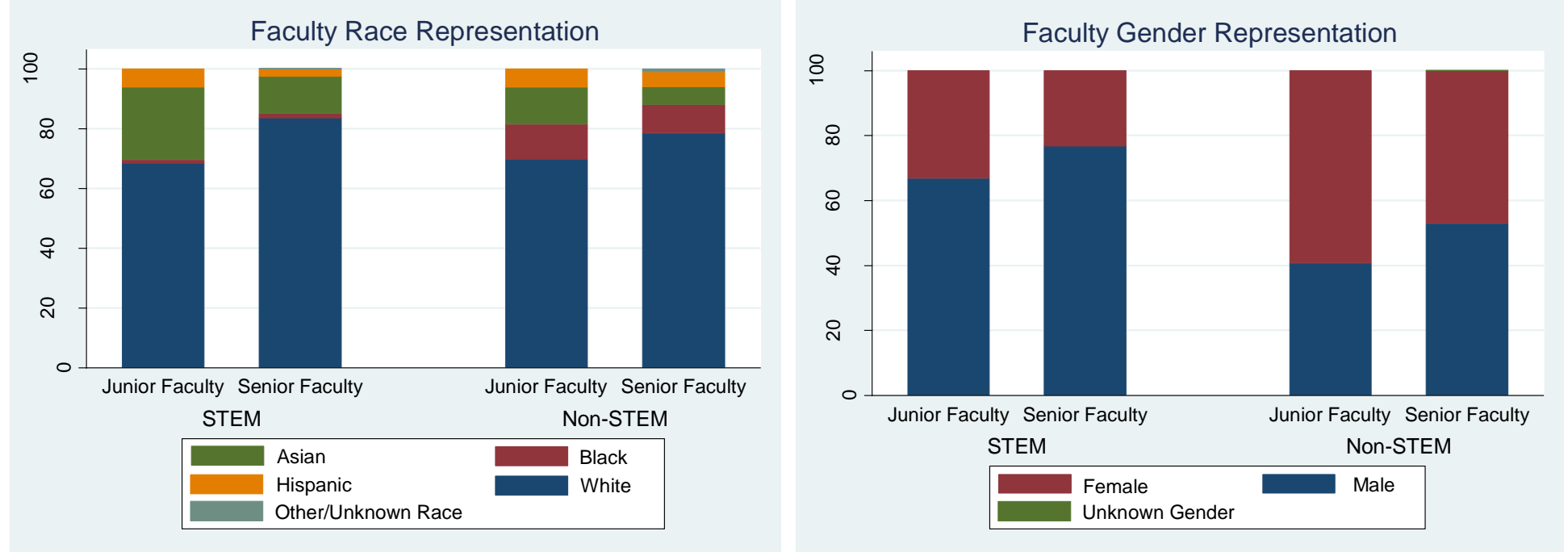

Notes: Assistant professors are coded as junior faculty and associate/full professors are coded as senior faculty. 
Table 1.1. Descriptive Statistics for Our Sample.

\begin{tabular}{|c|c|}
\hline Wage (Dollars) & $\begin{array}{c}\text { Mean (St Dev) } \\
120,194.70(52,662.41)\end{array}$ \\
\hline $\begin{array}{l}\text { Asian } \\
\text { Black } \\
\text { Hispanic } \\
\text { White } \\
\text { Race Other/Unknown }\end{array}$ & $\begin{array}{l}0.12(0.32) \\
0.05(0.21) \\
0.04(0.20) \\
0.79(0.41) \\
0.00(0.06)\end{array}$ \\
\hline $\begin{array}{l}\text { Female } \\
\text { Male } \\
\text { Gender Unknown }\end{array}$ & $\begin{array}{l}0.35(0.48) \\
0.65(0.48) \\
0.00(0.02)\end{array}$ \\
\hline $\begin{array}{l}\text { Assistant Professor } \\
\text { Associate Professor } \\
\text { Professor }\end{array}$ & $\begin{array}{l}0.20(0.40) \\
0.28(0.45) \\
0.52(0.50)\end{array}$ \\
\hline $\begin{array}{l}\text { Field: Biology } \\
\text { Field: Chemistry } \\
\text { Field: Economics } \\
\text { Field: Education Leadership/Policy } \\
\text { Field: English } \\
\text { Field: Sociology }\end{array}$ & $\begin{array}{l}0.33(0.47) \\
0.14(0.35) \\
0.14(0.34) \\
0.07(0.26) \\
0.22(0.41) \\
0.11(0.31)\end{array}$ \\
\hline $\begin{array}{l}\text { PhD School U.S. 1-10 } \\
\text { PhD School U.S. 11-50 } \\
\text { PhD School U.S. 50+ } \\
\text { PhD School Outside U.S. } \\
\text { PhD School Missing } \\
\text { No PhD (English only) }\end{array}$ & $\begin{array}{l}0.23(0.42) \\
0.33(0.47) \\
0.25(0.44) \\
0.11(0.31) \\
0.06(0.24) \\
0.01(0.12)\end{array}$ \\
\hline $\begin{array}{l}\text { Experience } \\
\text { Experience Source: CV/Website } \\
\text { Experience Source: Website (Pubs Based) } \\
\text { Experience Source: Scopus@ Publications } \\
\text { Experience Unavailable from Any Source }\end{array}$ & $\begin{array}{c}21.24(12.55) \\
0.77(0.42) \\
0.02(0.12) \\
0.19(0.39) \\
0.02(0.14)\end{array}$ \\
\hline $\begin{array}{l}\text { Scopus }{ }^{\circledR} \text { Publications } \\
\text { Scopus }{ }^{\circledR} \text { Citations } \\
\text { H-index } \\
\text { Scopus@ Missing }\end{array}$ & $\begin{array}{c}49.40(81.05) \\
2,068.73(4578.34) \\
15.44(16.04) \\
0.07(0.25)\end{array}$ \\
\hline $\mathrm{N}$ & 4,047 \\
\hline
\end{tabular}

Notes: The rankings for PhD-granting institutions are taken from the 2016 U.S. News and World Report, inclusive of private institutions. There are 56 faculty in sampled English departments who do not have a $\mathrm{PhD}$. These faculty have Master in Fine Arts (MFA) degrees instead (an MFA can be a terminal degree in the fine arts and performing arts). We report the sources of experience data where the options are (in order of our preference for where the data come from): (a) the faculty member's own profile based on the year the $\mathrm{PhD}$ was obtained, (b) the faculty member's own profile based on the year of the first publication, and (c) the year of the first publication reported in Scopus@. For two percent of faculty, we were unable to calculate experience using any of these three sources. 
Table 1.2. Comparison of Racial/Ethnic and Gender Representation in Our Data and IPEDS; Sample Percentages.

\begin{tabular}{lccc}
\hline & IPEDS: & IPEDS: & \\
Racial/Ethnic Shares & R1 Universities & Same Universities & Our Sample \\
Asian & 13.0 & 13.1 & 11.8 \\
Black & 3.6 & 3.5 & 4.7 \\
Hispanic & 4.2 & 4.1 & 4.1 \\
White & 75.7 & 75.9 & 78.9 \\
Other/Unknown & 3.5 & 3.4 & 0.4 \\
Gender Shares & & & \\
Female & 38.4 & 37.8 & 34.8 \\
Male & 61.6 & 62.2 & 65.2 \\
Unknown & 0.0 & 0.0 & 0.0 \\
N (Universities) & 108 & 40 & 40 \\
N (Faculty) & 195,606 & 82,521 & 4,047 \\
\hline
\end{tabular}

Notes: Each cell reports the percent of the sample indicated by the column that is accounted for by the group indicated by the row. In the IPEDS data, we construct a comparable "other/unknown" group for race/ethnicity by combining faculty identified as "American Indian or Alaska Native," Native Hawaiian or Other Pacific Islander," "Two or More Races" and "Race/Ethnicity Unknown." The group of faculty identified as being of two or more races contributes to the larger "other/unknown" group in the IPEDS data; there is no way for us to code such a category in our study. There is only one faculty member in our dataset for whom gender is coded as unknown (0.0002 percent). 
Table 1.3. Faculty Diversity by Field and U.S. Population Diversity (Percentages).

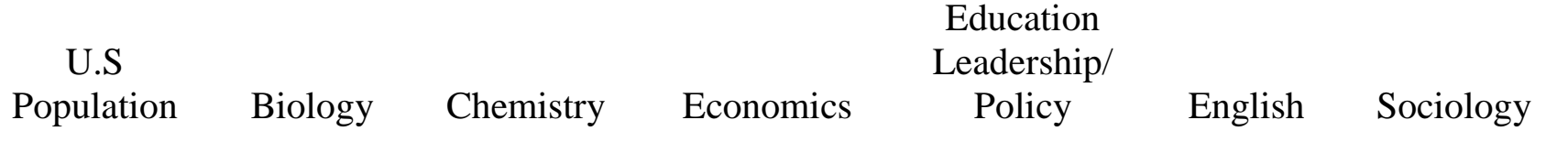

\section{Racial/Ethnic Shares}

\begin{tabular}{|c|c|c|c|c|c|c|c|}
\hline Asian & 4.7 & 12.9 & 14.4 & 20.9 & 8.5 & 5.6 & 8.4 \\
\hline Black & 12.2 & 0.7 & 1.4 & 2.9 & 15.1 & 8.8 & 8.9 \\
\hline Hispanic & 16.3 & 3.0 & 2.5 & 5.1 & 7.8 & 4.2 & 5.9 \\
\hline White & 63.7 & 83.3 & 81.7 & 70.9 & 68.7 & 79.8 & 76.6 \\
\hline own & 3.1 & 0.1 & 0.0 & 0.2 & 0.0 & 1.6 & 0.2 \\
\hline
\end{tabular}

\section{Gender Shares}

\begin{tabular}{lccccccc} 
Female & 50.8 & 31.1 & 18.1 & 19.7 & 53.2 & 48.7 & 47.1 \\
Male & 49.2 & 68.9 & 81.9 & 80.3 & 46.8 & 51.2 & 52.9 \\
Unknown & 0.0 & 0.0 & 0.0 & 0.0 & 0.0 & 0.1 & 0.0 \\
& & & & & & \\
N (Faculty) & -- & 1,325 & 569 & 554 & 284 & 888 & 427 \\
\hline
\end{tabular}

Notes: Each cell reports the percent of the sample indicated by the column that is accounted for by the group indicated by the row. The "U.S. Population" column shows racial/ethnic and gender percentages for the United States Population based on data from the 2010 United States Census. In the Census data, the "other/unknown" group consists of individuals identified as "American Indian or Alaska Native," Native Hawaiian or Other Pacific Islander," "Two or More Races," or some other race. 
Table 1.4. Comparison of Race/Ethnicity and Gender Representation by Field in PhD Production Data from the Survey of Earned Doctorates at Top-50 Universities, and Among Assistant Professors in Our Data (Percentages).

Biology Chemistry Economics $\quad$ Education

\section{Racial/Ethnic}

\section{Shares}

Asian

$13.7[20.3]$

$9.8[19.4]$

$16.8[34.2]$

(Leadership/Policy)

English

Sociology

Black

$3.6[0.4]$

$$
2.5[0.9]
$$

2.7 [2.4]

10.3 [17.5]

$5.3[12.8]$

12.2 [6.9]

Hispanic

6.2 [3.6]

6.8 [6.5]

5.0 [11.0]

15.5 [15.9]

1.8 [8.6]

3.9 [13.7]

White

70.6 [75.8]

74.7 [73.2]

70.0 [52.4]

7.2 [4.8]

8.5 [4.3]

8.3 [11.0]

Other/Unknown

$5.9[0.0]$

$6.2[0.0]$

$5.5[0.0]$

58.8 [61.9]

78.9 [74.4]

71.7 [61.5]

$8.2[0.0]$

$5.5[0.0]$

$3.9[0.0]$

\section{Gender Shares}

Female

$\begin{array}{lll}53.7[53.2] & 38.3[40.2] & 29.9[34.4] \\ 46.1[46.8] & 61.6[59.8] & 69.9[65.6]\end{array}$

63.1 [59.3]

54.3 [62.1]

63.8 [59.7]

Male

$0.2[0.0]$

$0.1[0.0]$

0.2 [0.0]

36.9 [40.7]

45.7 [37.9]

36.2 [40.3]

Unknown

3,506 [281]

1,020 [108]

581 [164]

$0.0[0.0]$

$0.0[0.0]$

$0.0[0.0]$

Notes: The first number in each cell is the SED percentage of degrees produced by field in 2013-14 at top-50 universities; the second number is square brackets the percentage of assistant professors in that field in our data from 2015-16. The SED data are restricted to doctorate recipients who graduated from universities on the U.S. News \& World Report "Best Colleges 2016" list of top-50 universities, inclusive of private universities.

[AUTHOR NOTE: THIS TABLE IS SHOWN AS PUBLISHED IN EDUCATIONAL RESEARCHER. AFTER PUBLICATION, WE BECAME AWARE OF ERRORS, PERTAINING PRIMARILY TO THE REPORTED GENDER SHARES AMONG ASSISTANT PROFESSORS IN OUR DATA, AND ISSUED A CORRECTION. PLEASE SEE THE ISSUED CORRECTION FOR DETAILS. INCORRECT VALUES ARE IN GREEN FONT ABOVE. 
Table 1.5. Wage Regressions.

\begin{tabular}{|c|c|c|c|c|c|c|}
\hline & (1) & (2) & (3) & (4) & (5) & (6) \\
\hline Asian & $\begin{array}{c}-\$ 6,589.14^{* *} \\
(2,795.01)\end{array}$ & $\begin{array}{c}-\$ 8,807.52 * * \\
(2,404.42)\end{array}$ & $\begin{array}{c}-\$ 13,919.52 * * \\
(2,333.07)\end{array}$ & $\begin{array}{c}-\$ 13,768.82 * * \\
(2,366.01)\end{array}$ & $\begin{array}{l}-\$ 2,206.89 \\
(1,998.44)\end{array}$ & $\begin{array}{l}-\$ 1,409.96 \\
(1,798.85)\end{array}$ \\
\hline Black & $\begin{array}{c}-\$ 14,469.94 * * \\
(3,898.22)\end{array}$ & $\begin{array}{c}-\$ 12,500.94 * * \\
(3,786.86)\end{array}$ & $\begin{array}{c}-\$ 8,318.78 * * \\
(3,934.62)\end{array}$ & $\begin{array}{c}-\$ 8,227.01 * * \\
(3,836.33)\end{array}$ & $\begin{array}{c}-\$ 1,956.08 \\
(3,236.47)\end{array}$ & $\begin{array}{l}\$ 3,316.14 \\
(3,218.97)\end{array}$ \\
\hline Hispanic & $\begin{array}{c}-\$ 10,949.26 * * \\
(2,998.61)\end{array}$ & $\begin{array}{c}-\$ 17,455.09 * * \\
(2,945.34)\end{array}$ & $\begin{array}{c}-\$ 16,229.58 * * \\
(2,640.69)\end{array}$ & $\begin{array}{c}-\$ 15,932.78 * * \\
(2,664.85)\end{array}$ & $\begin{array}{c}-\$ 4,178.76^{*} \\
(2,437.24)\end{array}$ & $\begin{array}{l}\$ 1,201.72 \\
(2,148.95)\end{array}$ \\
\hline Race Other/Unknown & $\begin{array}{c}-\$ 25,391.18^{* *} \\
(6,994.90)\end{array}$ & $\begin{array}{c}-\$ 17,259.17 * * \\
(6,046.08)\end{array}$ & $\begin{array}{l}-\$ 9,092.63 \\
(5,812.28)\end{array}$ & $\begin{array}{l}-\$ 9,189.97 \\
(5,465.85)\end{array}$ & $\begin{array}{l}-\$ 4,416.81 \\
(7,130.42)\end{array}$ & $\begin{array}{l}-\$ 3,001.76 \\
(5,063.69)\end{array}$ \\
\hline Female & $\begin{array}{c}-\$ 23,319.91 * * \\
(1,944.86)\end{array}$ & $\begin{array}{c}-\$ 20,403.74 * * \\
(2,080.60)\end{array}$ & $\begin{array}{c}-\$ 14,709.23 * * \\
(1,615.51)\end{array}$ & $\begin{array}{c}-\$ 14,615.75^{* *} \\
(1,623.47)\end{array}$ & $\begin{array}{c}-\$ 7,373.04 * * \\
(1,403.88)\end{array}$ & $\begin{array}{c}-\$ 4,279.70 * * \\
(1,091.66)\end{array}$ \\
\hline Gender Unknown & $\begin{array}{c}-\$ 28,055.67 * * \\
(6,696.32)\end{array}$ & $\begin{array}{c}-\$ 16,674.40 * * \\
(5,929.31)\end{array}$ & $\begin{array}{l}-\$ 1,800.27 \\
(6,693.14)\end{array}$ & $\begin{array}{l}-\$ 944.97 \\
(6,486.56)\end{array}$ & $\begin{array}{c}\$ 10,241.74 \\
(9,137.46)\end{array}$ & $\begin{array}{l}\$ 7,231.95 \\
(7,242.97)\end{array}$ \\
\hline University Fixed Effects & & $X$ & $X$ & $\mathrm{X}$ & $X$ & $X$ \\
\hline Field Fixed Effects & & & $X$ & $\mathrm{X}$ & $X$ & $X$ \\
\hline PhD School Rank & & & & $\mathrm{X}$ & $\mathrm{X}$ & $\mathrm{X}$ \\
\hline Experience & & & & & $\mathrm{X}$ & $\mathrm{X}$ \\
\hline Research Productivity & & & & & & $\mathrm{X}$ \\
\hline R-Squared & 0.05 & 0.17 & 0.25 & 0.25 & 0.41 & 0.53 \\
\hline $\mathrm{N}$ (Faculty) & 3,805 & 3,805 & 3,805 & 3,805 & 3,805 & 3,805 \\
\hline
\end{tabular}

Notes: The omitted groups are white and male faculty. Standard errors clustered at the university level are reported in parentheses. The sample size is smaller than in the preceding tables because individuals without wage data are excluded from the regressions. Coefficient estimates for all variables in the full model, as estimated in the last column, are reported in Appendix Table A.6.

$* * * *$ Indicates statistical significance at the 5/10 percent level. 
Table 1.6. Decompositions of Wage Gaps by Race/Ethnicity and Gender.

\begin{tabular}{|c|c|c|c|c|}
\hline Decomposition Components & Asian & Black & Hispanic & Female \\
\hline University & $\begin{array}{c}\$ 791.15 \\
-15.28 \% \\
(0.39)\end{array}$ & $\begin{array}{c}\$ 1,247.85 \\
-7.02 \% \\
(0.22)\end{array}$ & $\begin{array}{c}\$ 4,836.08 * * \\
-39.80 \% \\
(0.03)\end{array}$ & $\begin{array}{c}-\$ 730.98 \\
3.84 \% \\
(0.38)\end{array}$ \\
\hline Field & $\begin{array}{c}\$ 6,171.82 * * \\
-119.17 \% \\
(0.00)\end{array}$ & $\begin{array}{c}-\$ 5,470.91 * * \\
30.76 \% \\
(0.00)\end{array}$ & $\begin{array}{c}-\$ 1,281.94 \\
10.55 \% \\
(0.42)\end{array}$ & $\begin{array}{c}-\$ 6,816.16^{* *} \\
35.80 \% \\
(0.00)\end{array}$ \\
\hline Experience (linear) & $\begin{array}{c}-\$ 6,714.42 * * \\
129.64 \% \\
(0.00)\end{array}$ & $\begin{array}{c}-\$ 5,736.49 * * \\
32.25 \% \\
(0.00)\end{array}$ & $\begin{array}{c}-\$ 7,727.89 * * \\
63.60 \% \\
(0.00)\end{array}$ & $\begin{array}{c}-\$ 5,411.68 * * \\
28.42 \% \\
(0.00)\end{array}$ \\
\hline Prestige of PhD School & $\begin{array}{c}-\$ 243.16^{*} \\
4.70 \% \\
(0.10)\end{array}$ & $\begin{array}{c}\$ 288.87 \\
-1.62 \% \\
(0.34)\end{array}$ & $\begin{array}{c}-\$ 151.99 \\
1.25 \% \\
(0.43)\end{array}$ & $\begin{array}{l}\$ 66.46 \\
0.35 \% \\
(0.52)\end{array}$ \\
\hline Research Productivity & $\begin{array}{c}-\$ 5,184.57 * * \\
100.10 \% \\
(0.00)\end{array}$ & $\begin{array}{c}-\$ 8,115.40^{* *} \\
45.62 \% \\
(0.00)\end{array}$ & $\begin{array}{c}-\$ 7,825.25^{* *} \\
64.40 \% \\
(0.00)\end{array}$ & $\begin{array}{c}-\$ 6,147.85 * * \\
32.29 \% \\
(0.00)\end{array}$ \\
\hline Total Gap (Unconditional -Conditional) & $-\$ 5,179.18$ & $-\$ 17,786.08$ & $-\$ 12,150.98$ & $-\$ 19,040.21$ \\
\hline Percentage of Unconditional Gap Explained & $79 \%$ & $123 \%$ & $111 \%$ & $82 \%$ \\
\hline \multicolumn{5}{|c|}{$\begin{array}{l}\text { Notes: The gaps for Asian, black and Hispanic faculty are relative to white faculty; the gap for women is relative to men. The total gap subtracts the conditional } \\
\text { wage difference from the unconditional wage difference in Table 1.5.The percentage of the unconditional gap explained divides the total gap by the } \\
\text { unconditional gap. Each cell reports three numbers: (1) the contribution of the gap component measured in dollars, (2) the contribution of the gap component } \\
\text { measured as a percent of the total gap (the total gap is shown in the bottom row of the table), and (3) the p-value for the statistical significance of the gap } \\
\text { component calculating using Gelbach's (2016) method. Due to small sample sizes, we do not report decompositions for groups "race other/unknown," or "gender } \\
\text { unknown" (see Table 1.1). } \\
* * * * \text { Indicates statistical significance at the 5/10 percent level. }\end{array}$} \\
\hline
\end{tabular}




\section{Chapter 2}

\section{The Effect of Non-Resident Enrollment Growth on In-State College}

\section{Students}

\subsection{Introduction}

A historically large number of non-resident, i.e., out-of-state domestic and foreign students, have matriculated into public universities across the United States in the last decade. ${ }^{25}$ This has drawn attention from national media and sparked debates among policy makers about who should attend public universities (Anderson and Douglas-Gabriel, 2016; Courdriet, 2016; Loudenback, 2016; Powell, 2016). Public universities have traditionally prioritized in-state students, which is consistent with state appropriations being a primary source of revenue. However, between 2004 and 2014, the total number of in-state students only grew by 3 percent at the 50 state flagship universities. ${ }^{26}$ During this same period, the number of out-of-state students increased by 47 percent and the number of foreign students rose by 244 percent. $^{27}$

\footnotetext{
${ }^{25}$ Non-resident students are identified on the basis of public institutions' fee assessment policies. There are two types of non-resident students that are referred to separately in this paper, i.e., out-of-state domestic students and foreign students.

${ }^{26}$ Based on the author's calculation using the Integrated Postsecondary Education Data System (IPEDS) sample of first-time, degree-seeking undergraduates of 50 state flagship universities. The flagship university for each state is defined as the highest ranked university according to 2017 U.S. News and World Report Best Colleges Ranking.

${ }^{27}$ Meanwhile, there has been a national shift away from state appropriations as the primary source of funding for public universities. From fiscal year 2004 to 2014, state appropriations for flagship universities grew by 19 percent. During the same period, revenues from tuition and fees increased markedly, by 124 percent. As a result, tuition and fees revenue exceeded state appropriations for flagship universities in 2010 and the gap between them continues to grow. This is based on the author's calculation using IPEDS data on state appropriations and tuition and fees (after deducting discounts and allowances). The data are not adjusted for inflation.
} 
The magnitude of non-resident enrollment growth is changing the composition of students at public universities and may impact the educational experiences and attainment of in-state students. On one hand, non-resident students provide valuable tuition revenue, which could benefit in-state students by improving per-student resources. ${ }^{28}$ On the other hand, the influx of out-of-state and foreign students could bring stronger competition and make in-state students worse off. Policy makers have shown contrasting preferences. In states such as California and Virginia, state legislators have pressured public universities to limit non-resident enrollment growth to protect the interests of taxpayers (Bellows, 2017; Watanabi, 2017). In contrast, in Missouri, public universities have been encouraged to increase non-resident enrollment to generate revenue (Huguelet, 2017). To date there is little evidence on how non-resident enrollment growth affects in-state college students to inform this debate.

The influx of out-of-state and foreign students at the undergraduate level has been carefully documented in recent research (Bird and Turner, 2014; Bound et al., 2016; Jaquette and Curs, 2015; Jaquette et al., 2016; Rizzo and Ehrenberg, 2004).$^{29}$ Additionally, researchers have modeled the domestic and global market conditions for public universities that are related to enrollment changes (Cooke and Boyle, 2011; Hoxby, 1997; Kato and Sparber, 2013; Rosenzweig, 2006; Shih, 2015). In terms of the impact of non-resident enrollment growth on in-state student outcomes, there are just a small number of studies.

\footnotetext{
${ }^{28}$ Non-resident undergraduate students pay a significantly greater amount of tuition and fees than in-state students at public universities. In the 2015/16 academic year, tuition and fees for non-resident students at 50 flagship universities is on average 2.6 times as much as that for in-state students. This is based on the author's calculation using IPEDS data on tuition and fees for full-time, first-time undergraduate students (academic year programs) by student residency in the 2015/16 academic year.

${ }^{29}$ A number of relevant studies also focus on foreign enrollment growth at the graduate level (Borjas, 2007; Bound et al., 2009; Shih, 2016), or the K-12 level (Betts, 1998; Betts and Fairlie, 2003; Figlio and Ozek, 2017).
} 
Only a few studies aim to estimate the effects of either out-of-state (Curs and Jaquette, 2017) or foreign (Anelli et al., 2017; Machin and Murphy, 2014; Shen, 2016) undergraduate enrollment growth, and even fewer make use of administrative microdata. ${ }^{30}$ Studies to date have relied heavily on institutional data and focus primarily on initial enrollment as the key outcome of interest for in-state students; i.e., whether non-resident enrollment crowds out resident enrollment at the point of entry (Anelli et al., 2016, is an exception - they study how foreign enrollment growth affects domestic major choice).

In this study, I use student-level administrative data of first-time, degree-seeking, full-time students who entered University of Missouri-Columbia (MU) between 2004 and 2014 as college freshmen to study the effect of compositional shifts in the student body by resident status on in-state student outcomes. MU is currently ranked $29^{\text {th }}$ among state flagship universities by U.S. News and World Report. ${ }^{31}$ Also, as of 2014, it had the $19^{\text {th }}$ highest out-of-state enrollment share and the $25^{\text {th }}$ highest foreign enrollment share among flagship universities. ${ }^{32}$ MU's place in the middle of the distribution along these dimensions implies some degree of generalizability of my findings to a broad group of similar universities, particularly the 50 state flagships.

MU rapidly increased out-of-state enrollment beginning in fall-2008 and later expanded its recruiting efforts to foreign students in fall-2012. The characteristics and pre-

\footnotetext{
${ }^{30}$ Evidence on how non-resident enrollment affects in-state students is mixed. Anelli et al. (2017) find adverse effects of foreign enrollment on native students' likelihood of graduating in STEM fields. Machin and Murphy (2014) find no evidence of foreign enrollment crowding out native undergraduate students. Using IPEDS data, Curs and Jaquette (2017) show that out-of-state enrollment growth does not affect instate enrollment at their full sample of public universities. However, it does crowd out in-state enrollment at the most selective public universities. Similarly, Shen (2016) also uses IPEDS and finds no crowd-out effect of foreign enrollment at public universities overall, but for higher-ranked public universities the crowd-out effect is significant.

${ }^{31}$ According to 2017 U.S. News and World Report Best Colleges Ranking.

${ }^{32}$ Based on the author's calculation using IPEDS data of 2014 first-time, degree-seeking freshmen.
} 
entry qualifications of in-state students remain unchanged over the timespan of my data panel, as does the in-state share of high school graduates matriculating to MU. This suggests that the compositional shifts do not appear to hamper in-state students' access to MU, which is consistent with existing studies (Curs and Jaquette, 2017; Machin and Murphy, 2014; Shen, 2016), and facilitates my analysis of the effects of non-resident enrollment growth on in-state student outcomes during college.

To study the causal effects of non-resident enrollment growth on in-state student outcomes, I use continuous treatment differences-in-differences specifications that leverage within-major and cross-time variation in non-resident enrollment for identification. Validation tests of the identifying assumptions do not uncover evidence of violations. I also embed an instrument for the non-resident enrollment share in each major in my differences-in-differences specification, based on the predicted major-level enrollment of three residency groups (i.e., in-state, out-of-state and foreign) prior to the non-resident enrollment "boom" at MU. The instrument addresses the possibility that academic departments' non-resident enrollment growth is endogenous.

I find no evidence of negative effects of non-resident enrollment growth on the third-year persistence or performance outcomes for in-state students at MU. This result is robust to a variety of different model specifications and sample modifications. Additionally, a comparison of treatment effects by gender and race suggests non-resident enrollment growth does not particularly benefit or hurt female or minority in-state students. To explore the potential for effect heterogeneity depending on the type of non-resident student, I also separate the total non-resident enrollment share into its out-of-state and foreign components. The results reveal no adverse effects of out-of-state domestic 
enrollment growth on in-state students, and some results show small positive effects. The evidence on foreign students rules out substantial adverse effects, especially on performance outcomes. However, although modest in magnitude, there is some evidence that increasing foreign enrollment has negative effects on the postsecondary persistence of in-state students.

My study contributes to the literature in the following ways. First, my detailed data allow me to evaluate the impact of non-resident enrollment growth on various educational outcomes of in-state students beyond the point of entry, which extends most studies in the literature. Additionally, to the best of my knowledge, this paper is the first to study out-ofstate and foreign enrollment growth jointly. Descriptive statistics reveal substantial differences in the demographics, academic aptitude and initial major choice of students by residency status, especially between out-of-state and foreign students. This is consistent with the effect heterogeneity on in-state students implied by my analysis.

\subsection{Non-resident enrollment growth at MU}

MU rapidly increased out-of-state domestic enrollment beginning in fall-2008, and later expanded its recruiting efforts to foreign students in fall-2012. To promote the MU brand domestically, the university appointed regional representatives dedicated to recruiting high school students graduating out of specific geographic areas. The first two regional representatives were assigned in 2008 to cover two key areas in nearby states; now MU has more than ten regional representatives. ${ }^{33}$ These representatives regularly meet with local high school principals and students to pitch the university. One particularly favorable policy MU leverages is the lenient Missouri residency requirement. According to the

\footnotetext{
${ }^{33}$ The two MSAs are Chicago, IL and Dallas, TX, according to the MU admission office.
} 
Missouri Student Residency Requirement originally effective in 1979, a non-resident student can establish Missouri residency as soon as 12 months after arrival (Missouri Department of Education, 2017). This would subsequently allow the student to pay the instate tuition rate, reducing the total cost for an out-of-state student to earn a degree at MU. ${ }^{34}$ Although the Missouri residency policy limits the maximum amount of tuition revenue that can be generated from out-of-state enrollment, MU still benefits financially from enrolling more out-of-state students. ${ }^{35}$ More importantly, the policy makes MU more competitive on the domestic market of public universities, potentially swaying out-of-state students on the margin to come to MU. ${ }^{36}$ Additionally, MU established merit-based scholarships exclusively for out-of-state students. Previous studies show that financial incentives significantly affect a student's decision on whether or not to enroll in an out-of-state university (Abraham and Clark, 2006; Burd, 2015).

For foreign student recruiting, MU established the office of international admissions in 2011 as part of the non-resident enrollment growth plan. It then began to regularly send out international recruiting representatives to foreign countries such as China, which exports a large number of students into the U.S.. Similar to recruiting out-of-

\footnotetext{
${ }^{34}$ In the 2015/16 academic year, tuition and fees for non-resident students at MU are 2.6 times as much as those for in-state students. This is based on the author's calculation using IPEDS data on price of attendance for full-time, first-time undergraduate students (academic year programs) by student residency in the 2015/16 academic year.

${ }^{35}$ For instance, assuming an out-of-state freshman entered MU in 2012, converted to Missouri residency after freshman year, and graduated after four years, this student would have spent 1.4 times as much tuition and fees as an in-state student would have, who also entered MU in 2012 and graduated after four years. This is based on the author's calculation using IPEDS data on price of attendance for full-time, first-time undergraduate students (academic year programs) by student residency between the 2012/13 and 2015/16 academic year.

${ }^{36}$ For instance, a 2012 freshman out of Illinois who graduated after four or more years would have spent more on tuition and fees at the University of Illinois at Urbana-Champaign as an in-state student than she/he would have at MU if she/he converted to Missouri residency successfully after freshmen year. This is based on the author's calculation using IPEDS data on price of attendance for full-time, first-time undergraduate students (academic year programs) by student residency between the 2012/13 and 2015/16 academic year.
} 
state students, MU offers preferential financial incentives for foreign students. In addition to merit-based scholarships, MU also uses the same pricing for foreign and out-of-state students, although foreign students are not eligible for Missouri residency during their stay. ${ }^{37}$ Foreign high schoolers are not required to take the ACT or SAT to apply to MU. Admission of foreign students depends on English-language tests and the most recent four years of coursework. ${ }^{38}$ With these appealing features for foreign students, MU has experienced substantial growth in foreign enrollment since 2012. Based on a report from the MU International Center, the total number of foreign undergraduate students reached 1,000 for the first time during the 2015/16 academic year (MU International Center, 2016).

Figure 2.1 provides an overview of first-time, degree-seeking, full-time freshman enrollment at MU between fall-2004 and fall-2014. Total numbers of freshmen by year are shown in Panel A, and the data are further broken out by residency in three additional panels. The data demonstrate that the overall enrollment growth at MU between 2004 and 2014 is predominately driven by non-resident enrollment growth, and out-of-state enrollment growth in particular. Over the timespan of my data panel, out-of-state freshman enrollment shares grew from less than 20 percent to almost 40 percent. In terms of foreign students, Panel D shows their numbers and enrollment shares experience a minor increase in 2008, a dip in 2010, and significant growth since $2012 .{ }^{39}$ In fact, foreign enrollment doubled over a 3-year period between 2012 and 2014.

\footnotetext{
${ }^{37}$ Out-of-state students and foreign students often face different pricing scheme at public universities. Tuition and fees for foreign students are higher than for out-of-state students at institutions such as Iowa State University: http://financialaid.iastate.edu/cost/cost-of-attendance.php.

${ }^{38}$ Foreign students who do not meet the language test score requirement of MU participate in the Intensive English Program and are not fully admitted to MU.

${ }^{39}$ Per the MU office of international admissions, the moderate increase in the foreign enrollment that occurred in 2008 was likely the side effect of the initial recruiting efforts for out-of-state students around that time. MU did not target foreign enrollment growth at any time before the establishment of the office of international admissions.
} 
Panel B of Figure 2.1 shows that the number of in-state students enrolling annually fluctuates around 3,800 over the data panel, while in-state enrollment shares decline significantly. It is unclear, however, if in-state students are crowded out at entry since findings in Figure 2.1 are conditional on enrollment at MU. To investigate the possibility of crowd-out at entry, which would have significant implications for my ability to estimate the effect of non-resident enrollment on in-state student outcomes during college, I compare the total number of freshmen at MU between 2004 and 2014 with the number of Missouri high school graduates from the previous academic year. As shown in Figure 2.2, the in-state share of high school graduates matriculating to MU is flat between 2004 and 2014. Furthermore, Figure 2.2 shows the shares by gender and race, which are also flat. Additionally, in Figure 2.3 I show that the pre-entry qualifications of in-state students remain unchanged over the timespan of my data panel. The empirical evidence suggests that the influx of non-resident students did not impact in-state admissions at MU.

\subsection{Data}

I use administrative data provided by the Missouri Department of Higher Education (DHE) for my empirical analysis. The data contain student-level information including preentry background characteristics, qualifications and in-college outcomes. ${ }^{40}$ The data are updated annually, which allows me to track each student over time as long as she/he remains in the Missouri public system. This study focuses on first-time, degree-seeking, full-time students who entered MU between fall-2004 and fall-2014 as college freshmen.

\footnotetext{
40 The data include students' high school percentile rank and ACT scores, among other pre-entry qualification measures. According to previous studies, high school percentile rank and college entrance exam scores are strong predictors of a student's success in college (Arcidiacono and Koedel, 2014; Betts and Morrell, 1999). Therefore, including pre-entry qualifications in regression models is useful for removing selection bias that is caused by differential qualifications across individual students.
} 
I define three residency groups: in-state, out-of-state and foreign students. A student's residency is identified by the geographic origin of that student at the time of initial admission to MU. Table 2.1 shows the descriptive statistics for my sample. In-state students comprise my primary analytic sample, while out-of-state and foreign studentsnon-resident students - enter regression models as treatments. Although they are not part of the analytic sample, I report the descriptive statistics of out-of-state and foreign students in Table 2.1 to aid in the interpretation of my findings below.

Treatment is defined by exposure to non-resident students in an in-state student's prospective major. College students interact with their same-major peers most frequently, and non-resident enrollment growth most likely impacts in-state students through these interactions within a major. ${ }^{41}$ Overall, I identify 54 majors in the data. ${ }^{42}$ The treatment variable is measured by the non-resident enrollment share of each in-state student's initially identified major; i.e., the major a student declares upon entry at MU. ${ }^{43}$ Five third-year educational outcomes are assessed to evaluate the effect of exposure to non-resident enrollment on in-state students. The two performance measures, cumulative credit hours and cumulative GPA, are continuous variables. The three persistence measures, remaining enrolled in the same major at MU, remaining enrolled at MU, and remaining enrolled at

\footnotetext{
${ }^{41}$ I identify majors based on the Classification of Instructional Program (CIP), which is a taxonomic scheme developed by the U.S. Department of Education's National Center for Education Statistics (NCES). Specifically, I aggregate majors at the 4-digit CIP code level.

${ }^{42}$ Sparsely populated majors are dropped from the analytic sample, i.e., those with less than 50 total instate students between 2004 and 2014. These majors are too small to draw accurate inferences from. This restriction removes 24 majors and 592 in-state students.

${ }^{43}$ The initially identified major upon entry is best described as an "intended" major in that students are not formally required to follow through with their initial major choice.
} 
any Missouri public system campus, are binary variables. ${ }^{44}$ The outcome data are retrieved at the beginning of a student's third year in the Missouri public system. ${ }^{45}$

Using third-year outcomes instead of completion outcomes makes it possible to incorporate more cohorts of students into my analysis, including the most recent cohorts who have been exposed to the rapid foreign enrollment growth at MU. ${ }^{46}$ It also increases the statistical power of the regression models by including more cohorts. Third-year data also offer a good indication of a student's path toward graduation. This is because transfers are more frequent among freshmen and sophomores, and most students have settled on a degree program by the beginning of their junior year. ${ }^{47}$

Descriptive statistics for the three residency groups are provided separately in Table 2.1, including demographics, pre-entry and in-college academic aptitude, initial STEM major share, and major-level enrollment. For the analytic sample-i.e., in-state studentsI also report the sample averages for their third-year educational outcomes over the course of the full data panel. In terms of demographics, out-of-state students are more racially diverse than in-state students. Most notably, black representation among out-of-state students is 14 percent, which is twice as large as among in-state students. Although racial designation is not available for foreign students, who are simply coded as non-resident

\footnotetext{
${ }^{44}$ There are 13 public university campuses in the state of Missouri.

45 If a student's third-year data are unavailable due to early exit from the Missouri public system, her/his performance outcomes are retrieved instead from second-year data, or from first-year data if second-year records are also unavailable.

46 The latest update that is made available by Missouri DHE includes the completion data of the 2015-16 academic year. This means that the 2010 freshman class is the last cohort that can be used to evaluate completion outcomes, assuming I follow the convention of considering students who graduate within six years. However, MU did not begin seeking foreign enrollment expansion until fall-2012. Therefore, there would be no in-state cohort exposed to the foreign enrollment growth at MU if I were to use completion outcomes.

${ }^{47}$ Among ultimate bachelor degree recipients who entered MU between 2004 and 2010, 89 percent completed a degree in the major at MU in which they registered at the beginning of their third year.
} 
aliens in the data, supplementary data show that MU hosts foreign students from more than 100 countries around the world, which contributes to both geographic and racial diversity on campus.

In terms of pre-entry qualifications, out-of-state students mildly outperform in-state students on all three measures on average (ACT math scores, ACT English scores and high school percentile rank). Previous studies show similar results using institutional-level SAT data (Groen and White, 2004; Jaquette et al., 2016). ${ }^{48}$ I also show comparisons of ACT scores and class ranks for foreign students, but as noted in the table, the vast majority of foreign students do not have any pre-entry qualification data (recall from above that MU is test-optional for foreign undergraduate applicants). I do not draw strong inference from comparisons involving the small fraction of foreign students with pre-entry qualification data due to concerns about sample selection. ${ }^{49}$

Given the missing pre-entry qualification data for most foreign students, in Table 2.1 I also compare student preparedness by residency status using standardized first semester GPAs, which are available for most MU students including foreign students. ${ }^{50}$ The GPA comparisons reveal that foreign students are by far the most positively selected among the three residency groups. Table 2.1 also shows differential major choice patterns among residency groups. Foreign students are more likely than domestic students to choose STEM majors initially, which is in line with national data (National Science Board,

\footnotetext{
${ }^{48}$ Groen and White (2004) use their results to demonstrate that public universities set differential admission criteria that favor in-state students. This is not true for MU, which has the same admission standard for all domestic, undergraduate students.

${ }^{49}$ Anelli et al. (2017) use the administrative data of a public university in California and show that foreign students have higher average SAT math scores and lower average SAT verbal scores than their domestic peers.

${ }^{50}$ Standardized First Semester GPA is the residual generated from regressing first semester GPA on major and year fixed effects.
} 
2014). ${ }^{51}$ Out-of-state students are less concentrated in STEM fields than in-state students; a potential explanation is that MU has several highly-regarded non-STEM majors that may draw broad interest (most notably Journalism).

Finally, Table 2.1 also reports statistical differences between the two non-resident groups. The statistical tests confirm the visually apparent differences in demographics (gender), academic aptitude, and initial major choice. This hints at the possibility of effect heterogeneity based on the type of non-resident student to which in-state students are exposed.

\subsection{Empirical Strategy}

I leverage within-major and cross-time variation to identify the causal effects of changing non-resident enrollment on the outcomes of in-state college students. My main model is a continuous treatment differences-in-differences regression:

$Y_{i j t}=\beta_{0}+\beta_{1}$ ShareNR $_{j t}+\mathbf{X}_{\mathbf{i j t}} \boldsymbol{\gamma}+\delta_{j}+\varphi_{t}+\varepsilon_{i j t}$

In Equation (2.1), $Y_{i j t}$ is an outcome variable for in-state student $i$ who initially enters MU with major $j$ in year $t$. As stated in Section 2.3, five third-year outcomes of in-state students are assessed using Equation (2.1). Two performance measures, cumulative credit hours and cumulative GPA, are continuous variables; the three persistence measures at the major, university and system level, are binary variables. ${ }^{52}$ Share $N R_{j t}$ is the treatment variable. It measures the non-resident enrollment share in major $j$ and year $t$. Specifically, ShareNR $R_{j t}=\left(\frac{O O S_{j t}+F_{j t}}{I S_{j t}+O O S_{j t}+F_{j t}}\right) * 100$, where $I S_{j t}, O O S_{j t}$ and $F_{j t}$ denote the number of in-

${ }^{51}$ I match the CIP codes to the STEM Designated Degree Program list to recognize STEM and Non-STEM majors in the data (Department of Homeland Security, 2016).

${ }^{52}$ For the persistence measures, Equation (1.1) is specified as a linear probability model. 
state, out-of-state and foreign students, respectively, in major $j$ and year $t . \mathbf{X}_{\mathbf{i j t}}$ is a vector of individual student characteristics for in-state student $i$, including gender and race indicators, ACT math and English scores, and the high school percentile rank. Female and white students are the omitted groups. The model also includes missing-value indicators in cases where ACT scores and/or high school rank are not available. $\delta_{j}$ and $\varphi_{t}$ are major and year fixed effects and $\varepsilon_{i j t}$ is an idiosyncratic error term. The standard errors are clustered at the major level to account for heteroscedasticity and within-major correlation of the errors.

The model relies on within-major variation over time in the non-resident enrollment share for identification. Major fixed effects eliminate bias from time-invariant factors of majors. At the same time, year fixed effects account for common shocks to all majors over time. The model provides credible estimates of treatment effects on in-state students as long as there are no dynamic biasing factors within majors. The coefficient of interest is $\beta_{1}$, which is the differences-in-differences parameter. Conceptually, it is important to recognize that the estimates from Equation (2.1) capture the "total treatment effects" of the exposure to non-resident students on the outcomes of in-state students; i.e., the estimates embody all of the systematic differences in educational experience that come with changes in non-resident enrollment.

Next I expand the model by separating total non-resident enrollment into the outof-state and foreign enrollment shares. This allows me to explore the potential for effect heterogeneity. The expanded version of the main model is specified as follows:

$$
Y_{i j t}=\gamma_{0}+\gamma_{1} \text { ShareOOS }_{j t}+\gamma_{2} \text { ShareF }_{j t}+\mathbf{X}_{\mathbf{i j t}} \mathbf{\rho}+\delta_{j}+\varphi_{t}+\epsilon_{i j t}
$$


In Equation (2.2), the recurring variables follow the same definition as in Equation (2.1). The two treatment variables are $S_{h a r e O O S}$ and $S h a r e F_{j t}$, which measure the out-ofstate and foreign enrollment shares at the major level, respectively. The identifying assumptions for Equation (2.2) are the same as in Equation (2.1).

There are three key endogeneity concerns with these models. First is the possibility that non-resident enrollment growth crowds out in-state students at the point of entry into MU. If matriculating more non-resident students affects which in-state students enroll, then the estimates from Equations (2.1) and (2.2) will be potentially biased by sample selection. But as noted above, there is no evidence of a change in the admissions of in-state students over the course of my data panel. Figures 2.2 and 2.3 show that in-state student characteristics and pre-entry qualifications remain unchanged over the course of the data panel, as does the share of Missouri high school graduates matriculating to MU.

The second concern is the potential for endogenous sorting of in-state students to majors in response to changing non-resident enrollment. Conceptually, such sorting seems unlikely. Incoming freshmen are required to specify a major before taking any classes on campus. Therefore, they should not possess information about peer composition, which is necessary for endogenous sorting prior to entry. To provide empirical evidence on observed dimensions, I follow Anelli et al. (2017) and Figlio and Ozek (2017) by performing validation tests to evaluate the correlation between in-state student characteristics and major-level non-resident enrollment. Specifically, I replace the in-state student outcomes in Equation (2.1) with observable characteristics that should not change in the absence of endogenous sorting to majors based on non-resident enrollment growth, and estimate the model with major and year fixed effects. The results are reported in Table 2.2. Overall, 
there is one coefficient that is estimated to be significantly different from zero across eleven student characteristics. Using this result as evidence for endogenous sorting of in-state students can be misleading, because statistical significance could happen purely by chance with multiple hypothesis testing. Therefore, I follow Cullen et al. (2006) and Koedel et al. (2017) by performing a "randomized-inference test" to determine the probability of observing at least one statistically significant estimate by chance in this exercise. ${ }^{53}$ The overall p-value from this test is 0.74 , as reported in Table 2.2 , which indicates that the likelihood of observing at least one statistically significant estimate at the 10 percent level by chance is quite high. ${ }^{54}$ Thus, in addition to being intuitively unlikely, there is no empirical evidence of in-state student sorting to majors at entry in response to changes in non-resident enrollment.

The third endogeneity concern relates to academic departments. It is possible that some departments at MU were better positioned to absorb non-resident students as the university was expanding non-resident enrollment. The estimates from Equations (2.1) and (2) could be biased if major-level variation in non-resident enrollment growth is partly attributed to endogenous responses of departments. To address this concern, I exploit the initial distribution (i.e., the pre-2008 period) of students across majors by residency (i.e.,

\footnotetext{
${ }^{53}$ Specifically, I divide the data vertically into two subsets. The first subset contains major-level non-resident enrollment share, and the other subset contains in-state student characteristics. Then the order of the first subset is reshuffled and reconnected to the second subset so that each in-state student is randomly re-assigned with a major-level non-resident enrollment share. Covariance structure between student characteristic variables is kept unchanged in the second subset so that results generated by a reconstructed sample are comparable with the real data. I then perform validation tests for a reconstructed sample and store the number of statistically significant estimates at the 10 percent level. I repeat this procedure 3,000 times to construct an empirical distribution of statistical significance.

${ }^{54}$ For completeness, I also perform the validation tests for Equation (2.2) and discover no relationship between in-state student characteristics and major-level out-of-state or foreign enrollment. The results are reported in Appendix Table C.1, where each column shows results from a regression of an in-state observable student characteristic on the major-level out-of-state and foreign enrollment shares as well as major and year fixed effects. Only one coefficient out of 22 is statistically significant, and the "randomized inference test" suggests the overall p-value is 0.94 .
} 
in-state, out-of-state and foreign). Specifically, I instrument for the actual non-resident enrollment share in each major from 2008 onward by allocating total enrollment growth to the three residency groups in proportion to their major-level presence in the pre-2008 period, which is before the ramp-up in non-resident enrollment at MU. To create these instruments, I first predict the number of in-state students in major $j$ and year $t$ by $I S_{j t}^{\prime}=$ $I S_{j 0} *\left(\frac{I S_{t}}{I S_{0}}\right) . I S_{j 0}$ is the average number of in-state students in major $j$ over the pre-2008 period, denoted as the initial period by $t=0$. The growth factor of in-state students across all majors at MU between the initial period and year $t$ is represented by $\left(\frac{I S_{t}}{I S_{0}}\right)$. Similarly, the numbers of out-of-state and foreign students in major $j$ and year $t$ are predicted by $O O S_{j t}^{\prime}=O O S_{j 0} *\left(\frac{O O S_{t}}{O O S_{0}}\right)$ and $F_{j t}^{\prime}=F_{j 0} *\left(\frac{F_{t}}{F_{0}}\right)$, respectively.

Then, using two-stage least squares (2SLS), I estimate the following regressions:

$$
\begin{aligned}
& \text { ShareNR }_{j t}=\alpha_{0}+\alpha_{1} I S_{j t}^{\prime}+\alpha_{2} \text { OOS }_{j t}^{\prime}+\alpha_{3} F_{j t}^{\prime}+\mathbf{X}_{\mathrm{ijt}} \boldsymbol{\theta}+\delta_{j}+\varphi_{t}+\mu_{i j t} \\
& Y_{i j t}=\zeta_{0}+\zeta_{1} \text { ShareN }_{j t}+\mathbf{X}_{\mathrm{ijt}} \boldsymbol{\Psi}+\delta_{j}+\varphi_{t}+\omega_{i j t}
\end{aligned}
$$

Again, in Equations (2.3) and (2.4) the recurring variables follow the same definition as in Equation (2.1). Because treatment in the instrumental variables (IV) model is predicted by major-level enrollment before university policy changes, the estimates will not be biased by endogenous responses of academic departments along unobserved dimensions during the boom period of non-resident enrollment growth.

The IV model is closely related to the shift share approach used by Card (2001), Card and DiNardo (2000), and Peri et al. (2015). The validity of the instruments relies on the assumption that the pre-2008 distribution of students across majors does not affect educational outcomes of in-state students in the post-2008 period through channels other 
than by affecting future major-level non-resident enrollment, conditional on other controls in the model. ${ }^{55}$ Unfortunately this assumption is not directly testable, but it is intuitive that the initial distribution of students across majors has no direct impact on in-state students who enter MU in later years conditional on the major and year fixed effects.

\subsection{Results}

Table 2.3 shows the effects of changing non-resident enrollment on the outcomes of in-state students, estimated separately by the continuous treatment differences-indifferences model (Panel A) and the IV model (Panel B). Each column shows the effect of a one-percentage-point increase in the non-resident enrollment share on in-state student outcomes, as measured at the beginning of the third year after college entry. The results of the first-stage regression of the IV model are reported in Appendix Table C.2. The coefficients for student characteristics in the $X$-vector are omitted for brevity. Full output from Panel A is reported in Appendix Table C.4.

The coefficients for the non-resident enrollment effects in Panel A are small in an absolute sense and none are statistically significant at conventional levels. Note that the statistical insignificance is not due to lack of precision, as the standard errors are sufficiently small to detect meaningful effects. For example, the estimate for persistence in the same major at MU, if taken at face value, suggests that a one-standard-deviation increase in the non-resident enrollment share (17 percentage points) decreases the likelihood of in-state students remaining in the same major at MU by just 1.4 percentage points (i.e., $\left.-0.0008^{*} 17=-0.0136\right)$. The sample average of this outcome over the course of the full data panel is reported in Table 2.1, which is 38 percent. The same increase in non-

55 The post-2008 period includes 2008 and later years. 
resident enrollment nominally increases the likelihood of persistence at the university and system levels by 0.7 and 0.2 percentage points, respectively. The sample means of these outcomes are 77 and 86 percent. The insignificant point estimates for cumulative credit hours and GPA are similarly small. Overall, there is no evidence to suggest that changing non-resident enrollment affects in-state student outcomes.

Panel B of Table 2.3 shows that the IV model yields similar null results, although the estimates are much less precise. The loss of precision is expected given that the model leverages less identifying variation and the instruments are not particularly strong. ${ }^{56}$ That said, like Panel A, the results are generally small in magnitude and none are statistically significant. The comparison between Panels A and B suggests endogenous responses of academic departments to university-wide changes in non-resident enrollment are unlikely. If better-positioned academic departments endogenously took up more non-resident students, estimates from the IV model should be more negative than the main results, but this is not the case. ${ }^{57}$

In Table 2.4 I expand the main model by separating total non-resident enrollment into out-of-state and foreign components. ${ }^{58}$ As discussed in Section 2.3, out-of-state and foreign students differ substantially along observed dimensions. This motivates an assessment of whether there are heterogeneous treatment effects on in-state students, which

\footnotetext{
${ }^{56}$ Appendix Table C.2 shows that the first-stage F-statistic is 13.23, which is below the Stock and Yogo (2005) weak identification threshold value of 22 (10\% maximal IV size).

${ }^{57}$ In Panel A of Appendix Table C.5 I report the results from analogous continuous treatment model using data from the same years as in the IV model, i.e., 2008-2014 subsample. I also replicate the results from the IV model in Panel B for ease of comparison. Like Table 2.3, the IV results are not consistently more negative in Appendix Table C.5.

${ }^{58}$ Having additional endogenous regressors in the IV model further undermines the predictive power of the instrumental variables. Therefore, I do not expand the IV model along this line.
} 
could have important policy implications. To better gauge the magnitude of effect heterogeneity, I report results from statistical tests of equal effects, i.e., $\mathrm{H}_{0}: \gamma_{1}=\gamma_{2}$.

The estimates in Table 2.4 for exposure to out-of-state domestic enrollment align closely with the main results in Panel A of Table 2.3. This is unsurprising because most non-resident enrollment at MU is out-of-state domestic enrollment. Specifically, the coefficients on the out-of-state enrollment share in all five models are small and statistically insignificant. For exposure to foreign enrollment the coefficients are invariably negative. The estimates for cumulative credit hours and GPA are small and insignificant, implying that changes in foreign enrollment do not negatively impact in-state students along these dimensions. But the effects on all three persistence measures are negative and statistically significant. For example, a one-standard-deviation increase in the foreign enrollment share (5 percentage points) decreases the likelihood of in-state students remaining enrolled in the same major at MU by 2.5 percentage points. The same increase in foreign enrollment also decreases in-state students' likelihood of persistence at the university and system levels by 1.2 and 1.0 percentage points, respectively. These effects are of limited consequence at MU because the foreign enrollment shares across majors are low (about 1 percent on average). However, the potential for meaningful adverse effects cannot be ruled out if foreign enrollment were to continue to expand.

Previous studies have discussed two mechanisms through which non-resident enrollment influences in-state college students (Anelli et al., 2017; Bound et al., 2016; Groen and White, 2004; Jaquette and Curs, 2015; Rizzo and Ehrenberg, 2004; Shen, 2016). One is that the influx of non-resident students brings stronger competition and makes instate students worse off. The competition effects are likely reflected by the negative 
coefficients on the foreign enrollment share, considering that foreign students are positively selected (per Table 2.1). Another mechanism is that non-resident enrollment increases tuition revenue, which can benefit in-state students by improving per-student resources. To further explore changes in per-student resources at MU, in Appendix Table C.3 I compare the numbers and average salaries of faculty between majors that experienced the most and the least out-of-state enrollment growth over the timespan of my data panel. Both the numbers of faculty and the average salaries grew at comparable rates between the groups of majors. Thus, out-of-state enrollment growth does not appear to have significantly improved per-student resources disproportionately in majors that experienced the most growth. ${ }^{59}$ This is consistent with the null results for changes in out-of-state domestic enrollment.

\subsection{Robustness}

In Table 2.5 I test the robustness of the main results to specification and sample modifications. For ease of comparison, I reproduce the main estimates from Panel A of Table 2.3 in Column (1). The first robustness test in Column (2) examines model sensitivity by modifying the preferred specification to include time-varying characteristics of majors. Specifically, I include in-state enrollment, race and gender shares, average ACT math and English scores, and the average high school percentile rank. The results are broadly similar to the main results in Column (1), indicating that the main results are robust to including the time-varying major characteristics.

A related specification adjustment is to drop individual student characteristics from the model. As discussed in Section 2.4, there is no evidence that in-state students sort to

\footnotetext{
${ }^{59}$ It is important to acknowledge the possibility that in-state students might have benefitted from other types of resource improvement that are not reflected by the measures used in Appendix Table C.3.
} 
majors at entry in response to changes in non-resident enrollment. Therefore, the coefficients of interest should not vary significantly depending on whether student characteristics are included when major and year fixed effects are included. This is verified by the results in Column (3), as they do not differ substantially from the main estimates in Column (1). In sum, these two robustness tests show that the main results are not sensitive to including or excluding major and student characteristics, which is consistent with identification resting on the primary differences-in-differences assumptions unconditionally.

Next I consider robustness to modifying the sample. Namely, I drop students who initially enroll in MU's Interdisciplinary Studies major. As discussed in Section 2.4, incoming freshmen are required to declare a major before taking any classes on campus. For those who intend to enter undecided, MU places them in the Interdisciplinary Studies major, along with students who actively declare this major. ${ }^{60}$ Initial enrollment in the Interdisciplinary Studies major accounts for 13 percent of the analytic sample. A concern with including these students in the analysis is that they are likely to interact less with their same-major peers, which in my context would effectively mean a weaker treatment. Column (4) of Table 2.5 reports estimates from the main model after dropping students who initially enroll in the Interdisciplinary Studies major. The results align closely with the main results, suggesting Interdisciplinary Studies students do not drive my findings.

\subsection{Extensions}

2.7.1 Effect Heterogeneity by the Gender and Race of In-State Students

\footnotetext{
${ }^{60}$ Empirically, it effectively serves as a substitute for undecided major at MU, as most of the students who were in the major initially transferred out during the first two years ( 86 percent).
} 
Changes in non-resident enrollment could differentially affect in-state students depending on their gender and race. To examine this possibility, I add interaction terms between the non-resident enrollment share and gender and race indicators to Equation (2.1). The results are shown in Table 2.6. Male and white in-state students are the omitted groups, and thus the effects for all other groups are estimated relative to them. The baseline estimates are small and insignificant for white males. For female and minority in-state students, the results are mixed in sign and small in magnitude. Of the fifteen coefficients, only three are statistically significant at the 10 percent level and none are significant at the 5 percent level. Overall, the results in Table 2.6 provide no evidence of meaningful effect heterogeneity by the gender and race of in-state students.

\subsubsection{Binned Model}

Instead of using continuous treatment variables, the differences-in-differences identification strategy can also be executed within a more standard framework using the following binned model:

$$
Y_{i j t}=\eta_{0}+\eta_{1} \text { Post }_{t}^{\text {oos }} Q_{j}^{\text {oos }}+\eta_{2} \text { Post }_{t}^{F} Q_{j}^{F}+\mathbf{X}_{\mathrm{ijt}} \mathbf{\tau}+\delta_{j}+\varphi_{t}+v_{i j t}
$$

In Equation (2.5), the recurring variables follow the same definition as in Equation (2.2). Post $_{t}^{\text {Oos }}$ is an indicator set to one for 2008 and later years to represent the post-treatment period for out-of-state enrollment growth. Similarly, Post $t_{t}^{F}$ is an indicator set to one for 2012 and later years for foreign enrollment growth. ${ }^{61} Q_{j}^{O O S}$ is a binary variable that indicates if major $j$ is in the top quartile of out-of-state enrollment growth between the pre-

\footnotetext{
${ }^{61}$ Binned model is well-suited for splitting total non-resident enrollment into out-of-state domestic and foreign components since MU began seeking for out-of-state domestic and foreign enrollment growth at different points of time. For the same reason, I do not expand Equation (2.1) along this line as the postperiods are different for out-of-state and foreign enrollment growth in the standard differences-indifferences framework.
} 
2008 and post-2008 periods; similarly, $Q_{j}^{F}$ is set to one if major $j$ is in the top quartile of foreign enrollment growth between the pre-2012 and post-2012 periods.

The identifying assumptions for Equation (2.5) are the same as in Equation (2.2). However, the binned model facilitates larger contrasts in out-of-state and foreign enrollment "treatments" by isolating top quartile majors and comparing them to other majors. Additionally, the model relaxes the linear treatment effect assumption in Equation (2.2). By comparing majors that experienced more pronounced differences in out-of-state and foreign enrollment growth, the model is able to pick up non-linear treatment effects that the continuous treatment model cannot.

The results are presented in Table 2.7. For out-of-state enrollment growth, all five point estimates are positive and two are statistically significant. The implied effect sizes remain small, but the results in Table 2.7 give at least some indication that expanded outof-state domestic enrollment improves the outcomes of in-state students.

For foreign enrollment growth, the findings are qualitatively consistent with Table 2.4. Specifically, the point estimates are invariably negative and two out of three estimates for the persistence measures are statistically significant. Table 2.7 also reports p-values from statistical tests of the null hypothesis that the effects of out-of-state and foreign enrollment growth are equal using estimates from the new model, i.e., $\mathrm{H}_{0}: \eta_{1}=\eta_{2}$. The results affirm the general pattern in Table 2.4. The differences between the out-of-state and foreign treatment effect estimates are more pronounced in Table 2.7 when isolating topquartile majors, especially for the persistence measures. ${ }^{62}$

\footnotetext{
62 The estimates in Table 2.7 can be converted to a form that is comparable to the estimates reported in Table 2.4. For instance, the difference in out-of-state enrollment growth between top quartile majors and the other majors is 12 percentage points. Thus, the point estimate for persistence at MU in Table 2.7 can be translated to an effect size of 0.14 percentage points for a one-percentage-point increase in the out-of-state
} 


\subsubsection{Effects on Graduation Outcomes}

The analysis thus far has focused on third-year educational outcomes of in-state students. Using third-year outcomes instead of graduation outcomes allows me to incorporate more cohorts of students who have been exposed to the recent influx of foreign students. However, a concern is that over the first two years of college there is not as much cross-major variation in interactions with same-major peers, as freshmen and sophomores tend to take general education courses in addition to courses that are required on the paths to their respective majors. To further investigate the possibility that the findings are influenced by a lack of meaningful variation in exposure to non-resident students across majors, I replace the outcomes in the preferred specification by graduation outcomes and focus on a restricted sample of cohorts from 2004-2010, for whom I can track 6-year graduation outcomes with my data panel. ${ }^{63}$ If in-state students have limited exposure to non-resident students initially, I would expect the estimates using graduation outcomes to be subject to less attenuation bias because same-major peers should increasingly overlap later in the college career.

The results are reported in Appendix Table C.6. Overall, the coefficients are small in an absolute sense and none are statistically significant at conventional levels, indicating the changes in overall non-resident enrollment do not significantly affect 6-year graduation outcomes for in-state students. Importantly, the estimates reveal no evidence of more pronounced effects on in-state students, compared to my primary estimates in Table 2.3.

\footnotetext{
enrollment share, i.e. $0.0162 / 12=0.0014$. Overall, if I attempt to linearize the estimated effects from the model in Table 2.7, the implied magnitudes of the translated estimates are about twice the size of the corresponding estimates reported in Table 2.4, suggesting the treatment effects on in-state students may not be linear.

63 The last year of my data panel is for the 2015-16 academic year, which means that the 2010 freshman class is the last cohort that can be used to evaluate 6-year graduation outcomes.
} 
The similarity of results implies that a lack of variation in the exposure to non-resident students during the first two years at MU is unlikely to bias my findings.

\subsection{Concluding Remarks}

The political debate about whether public universities should limit non-resident enrollment growth depends critically on how non-resident enrollment growth affects the educational outcomes of in-state college students. I use student-level administrative data

of first-time, degree-seeking, full-time students who entered the University of MissouriColumbia (MU) between 2004 and 2014 as college freshmen to study the effect of compositional shifts in the student body by resident status on in-state student outcomes. Descriptive analysis shows that the rapid expansion of non-resident enrollment at MU did not crowd out in-state students at entry, and it has enhanced both geographic and racial diversity on campus. I leverage within-major and cross-time variation to estimate the causal effect of non-resident enrollment growth on five third-year outcomes of in-state students and find no evidence of negative effects of exposure to total non-resident enrollment on persistence or performance outcomes among in-state students. Moreover, a comparison of treatment effects by gender and race indicates that non-resident enrollment growth does not particularly benefit or hurt female or minority in-state students.

I also separate total non-resident enrollment into out-of-state domestic and foreign components and discover some evidence of effect heterogeneity. Specifically, the results suggest no adverse effects of out-of-state domestic enrollment growth on in-state students, and some results show marginally positive effects. The evidence on the influx of foreign students rules out substantial adverse effects, especially on performance outcomes, but there is evidence of modest negative effects of foreign enrollment growth on the persistence 
of in-state students in their majors, at MU, and in the Missouri public university system. The adverse effects are not meaningful substantively at MU given the currently small foreign enrollment share, but could be more problematic in the future if they persist and foreign enrollment growth continues. 
Figure 2.1. Freshman Enrollment Trends at MU by Residency Status.

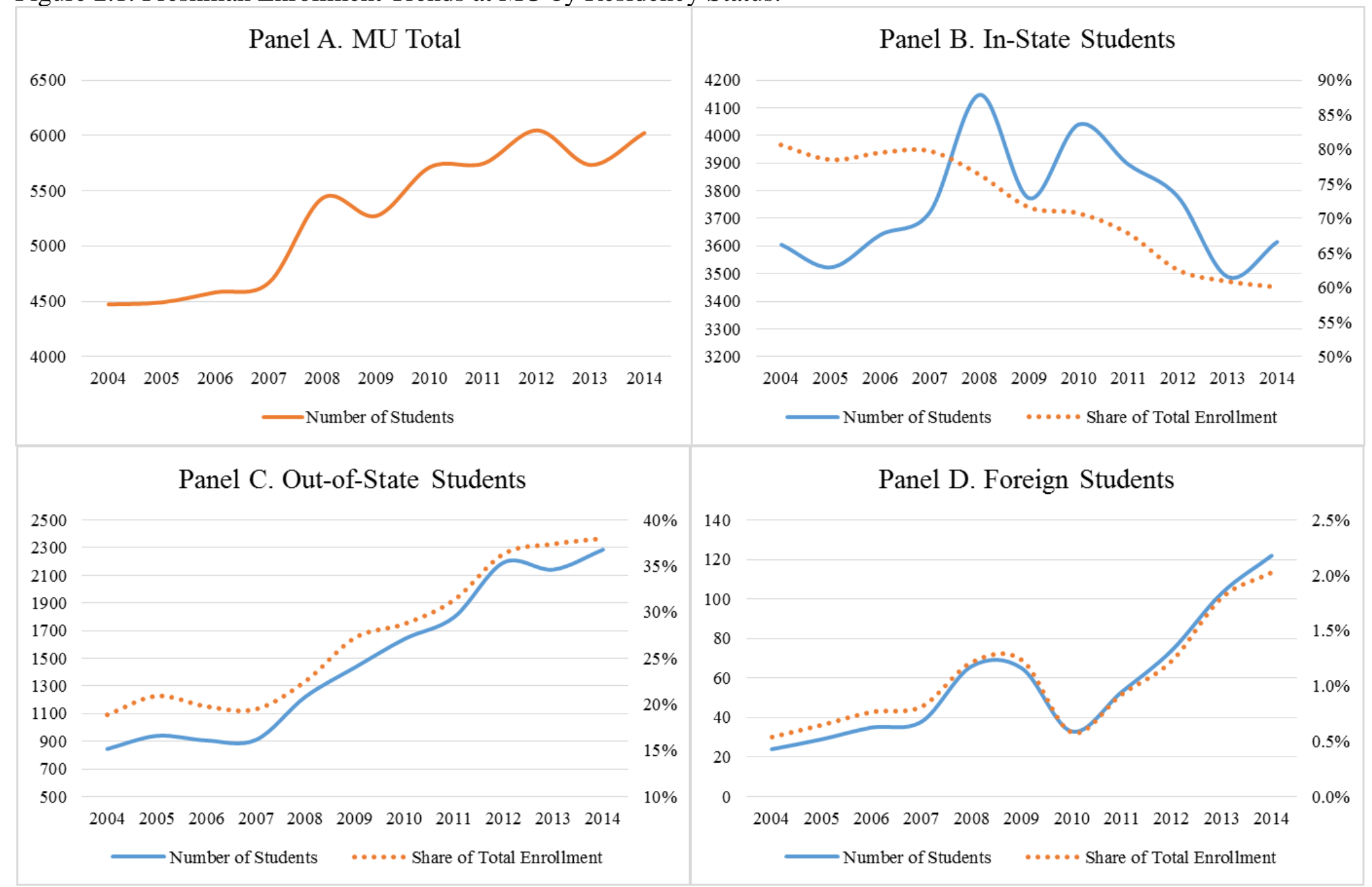

Notes: This graph displays enrollment trends at University of Missouri-Columbia (MU) by residency status using data of first-time, degree-seeking, full-time students entering MU as college freshmen from 2004 to 2014. Left axis in each panel corresponds to Number of Students. In Panel B, Panel C and Panel D, right axis corresponds to Share of Total Enrollment. 
Figure 2.2. Comparison between In-state Freshman Enrollment at MU and Number of High School Graduates in Missouri.

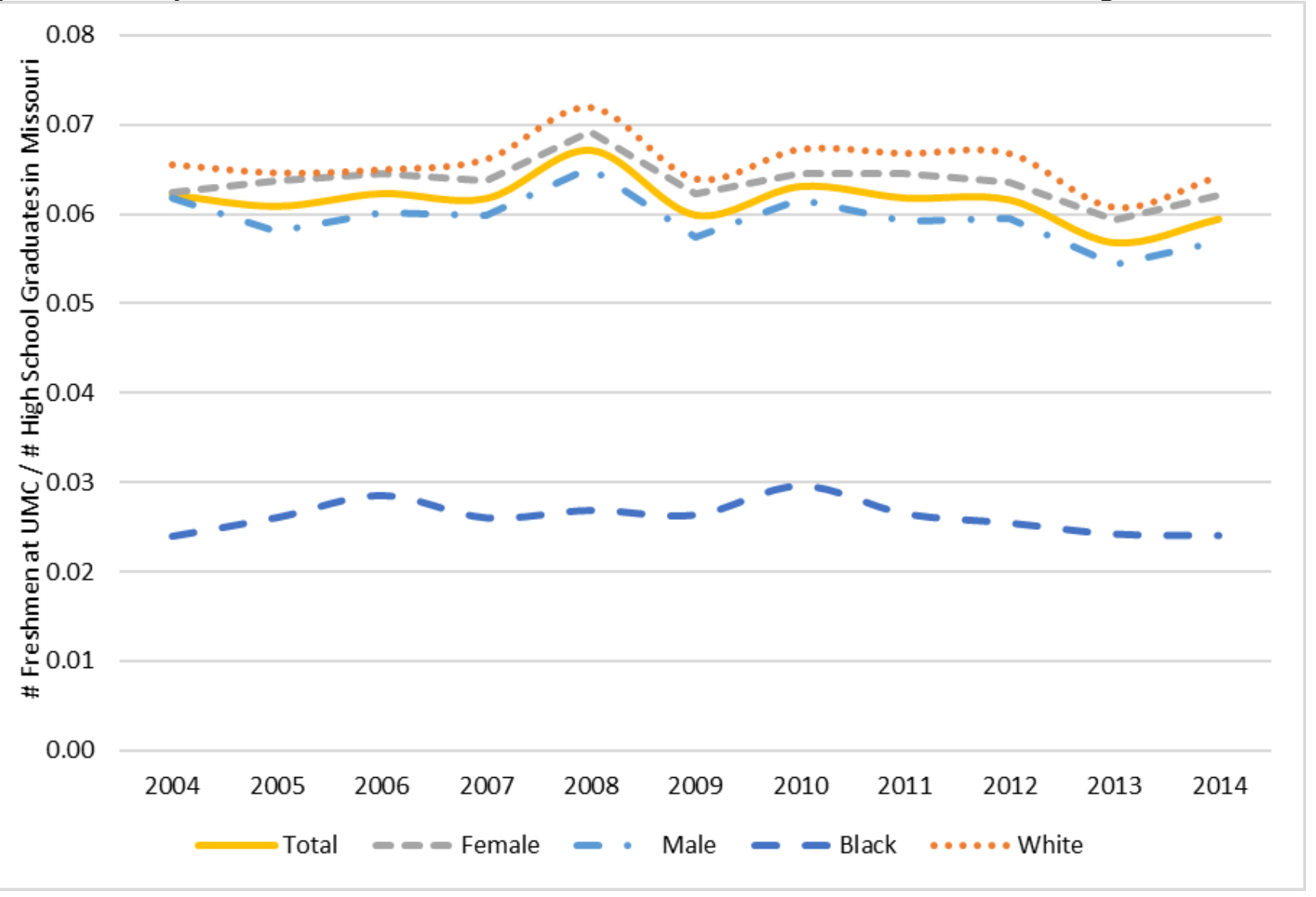

Notes: This graph depicts time trend of the ratio of number of first-time, degree-seeking, full-time in-state students at MU to number of high school graduates in Missouri. Solid line represents the ratio for all in-state students. Dashed lines show the ratio separately for each gender and race. The data for high school completers is retrieved from Knocking at the College Door: Projections of High School Graduates (Western Interstate Commission for Higher Education, 2016). Total number of high school graduates in Missouri includes both public and private schools; by-gender and by-race data is only available for public schools in Missouri. Asian/ Pacific Islander, Hispanic and Other Races are omitted because small sample size of these groups causes their trend to be susceptible to noise. The data for public schools is based on actual numbers from 2004 to 2013, and based on projection in 2014; the data for private schools is based on actual numbers from 2004 to 2011, and based on projection from 2012 to 2014. 
Figure 2.3. Pre-entry Qualifications of In-State Freshman Students at MU.

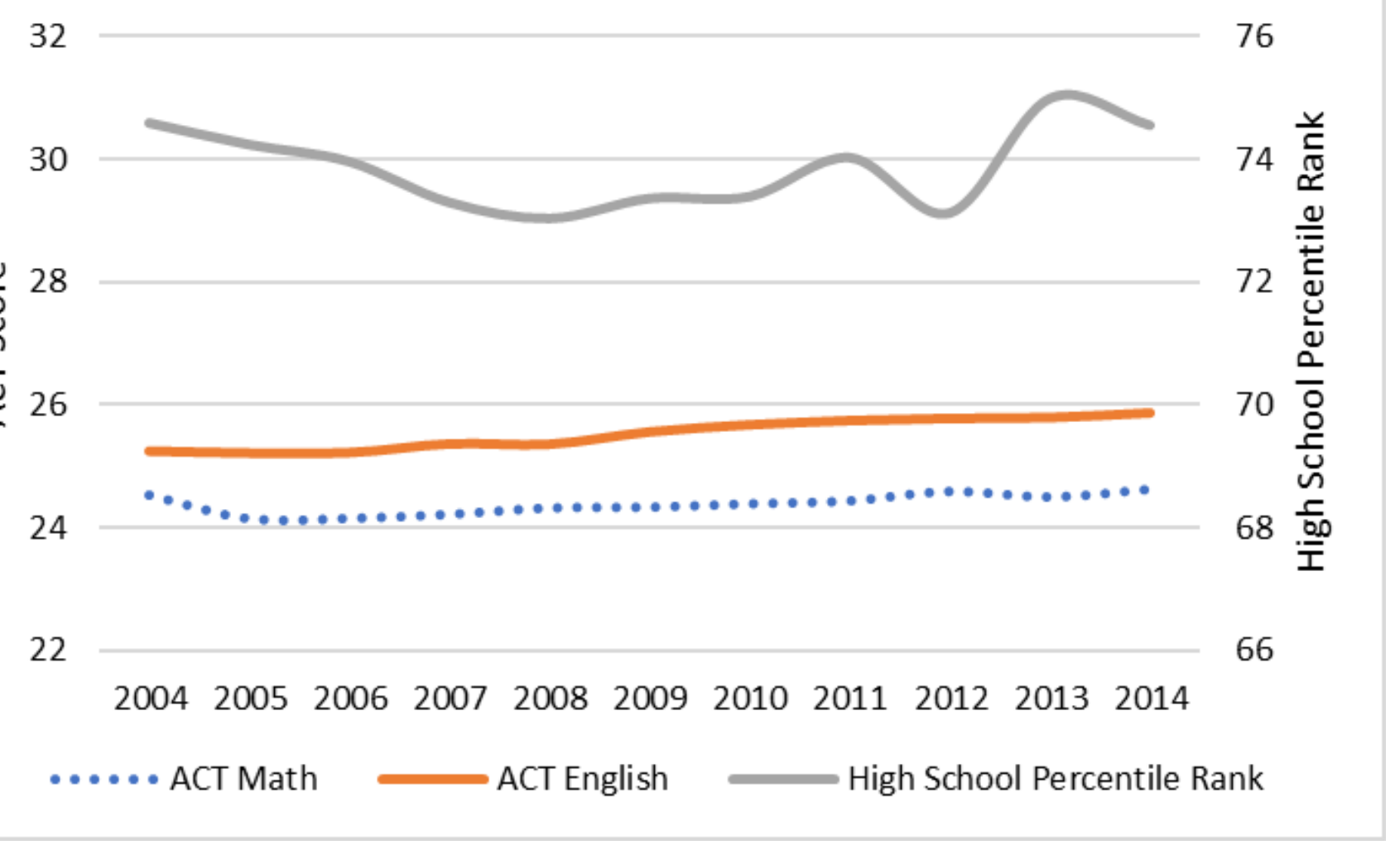

Notes: This graph depicts time trend of three pre-entry qualifications of first-time, degree-seeking, full-time in-state students at MU from 2004 to 2014, i.e., ACT math score, ACT English score and high school percentile rank. Left axis corresponds to ACT math score and ACT English score, right axis corresponds to high school percentile rank. 
Table 2.1. Descriptive Statistics of Each Residency Group.

\begin{tabular}{|c|c|c|c|}
\hline & $\begin{array}{l}\text { In-State Students } \\
\text { Mean (St Dev) }\end{array}$ & $\begin{array}{c}\text { Out-of-State Students } \\
\text { Mean (St Dev) }\end{array}$ & $\begin{array}{c}\text { Foreign Students } \\
\text { Mean (St Dev) }\end{array}$ \\
\hline Female & $0.52(0.50)$ & $0.58(0.49)$ & $0.51(0.50) * *$ \\
\hline Male & $0.48(0.50)$ & $0.42(0.49)$ & $0.49(0.50) * *$ \\
\hline Asian/ Pacific Islander & $0.02(0.15)$ & $0.02(0.14)$ & - \\
\hline Black & $0.07(0.25)$ & $0.14(0.35)$ & - \\
\hline Hispanic & $0.01(0.11)$ & $0.02(0.14)$ & - \\
\hline White & $0.85(0.36)$ & $0.75(0.43)$ & - \\
\hline Other Races & $0.05(0.21)$ & $0.07(0.25)$ & - \\
\hline ACT Math & $24.39(4.10)$ & $24.83(3.64)$ & $24.87(2.03)$ \\
\hline ACT Math Missing Indicator & $0.01(0.09)$ & $0.10(0.30)$ & $0.83(0.38) * *$ \\
\hline ACT English & $25.53(4.51)$ & $26.11(4.08)$ & $25.43(2.30) * *$ \\
\hline ACT English Missing Indicator & $0.01(0.09)$ & $0.10(0.30)$ & $0.83(0.38) * *$ \\
\hline High School Percentile Rank & $73.81(18.10)$ & $71.56(17.24)$ & $72.79(7.21) *$ \\
\hline High School Percentile Rank Missing Indicator & $0.19(0.39)$ & $0.31(0.46)$ & $0.90(0.30) * *$ \\
\hline Standardized First Semester GPA & $-0.00(0.81)$ & $0.00(0.74)$ & $0.10(0.84) * *$ \\
\hline First Semester GPA Missing Indicator & $0.02(0.13)$ & $0.02(0.12)$ & $0.05(0.23) * *$ \\
\hline STEM Major & $0.27(0.45)$ & $0.16(0.37)$ & $0.40(0.49) * *$ \\
\hline \multicolumn{4}{|l|}{ Third-year Outcomes: } \\
\hline Remaining Enrolled in the Same Major at MU & $0.38(0.49)$ & - & - \\
\hline Remaining Enrolled at MU & $0.77(0.42)$ & - & - \\
\hline Remaining Enrolled at Any System Campus & $0.86(0.34)$ & - & - \\
\hline Cumulative Credit Hours & $58.83(24.29)$ & - & - \\
\hline Cumulative GPA & $2.91(0.74)$ & - & - \\
\hline Major-level Enrollment & $69.23(126.64)$ & $27.44(69.02)$ & $1.07(2.88)$ \\
\hline $\mathrm{N}$ & 40,638 & 16,108 & 627 \\
\hline \multicolumn{4}{|c|}{$\begin{array}{l}\text { Notes: Racial designation is not available for foreign students as they are coded as "Non-Resident Alien" in } \\
\text { the administrative data. Other Races combine students identified as "American Indian/Alaska Native", } \\
\text { "Two or More Races" and "Other/Unknown" in the data. Standardized First Semester GPA shown in the } \\
\text { table is the residual generated from regressing first semester GPA on major and year fixed effects. * } \\
\text { Indicates statistically significant differences between out-of-state and foreign statistics at the } 10 \text { percent } \\
\text { level or better. ** Indicates statistically significant difference between out-of-state and foreign statistics at } \\
\text { the } 5 \text { percent level or better. }\end{array}$} \\
\hline
\end{tabular}


Table 2.2. Validation Tests of Endogenous Student Sorting.

\begin{tabular}{|c|c|c|c|c|c|c|c|c|c|c|c|}
\hline & Male & Asian & Black & Hispanic & Other Races & ACT Math & $\begin{array}{l}\text { ACT Math } \\
\text { Missing }\end{array}$ & $\begin{array}{c}\text { ACT } \\
\text { English }\end{array}$ & $\begin{array}{l}\text { ACT English } \\
\text { Missing }\end{array}$ & $\begin{array}{l}\text { HS. Pctile. } \\
\text { Rank }\end{array}$ & $\begin{array}{c}\text { HS. Pctile. } \\
\text { Rank } \\
\text { Missing }\end{array}$ \\
\hline Non-Resident Enrollment Share & $\begin{array}{c}0.0011 \\
(0.0007)\end{array}$ & $\begin{array}{l}-0.0001 \\
(0.0001)\end{array}$ & $\begin{array}{l}0.0006^{*} \\
(0.0004)\end{array}$ & $\begin{array}{l}-0.0000 \\
(0.0001)\end{array}$ & $\begin{array}{c}0.0000 \\
(0.0002)\end{array}$ & $\begin{array}{l}-0.0090 \\
(0.0085)\end{array}$ & $\begin{array}{c}0.0001 \\
(0.0001)\end{array}$ & $\begin{array}{l}-0.0071 \\
(0.0104)\end{array}$ & $\begin{array}{c}0.0000 \\
(0.0001)\end{array}$ & $\begin{array}{l}-0.0287 \\
(0.0402)\end{array}$ & $\begin{array}{c}0.0006 \\
(0.0005)\end{array}$ \\
\hline Overall P-value & 0.74 & & & & & & & & & & \\
\hline Major Fixed Effects & $\mathrm{X}$ & $\mathrm{X}$ & $\mathrm{X}$ & $\mathrm{X}$ & $\mathrm{X}$ & $\mathrm{X}$ & $\mathrm{X}$ & $\mathrm{X}$ & $\mathrm{X}$ & $\mathrm{X}$ & $\mathrm{X}$ \\
\hline Year Fixed Effects & $\mathrm{X}$ & $\mathrm{X}$ & $\mathrm{X}$ & $\mathrm{X}$ & $\mathrm{X}$ & $\mathrm{X}$ & $\mathrm{X}$ & $\mathrm{X}$ & $\mathrm{X}$ & $\mathrm{X}$ & $\mathrm{X}$ \\
\hline R-squared & 0.20 & 0.01 & 0.01 & 0.01 & 0.01 & 0.14 & 0.01 & 0.08 & 0.01 & 0.07 & 0.06 \\
\hline $\mathrm{N}$ & 40,638 & 40,638 & 40,638 & 40,638 & 40,638 & 40,638 & 40,638 & 40,638 & 40,638 & 40,638 & 40,638 \\
\hline
\end{tabular}

Notes: This table displays estimates from validation tests of endogenous student sorting. Female and white are the omitted groups. Robust standard errors in parentheses are clustered at the major level. Significance levels: ** 5 percent level, * 10 percent level.

Table 2.3. Estimates of the Effects of Non-Resident Enrollment Growth on Third-Year Outcomes for In-State Students. 


\begin{tabular}{|c|c|c|c|c|c|}
\hline & $\begin{array}{c}\text { Enrolled in } \\
\text { the Same } \\
\text { Major at } \\
\text { MU }\end{array}$ & $\begin{array}{c}\text { Enrolled at } \\
\text { MU }\end{array}$ & $\begin{array}{c}\text { Enrolled at } \\
\text { Any System } \\
\text { Campus }\end{array}$ & $\begin{array}{c}\text { Cum. Credit } \\
\text { Hrs. }\end{array}$ & Cum. GPA \\
\hline \multicolumn{6}{|c|}{$\begin{array}{l}\text { Panel A. Continuous Treatment Differences-in- } \\
\text { Differences Model }\end{array}$} \\
\hline Non-Resident Enrollment Share & $\begin{array}{l}-0.0008 \\
(0.0016)\end{array}$ & $\begin{array}{c}0.0004 \\
(0.0004)\end{array}$ & $\begin{array}{c}0.0001 \\
(0.0003)\end{array}$ & $\begin{array}{c}0.0228 \\
(0.0280)\end{array}$ & $\begin{array}{c}0.0006 \\
(0.0007)\end{array}$ \\
\hline R-squared & 0.13 & 0.06 & 0.04 & 0.21 & 0.30 \\
\hline $\mathrm{N}$ & 40,638 & 40,638 & 40,638 & 40,638 & 40,638 \\
\hline \multicolumn{6}{|l|}{ Panel B. IV Model } \\
\hline Non-Resident Enrollment Share & $\begin{array}{l}-0.0050 \\
(0.0164)\end{array}$ & $\begin{array}{c}0.0008 \\
(0.0019)\end{array}$ & $\begin{array}{c}0.0016 \\
(0.0013)\end{array}$ & $\begin{array}{c}-0.0633 \\
(0.0716)\end{array}$ & $\begin{array}{c}0.0004 \\
(0.0052)\end{array}$ \\
\hline R-squared & 0.15 & 0.06 & 0.04 & 0.21 & 0.28 \\
\hline $\mathrm{N}$ & 26,368 & 26,368 & 26,368 & 26,368 & 26,368 \\
\hline Major Fixed Effects & $\mathrm{X}$ & $\mathrm{X}$ & $\mathrm{X}$ & $\mathrm{X}$ & $\mathrm{X}$ \\
\hline Year Fixed Effects & $X$ & $\mathrm{X}$ & $X$ & $\mathrm{X}$ & $X$ \\
\hline Student Characteristics & $\mathrm{X}$ & $\mathrm{X}$ & $\mathrm{X}$ & $\mathrm{X}$ & $\mathrm{X}$ \\
\hline
\end{tabular}

Notes: Major fixed effects, year fixed effects and student characteristics are included in the continuous treatment differences-in-differences model and the IV model. The coefficients for student characteristics are excluded for brevity. Robust standard errors in parentheses are clustered at the major level. Significance levels: ** 5 percent level, * 10 percent level. 
Table 2.4. Continuous Treatment Differences-in-Differences Model Estimates of the Effects of Out-of-State and Foreign Enrollment Growth on Third-Year Outcomes for In-State Students.

\begin{tabular}{|c|c|c|c|c|c|}
\hline & $\begin{array}{c}\text { Enrolled in } \\
\text { the Same } \\
\text { Major at MU }\end{array}$ & Enrolled at MU & $\begin{array}{l}\text { Enrolled at Any } \\
\text { System Campus }\end{array}$ & Cum. Credit Hrs. & Cum. GPA \\
\hline \multirow[t]{2}{*}{ Out-of-State Enrollment Share } & -0.0004 & 0.0006 & 0.0003 & 0.0265 & 0.0010 \\
\hline & $(0.0017)$ & $(0.0004)$ & $(0.0003)$ & $(0.0284)$ & $(0.0007)$ \\
\hline \multirow[t]{2}{*}{ Foreign Enrollment Share } & $-0.0050 * *$ & $-0.0024 *$ & $-0.0019 *$ & -0.0216 & -0.0034 \\
\hline & $(0.0025)$ & $(0.0014)$ & $(0.0010)$ & $(0.0626)$ & $(0.0021)$ \\
\hline \multicolumn{6}{|l|}{$\mathrm{H}_{0}: \gamma_{1}=\gamma_{2}$} \\
\hline P-Value & 0.144 & 0.039 & 0.030 & 0.434 & 0.037 \\
\hline Major Fixed Effects & $\mathrm{X}$ & $\mathrm{X}$ & $\mathrm{X}$ & $\mathrm{X}$ & $\mathrm{X}$ \\
\hline Year Fixed Effects & $\mathrm{X}$ & $\mathrm{X}$ & $\mathrm{X}$ & $\mathrm{X}$ & $X$ \\
\hline Student Characteristics & $\mathrm{X}$ & $\mathrm{X}$ & $\mathrm{X}$ & $\mathrm{X}$ & $\mathrm{X}$ \\
\hline R-squared & 0.13 & 0.06 & 0.04 & 0.21 & 0.30 \\
\hline $\mathrm{N}$ & 40,638 & 40,638 & 40,638 & 40,638 & 40,638 \\
\hline
\end{tabular}

Notes: $\mathrm{H}_{0}: \gamma_{1}=\gamma_{2}$ is in reference to Equation (2), the null hypothesis is that the coefficients on out-of-state and foreign enrollment shares are equal. The coefficients for student characteristics are excluded for brevity. Robust standard errors in parentheses are clustered at the major level. Significance levels: $* * 5$ percent level, * 10 percent level. 
Table 2.5. Robustness Tests for the Main Estimates of the Effects of Non-Resident Enrollment Growth on Third-Year Outcomes for In- State Students.

Enrolled in the Same Major at MU

Enrolled at MU

Enrolled at Any System Campus

Cum. Credit Hrs.

Cum. GPA

Major Fixed Effects

Year Fixed Effects

Major Characteristics

Student Characteristics

Data

$\mathrm{N}$
(1)

(2)

\begin{abstract}
$-0.0008(0.0016)$
\end{abstract}
$0.0004(0.0004)$

$0.0001(0.0003)$

$0.0228(0.0280)$

$0.0006(0.0007)$

Analytic Sample

$\begin{array}{ll}X & X \\ X & X \\ & X \\ X & X\end{array}$

(3)

$$
-0.0007(0.0013)
$$$$
0.0002(0.0004)
$$

$-0.0000(0.0004)$

$0.0193(0.0269)$

$0.0006(0.0007)$

Analytic Sample

40,638

40,638
$\mathrm{X}$

Analytic Sample

40,638
(4)

$-0.0007(0.0015)$

$0.0004(0.0004)$

$0.0001(0.0004)$

$0.0257(0.0281)$

$0.0006(0.0007)$

$\mathrm{X}$

$\mathrm{X}$

$\mathrm{X}$

Excluding Interdisciplinary Studies Students 35,398

Notes: The coefficients for major and student characteristics are excluded for brevity. Robust standard errors in parentheses are clustered at the major level. Significance levels: $* * 5$ percent level, $* 10$ percent level. 
Table 2.6. Continuous Treatment Differences-in-Differences Model Estimates of the Effects of Non-Resident Enrollment Growth on Third-Year Outcomes for In-state Students, by Gender and Race.

\begin{tabular}{|c|c|c|c|c|c|}
\hline & $\begin{array}{l}\text { Enrolled in } \\
\text { the Same } \\
\text { Major at MU }\end{array}$ & $\begin{array}{c}\text { Enrolled at } \\
\text { MU }\end{array}$ & $\begin{array}{c}\text { Enrolled at } \\
\text { Any System } \\
\text { Campus }\end{array}$ & $\begin{array}{c}\text { Cum. Credit } \\
\text { Hrs. }\end{array}$ & Cum. GPA \\
\hline \multirow[t]{2}{*}{ Non-Resident Enrollment Share } & -0.0014 & 0.0001 & -0.0001 & 0.0098 & 0.0002 \\
\hline & $(0.0019)$ & $(0.0004)$ & $(0.0004)$ & $(0.0291)$ & $(0.0008)$ \\
\hline \multirow[t]{2}{*}{ Non-Resident Enrollment Share*Female } & 0.0013 & 0.0006 & 0.0004 & $0.0301 *$ & $0.0009 *$ \\
\hline & $(0.0008)$ & $(0.0004)$ & $(0.0003)$ & $(0.0174)$ & $(0.0005)$ \\
\hline \multirow[t]{2}{*}{ Non-Resident Enrollment Share*Black } & 0.0005 & -0.0002 & 0.0001 & -0.0282 & 0.0005 \\
\hline & $(0.0010)$ & $(0.0005)$ & $(0.0003)$ & $(0.0317)$ & $(0.0009)$ \\
\hline \multirow[t]{2}{*}{ Non-Resident Enrollment Share*All Other Races } & -0.0006 & -0.0006 & 0.0002 & 0.0021 & $-0.0010 *$ \\
\hline & $(0.0010)$ & $(0.0004)$ & $(0.0004)$ & $(0.0244)$ & $(0.0005)$ \\
\hline Major Fixed Effects & $X$ & $X$ & $X$ & $X$ & $X$ \\
\hline Year Fixed Effects & $X$ & $X$ & $\mathrm{X}$ & $X$ & $\mathrm{X}$ \\
\hline Student Characteristics & $X$ & $\mathrm{X}$ & $\mathrm{X}$ & $X$ & $X$ \\
\hline R-squared & 0.13 & 0.06 & 0.04 & 0.21 & 0.30 \\
\hline $\mathrm{N}$ & 40,638 & 40,638 & 40,638 & 40,638 & 40,638 \\
\hline
\end{tabular}

Notes: All Other Races combines in-state students identified as Asian/ Pacific Islander, Hispanic and Other Races in Table 2.1, due to small sample size of these racial groups. White and male are the omitted groups in the regressions. Estimates for Non-Resident Enrollment Share are for the baseline group, i.e., white male in-state students. The coefficients for student characteristics are excluded for brevity. Robust standard errors in parentheses are clustered at the major level.

Significance levels: $* * 5$ percent level, $* 10$ percent level. 
Table 2.7. Binned Model Estimates of the Effects of Out-of-State and Foreign Enrollment Growth on Third-Year Outcomes for InState Students.

\begin{tabular}{|c|c|c|c|c|c|}
\hline & $\begin{array}{c}\text { Enrolled in } \\
\text { the Same } \\
\text { Major at MU }\end{array}$ & Enrolled at MU & $\begin{array}{c}\text { Enrolled at } \\
\text { Any System } \\
\text { Campus }\end{array}$ & $\begin{array}{c}\text { Cum. Credit } \\
\text { Hrs. }\end{array}$ & Cum. GPA \\
\hline Top Quartile Out-of-State*Post Out-of-State & $\begin{array}{c}0.0137 \\
(0.0347)\end{array}$ & $\begin{array}{c}0.0162 * * \\
(0.0070)\end{array}$ & $\begin{array}{c}0.0065 \\
(0.0049)\end{array}$ & $\begin{array}{c}0.4386 \\
(0.4001)\end{array}$ & $\begin{array}{l}0.0260 * \\
(0.0144)\end{array}$ \\
\hline Top Quartile Foreign*Post Foreign & $\begin{array}{l}-0.0528 \\
(0.0476)\end{array}$ & $\begin{array}{l}-0.0251 * \\
(0.0134)\end{array}$ & $\begin{array}{c}-0.0280 * * \\
(0.0115)\end{array}$ & $\begin{array}{l}-0.4031 \\
(0.6839)\end{array}$ & $\begin{array}{l}-0.0190 \\
(0.0175)\end{array}$ \\
\hline $\begin{array}{l}\mathrm{H}_{0}: \eta_{1}=\eta_{2} \\
\text { P-Value }\end{array}$ & 0.280 & 0.003 & 0.006 & 0.266 & 0.054 \\
\hline Major Fixed Effects & $\mathrm{X}$ & $\mathrm{X}$ & $\mathrm{X}$ & $\mathrm{X}$ & $\mathrm{X}$ \\
\hline Year Fixed Effects & $\mathrm{X}$ & $\mathrm{X}$ & $\mathrm{X}$ & $\mathrm{X}$ & $\mathrm{X}$ \\
\hline Student Characteristics & $X$ & $\mathrm{X}$ & $X$ & $\mathrm{X}$ & $\mathrm{X}$ \\
\hline R-squared & 0.13 & 0.06 & 0.04 & 0.21 & 0.30 \\
\hline $\mathrm{N}$ & 40,638 & 40,638 & 40,638 & 40,638 & 40,638 \\
\hline
\end{tabular}

Notes: Post Out-of-State is for year 2008 and after; Post Foreign is for year 2012 and after. $\mathrm{H}_{0}: \eta_{1}=\eta_{2}$ is in reference to Equation (5), the null hypothesis is that the coefficients on out-of-state and foreign enrollment interaction terms are equal. The coefficients for student characteristics are excluded for brevity. Robust standard errors in parentheses are clustered at the major level. Significance levels: ** 5 percent level, * 10 percent level. 


\section{Chapter 3.}

\section{Changes in Student Demand for Majors and Faculty Investment}

\subsection{Introduction}

A growing number of studies focus on how supply-side factors influence college students' educational outcomes, such as student-faculty ratios, public funding and expenditures, and college quality (Bound and Turner, 2007; Bound et al., 2010; Cohodes and Goodman, 2014; Light and Strayer, 2000; Scott et al., 2006; Zhang, 2009). ${ }^{64}$ While most of the studies have highlighted the variation of resources at the university or higher levels, the access to resources also likely varies within universities. However, there is no empirical evidence to date on how universities adjust resources internally in response to changes in student demand for majors. The research question this paper aims to investigate is that if resources, as measured by faculty size and salary expenditures, are responsive to changes in student demand within universities.

To answer this question I use an administrative data panel from the University of Missouri-Columbia (MU) that covers the years 2004-05 to 2014-15. I use student-level data to construct annual counts of freshman enrolled by major, and bachelor's degrees conferred, and merge this information with faculty salary data by academic department. With the merged data panel I examine how faculty resources on both the extensive (the numbers of faculty) and intensive (the salaries of faculty) margins are related to changes in student demand over time.

\footnotetext{
64 There is also a large literature on the effect of school resources on student performance at the K-12 level,
} see Card and Krueger (1996) and Hanushek (1997) for comprehensive reviews. 
In levels I show that departments with more student demand, as measured by freshman enrollment and bachelor's degrees conferred, have larger faculty stocks and total salary expenditures. However, I find no evidence that fluctuations in student demand over my 11-year data panel map to changes in faculty size or salary expenditures. Specifically, the coefficient estimates from regressions of the growth in faculty supply on the growth in student demand are small and mostly statistically insignificant. These findings are robust to a variety of different ways of weighting the data, various sample modifications, and using different measures of growth.

To the best of my knowledge, this study is the first to document the relationship between growth in student demand and faculty resources within a university. Although only a single institution, MU is an instructive case given its place in the middle of the distribution among state flagship universities, which suggests some degree of generalizability. ${ }^{65}$ Noting the above-mentioned causal evidence showing that institutional resources have important effects on student outcomes at the university or higher levels, the descriptive evidence presented here can serve as a point of departure for deeper studies into within-institution resource allocations. ${ }^{66}$

\subsection{Data}

I use two different data sources for my empirical analysis. First, I use administrative data provided by the Missouri Department of Higher Education (DHE) following students, which allows me to measure student demand for specific majors at MU. I focus specifically

\footnotetext{
${ }^{65} \mathrm{MU}$ is ranked 29th among the 50 state flagship universities by U.S. News and World Report. As of 2016, it had the 27th largest freshman enrollment, the 18th largest number of bachelor's degrees conferred, the 26th largest full-time instructional faculty and the 32th largest salary outlays among flagship universities.

${ }^{66}$ As Loeb et al. (2017) points out, descriptive analysis is an integral part of scientific research, particularly education research.
} 
on freshman enrollment and bachelor's degrees conferred at the University of MissouriColumbia (MU) between the 2004-05 and 2014-15 academic years as the two measures of student demand (for presentational convenience I refer to academic years by the fall year throughout this study, e.g., 2004 for 2004-05).

Figure 3.1 provides an overview of freshman enrollment and bachelor's degrees conferred at MU over the course of the data panel. ${ }^{67}$ The data demonstrate substantial growth in freshman enrollment overall at MU, especially since 2008 . This is predominately driven by a university-wide expansion of non-resident enrollment. ${ }^{68}$ The number of bachelor's degrees conferred at MU also grew markedly over the course of my data panel, particularly between 2011 and 2014, which is consistent with the freshman enrollment trend.

The second data source is the University of Missouri System Annual Salary Report. The report contains faculty salary data and includes each employee's name, academic department, title and annual base salary. I focus on all faculty members whose position involved at least some teaching at MU between 2004 and 2014. Faculty appointments are further classified into three groups, i.e., full-time tenure-track faculty, full-time non-tenuretrack teaching faculty, and part-time teaching faculty. ${ }^{69}$ Below I report on two measures of

\footnotetext{
${ }^{67}$ Freshman enrollment data are restricted to first-time, degree-seeking, full-time students entering MU as college freshmen from 2004 to 2014.

${ }^{68} \mathrm{MU}$ rapidly increased out-of-state domestic enrollment beginning in fall-2008, and later expanded its recruiting efforts to foreign students in fall-2012. See $\mathrm{Li}$ (2018) for detailed discussion.

${ }^{69}$ Emeritus faculty and research faculty are excluded for the purpose of this study. Examples of part-time faculty includes adjunct and visiting faculty. See Collected Rules and Regulations for faculty at University of Missouri System for further discussions on academic appointments: https://www.umsystem.edu/ums/rules/collected_rules/faculty/ch310/310.035_non-tenure_track_faculty.
} 
faculty resources at the department level: the number of faculty and the total (base) salary expenditure. ${ }^{70}$

Figure 3.2 shows trends of the number and total salary of faculty at MU between 2004 and 2014 for tenure-track and all faculty, respectively. Panel A shows the number of tenure-track faculty is flat over the course of my data panel, while the number of all faculty increases by 25 percent, driven by growth in full-time teaching and part-time faculty. The change in the composition of faculty could have important policy implications as previous studies find adverse effects of increased usage of non-tenure-track faculty on student educational outcomes at the postsecondary level (Ehrenberg and Zhang, 2004; Jacoby, 2006; Calcagno et al., 2008). ${ }^{71}$ Panel B demonstrates that total annual salaries have grown at comparable rates between tenure-track and all faculty, although there is some divergence for the all-faculty trend attributable to the expansion of the non-tenure-track workforce.

To investigate how the faculty resources respond to changes in student demand across academic departments, I aggregate the student administrative data and faculty salary data at the department level and merge them. ${ }^{72}$ Overall, I identify 48 academic departments in my analytic sample. ${ }^{73}$ The merged data contain the numbers of freshman and bachelor's degrees conferred, in addition to faculty counts and total annual salary expenditures for

\footnotetext{
${ }^{70}$ Empirically, results for full-time faculty (i.e., full-time tenure-track and non-tenure-track teaching faculty) align closely with the findings for all faculty. Results for full-time faculty are omitted for brevity.

${ }^{71}$ Although there is some disagreement in the literature. For a recent counterexample, see Figlio et al. (2015).

${ }^{72}$ I identify academic departments in student administrative data based on the Classification of Instructional Program (CIP), which is a taxonomic scheme developed by the U.S. Department of Education's National Center for Education Statistics (NCES). The matching between CIP codes and academic departments is aided by a crosswalk provided by MU Institutional Research. CIP codes corresponding to interdepartmental programs, such as general studies, linguistics and interdisciplinary studies, are dropped due to lack of a match to any specific academic department reported in faculty salary data.

${ }^{73}$ There are 54 academic departments when matched to bachelor's degree CIP codes. This is because incoming freshmen in schools of business and engineering at MU are placed under the "undecided" CIP code within that school, and the academic apartments within the two schools need to be further aggregated up to the school level for the freshman enrollment data.
} 
each department. The analytic work that follows uses freshman enrollment as the primary measure of student demand. ${ }^{74}$ That said, similar results are obtained throughout if bachelor's degrees conferred is used instead, as shown in the appendix.

\subsection{Empirical Analysis and Results}

In this section I regress the measures of faculty resources on student demand at the department level. I begin with a simple regression model as follows:

Faculty $_{i t}=\beta_{0}+\beta_{1}$ Enrollment $_{i t}+\varphi_{t}+\varepsilon_{i t}$

In Equation (3.1), Faculty $_{i t}$ is a measure of faculty resources for academic department $i$ in year $t$. Four measures of faculty resources are used: (1) the number of tenure-track faculty, (2) the total number of faculty with a teaching role, (2) the total annual base salary expenditure for tenure-track faculty, and (4) the total annual base salary expenditure for all faculty with a teaching role. ${ }^{75}$ Enrollment $_{i t}$ captures the number of freshmen enrolled in department $i$ and year $t . \varphi_{t}$ is a year fixed effect, which accounts for common shocks over time across all departments. $\varepsilon_{i t}$ is an idiosyncratic error term. The standard errors are clustered at the department level.

Table 3.1 shows the output from regressions of the different faculty-resource measures on the number of freshmen and the year fixed effect. For each outcome I report results with and without faculty population weights. The faculty population weights reweight the data so that each academic department contributes to the estimates in proportion to the number of full-time tenure-track faculty in that department as of 2004; i.e., the first year of my data panel. There is substantial variability in department sizes, and therefore

\footnotetext{
${ }^{74}$ Given that majors are the product of supply and demand, the number of freshmen is a more credible measure of student demand at the department level.

${ }^{75}$ Replacing all faculty with full-time faculty does not affect the main findings; for presentational convenience the results for full-time faculty are omitted for brevity.
} 
unweighted estimates can be significantly influenced by noisy observations. The rationale behind the faculty population weights is to give more weight to observations from larger departments, which are less susceptible to wild fluctuations in faculty resources and student demand..$^{76}$

Table 3.1 illustrates that the number of freshmen is positively and significantly associated with all four measures of faculty resources. Estimates with and without faculty population weights are closely aligned, indicating that the results are not sensitive to data weighting. The results suggest that a one-standard-deviation increase in the number of freshmen (209) within a department is associated with increases in the numbers of tenuretrack and all faculty of 8 (i.e., $209 * 0.04=8.36$ ) and 17 , respectively. The same increment in the number of degrees conferred is also associated with larger total salary expenditures of tenure-track and all faculty by 1.2 and 1.6 million dollars. Given the sample averages of these variables, which are shown in Panel A of Appendix Table D.1, the magnitudes of the positive linear relationships between degrees and faculty resources are substantial. As noted above, similar results are obtained if I measure student demand using bachelor's degrees conferred (see Appendix Table D.2). Overall, the empirical evidence confirms that departments with more students have more faculty resources.

Despite the findings in Table 3.1, the response of the university to increased student demand in terms of changes to resource allocations over time is unclear. To investigate this issue I regress the annual growth rate of faculty resources over time on the annual growth rate of freshman enrollment. My main results are shown in Figures 3.3 (number of faculty)

\footnotetext{
${ }^{76}$ My findings are not sensitive to the type of weights applied to the data. In results omitted for brevity, I replace faculty population weights by student population weights where the data are re-weighted by the number of degrees in 2004 , and the estimates do not change significantly.
} 
and 3.4 (faculty salary expenditures), estimated separately for tenure-track (Panel A) and all faculty (Panel B). Each panel shows scatterplots overlaid with a regression-fit line demonstrating the linear relationship between the measures. The regression coefficient estimate and its statistical significance are also reported. The figures show results from weighted regressions (again using the 2004 faculty population weights) to reduce the influence of smaller departments on coefficient estimates.

Focusing first on the relationships between growth in freshman enrollment and faculty sizes, Figure 3.3 shows that departments with a higher average annual growth rate in freshman enrollment do not appear to experience a proportionate growth rate in the number of faculty. The scatterplots and fitted lines provide only weak visual evidence of a relationship and the regression coefficients are substantively small and statistically insignificant. For example, the insignificant relationships, if taken at face value, suggest that a one-percentage-point higher average annual growth rate in the number of degrees is associated with a 0.01 -percentage-point lower average growth rate in the number of tenuretrack faculty. The same increment is also associated with a 0.01-percentage-point higher average growth rate in the number of all faculty. ${ }^{77}$ Overall, there is no evidence to suggest that the number of freshmen and faculty grew at comparable rates during the timespan of my data panel.

Figure 3.4 shows the analogous linear relationships for faculty salary expenditures, which indicate similar null results. Like Figure 3.3, the regression estimates are substantively small, and neither is statistically significant. Overall, Figures 3.3 and 3.4

\footnotetext{
77 The sample averages of these outcomes are reported in Panel B of Appendix Table D.1.
} 
provide no indication that an increase in student demand is associated with a proportionate increase in faculty resources.

One possible explanation for the null results is the usage of an incremental budget model. According to a report from Education Advisory Board (EAB) in 2014, 66 percent of higher education institutions use an incremental budget model, where each academic unit's budget is based on its resource allocation in the previous year and across-the-board increases or decreases depend on total institutional resources (EAB, 2014). Known for its simplicity, this standard model is difficult to maintain without continuous growth in revenue, such as when state appropriations have been declining for public universities, including MU, over the last decade (University of Missouri System, 2018). Although the amount of discretion afforded to administrators in terms of resource allocation is unclear under an incremental budget model, the lack of an explicit link between growth in student demand and investment in faculty resources in the budget model likely contributes to the lack of responsiveness in the adjustment of faculty supply to changes in student demand at MU over the timespan of my data panel.

\subsection{Robustness Tests}

I perform a number of robustness tests to stress-test these results in the appendix. Appendix Figures D.1 and D.2 replicate the main results in Figures 3.3 and 3.4 but use growth in degrees conferred, rather than freshman enrollment, to measure changes in student demand. The results do not change qualitatively, as all point estimates are substantively small and statistically insignificant. Appendix Figures D.3 and D.4 replicate the main results without the faculty population weights. The results do not change significantly from Figures 3.3 and 3.4. In results omitted for brevity, I also estimate the 
relationships using degrees conferred without weighting and the results are again very similar.

The analysis thus far has measured growth using the annual average over the course of my data panel. An alternative growth measure is the cumulative growth rate between two separate time periods. In Appendix Figures D.5 and D.6 I show the relationships between growth rates of freshman enrollment and faculty resources as measured by the increase on average over the pre-2008 and post-2008 periods. As shown in Figure 3.1, the overall number of freshmen at MU grew markedly since 2008 due to the university-wide expansion on non-resident enrollment.

Appendix Figures D.5 and D.6 provides no evidence of a relationship between growths in freshman enrollment and faculty resources. To further explore the sensitivity of the findings to how growth is measured, in results omitted for brevity I replicate the analysis in Appendix Figures D.5 and D.6, but use degrees conferred rather than freshman enrollment to capture student demand and the results are broadly similar. ${ }^{78}$ Overall, the totality of the empirical evidence does not indicate increased student demand is accompanied by an increase in faculty resources at the department level during the timespan of my data panel.

\subsection{Concluding Remarks}

I construct an 11-year data panel that combines information about freshman enrollment and degrees conferred at the department level with information about faculty resources at the University of Missouri-Columbia (MU). These data facilitate an

\footnotetext{
${ }^{78}$ In results omitted for brevity, I also construct an additional measure of growth that measures the change from the first two years of my data panel, 2004 and 2005, to the last two years, 2013 and 2014. The results do not change significantly.
} 
exploratory investigation of how changes in faculty resources are associated with changes in student demand over time within the university. In levels, larger numbers of freshmen and degrees conferred are associated with larger faculty stocks and salary expenditures; however, faculty resources have not adjusted commensurate with changes to student demand at the department level over the 11 years covered by my study. The coefficient estimates from regressions of the growth in faculty resources on the growth in student demand are substantively small and mostly statistically insignificant.

As stated above, given that there has not been empirical evidence of withininstitution resource allocations, to the aim of this paper was to provide descriptive analysis that can serve as the first step for causal studies in the future. However, the null results presented above allow for some causal inference, implying that investment in faculty supply at the department level is not affected by the changes in student demand at MU during the timespan of my data panel. It is difficult to identify a potential source of bias that could be responsible for the null findings if there was a true, positive relationship.

I conclude by briefly discussing the policy implication of my findings that increased student demand is not accompanied by an increase in faculty resources at the department level over the timespan of my data panel. Given that previous studies have shown the importance of institutional resources as a determinant of educational outcomes at the postsecondary level (Bound and Turner, 2007; Bound et al., 2010; Scott et al., 2006; Zhang, 2009), targeted effort to align changes in resources to changes in student demand could improve production efficiency in postsecondary education. 
Figure 3.1. Trends of Freshman Enrollment and Bachelor's Degrees Conferred at MU.

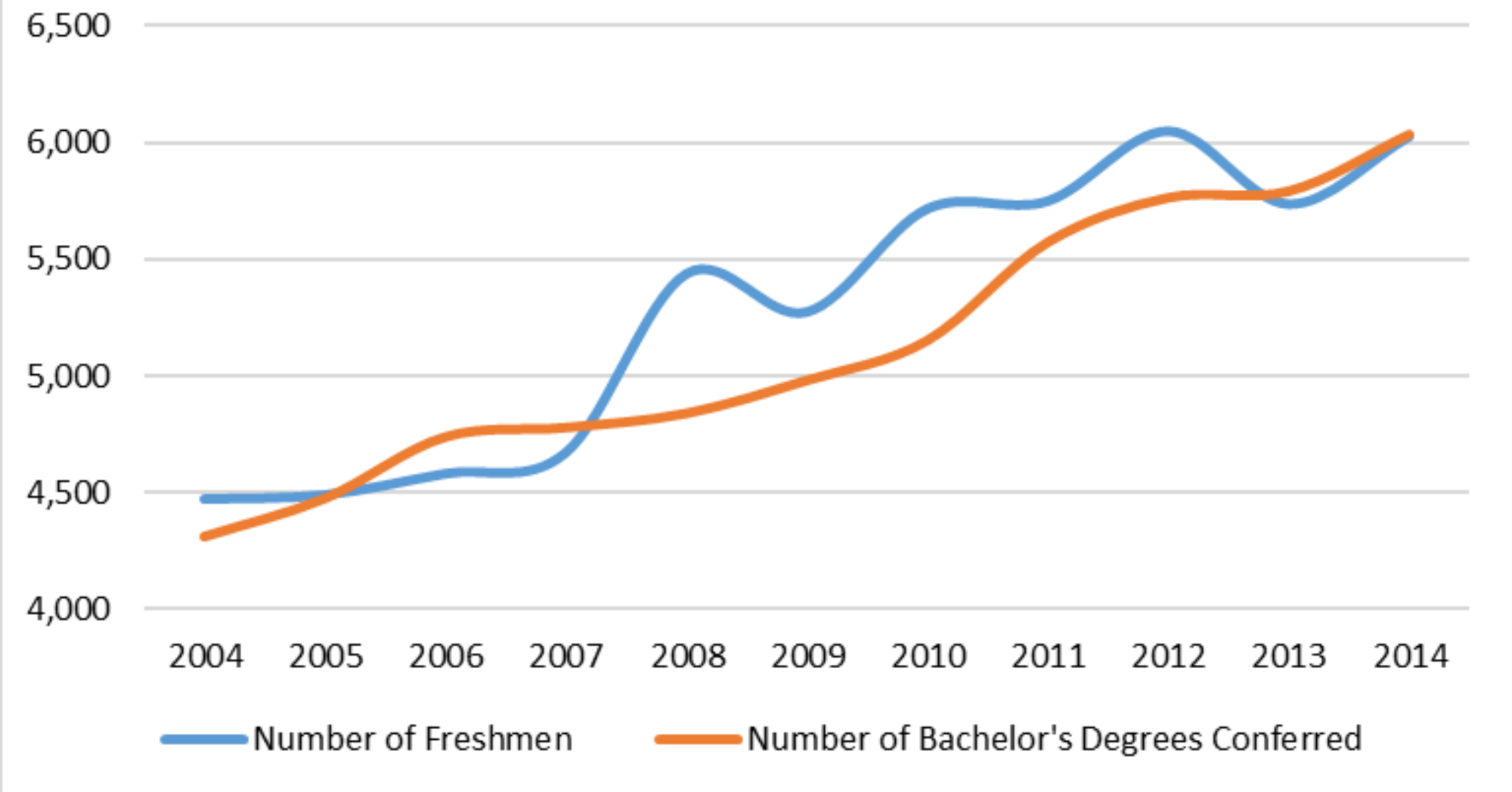

Notes: This graph displays freshman enrollment and bachelor's degrees trends at University of Missouri-Columbia (MU) from 2004/05 (2004) to 2014/15 (2014) academic years. Freshman enrollment data are restricted to first-time, degree-seeking, full-time students entering MU as college freshmen from 2004 to 2014. 
Figure 3.2. Number and Total Annual Salaries of Faculty at MU.

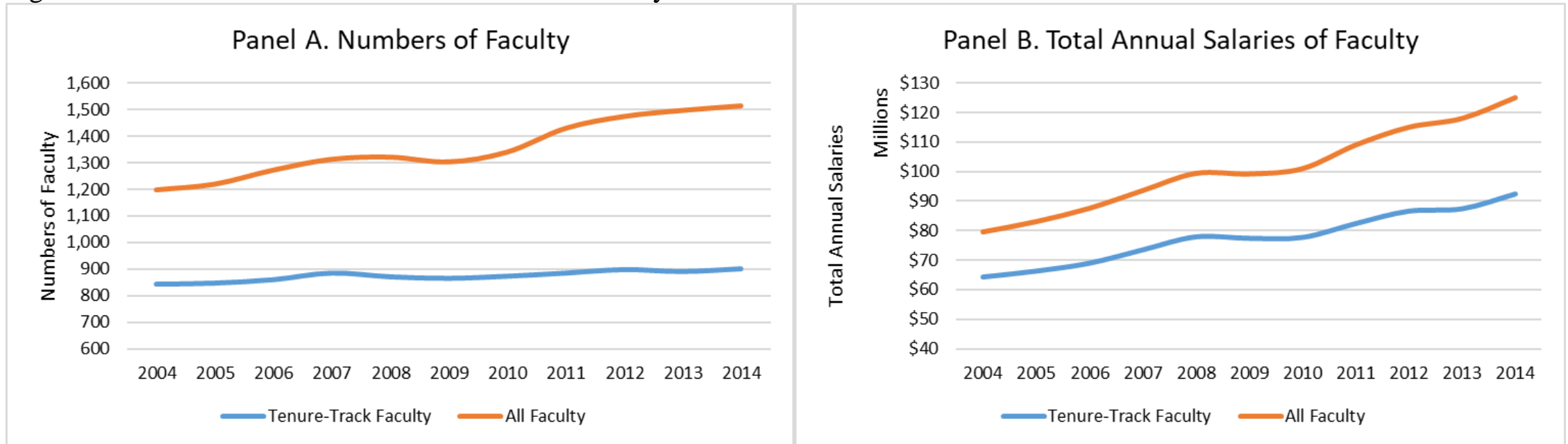

Notes: This graph displays trends for the numbers and total annual salaries of faculty at University of Missouri-Columbia (MU) from 2004/05 (2004) to 2014/15 (2014) academic years. All Faculty includes every faculty member whose position involved at least some teaching. All Faculty are further classified into three groups, i.e., full-time tenure-track faculty, full-time non-tenure-track teaching faculty and part-time faculty. Tenure-Track Faculty displayed in this graph restricts the data to full-time tenure-track faculty. 
Figure 3.3. Relationships between the Annual Growths in Freshman Enrollment and Faculty Size, with Faculty Population Weighting.

Panel A. Tenure-Track Faculty

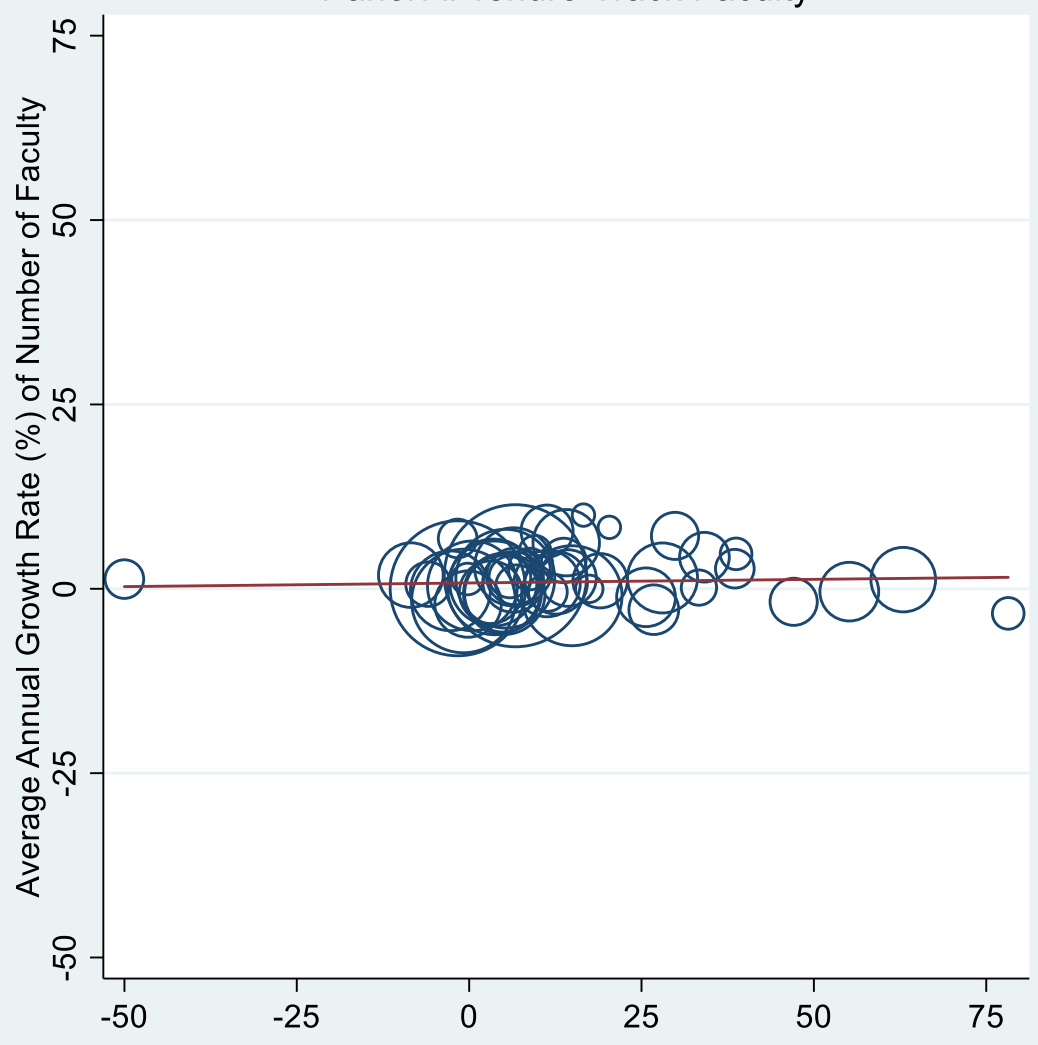

Slope $=0.01, P$-value $=0.62, \mathrm{~N}=48$

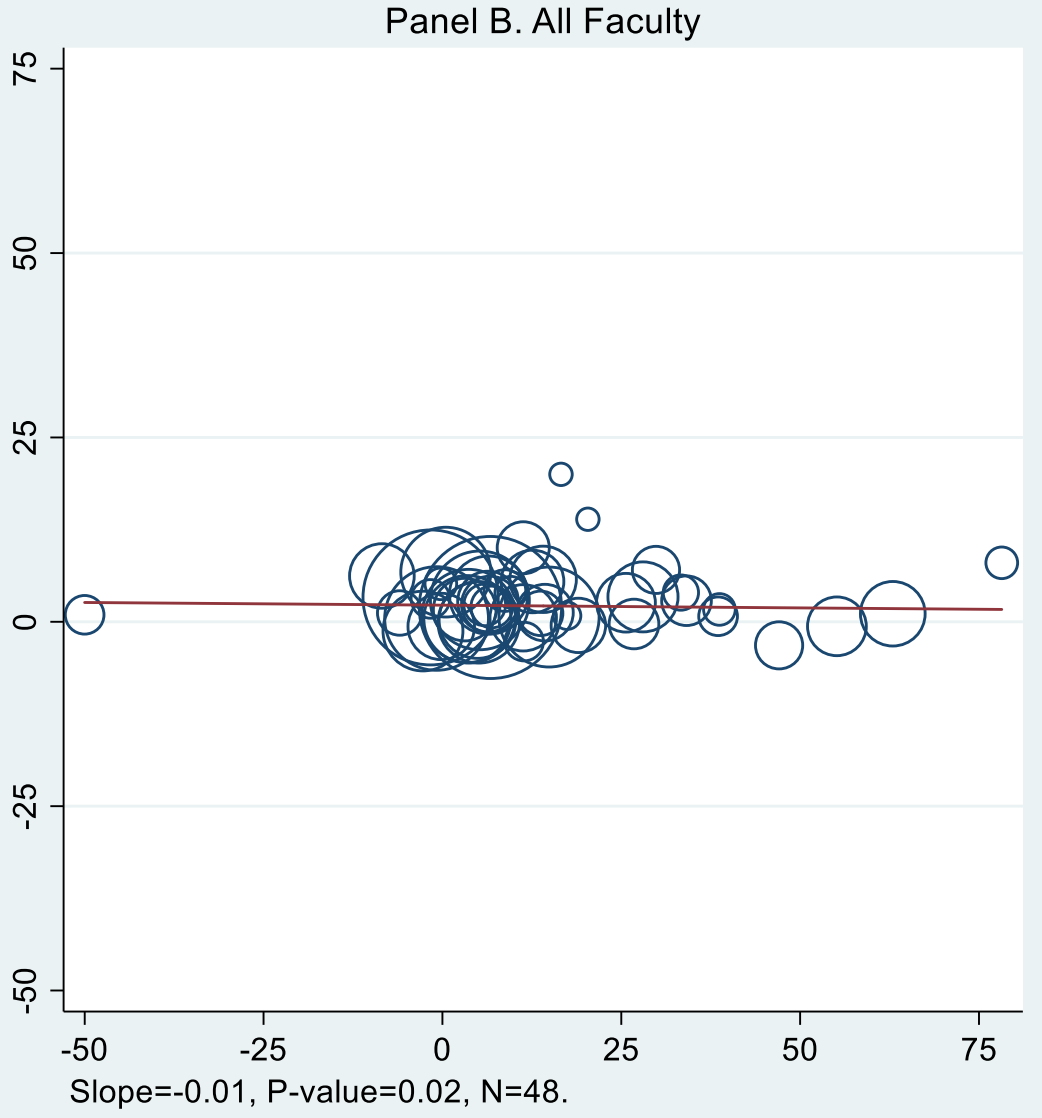

Average Annual Growth Rate (\%) of Number of Freshmen

Notes: Faculty population weighting is such that all academic departments receive a weight equal to the number of tenure-track faculty in that department and 2004/05 academic year, i.e., the first year of my data panel. 
Figure 3.4. Relationships between the Annual Growths in Freshman Enrollment and Total Salaries of Faculty, with Faculty Population Weighting.
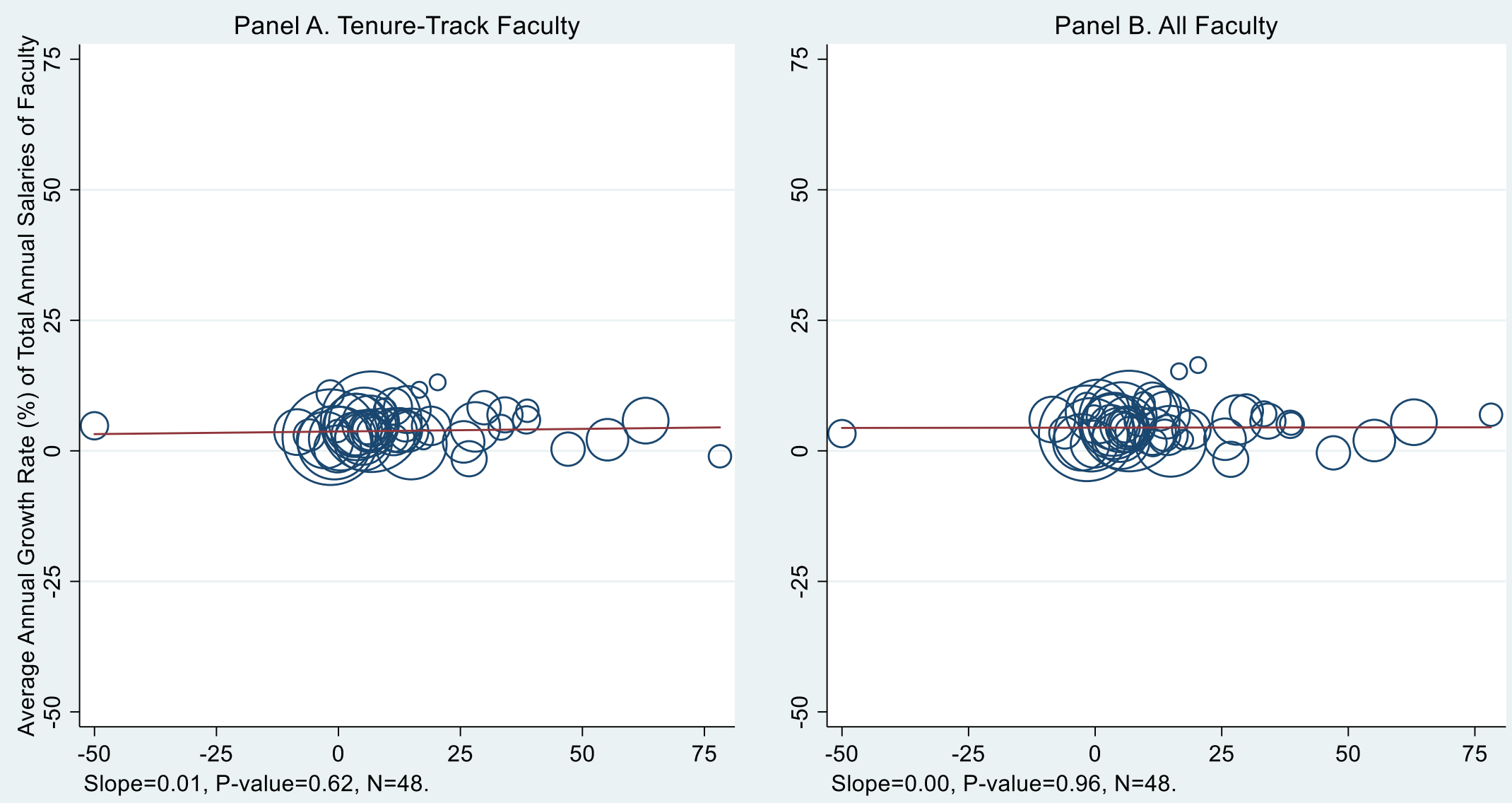

Average Annual Growth Rate (\%) of Number of Freshmen

Notes: Faculty population weighting is such that all academic departments receive a weight equal to the number of tenure-track faculty in that department and 2004/05 academic year, i.e., the first year of my data panel. 
Table 3.1. Output from Regressions of Faculty Resources on Freshman Enrollment.

\begin{tabular}{ccccccccc}
\hline & \multicolumn{2}{c}{$\begin{array}{c}\text { Number of Tenure- } \\
\text { Track Faculty }\end{array}$} & \multicolumn{2}{c}{ Number of All } & \multicolumn{2}{c}{ Total Annual Salaries of } & \multicolumn{2}{c}{ Total Annual Salaries of } \\
Number of Freshmen & $0.05^{* *}$ & $0.04^{* *}$ & $0.09 * *$ & $0.08^{* *}$ & $5648.52^{* *}$ & $5851.66^{* *}$ & $8542.72^{* *}$ & $7864.35^{* *}$ \\
& $(0.01)$ & $(0.02)$ & $(0.02)$ & $(0.02)$ & $(1755.11)$ & $(2234.52)$ & $(1717.83)$ & $(1813.92)$
\end{tabular}

Faculty Population Weights

Year Fixed Effects

$\begin{array}{cccccccc} & \mathrm{X} & & \mathrm{X} & & \mathrm{X} & \mathrm{X} \\ \mathrm{X} & \mathrm{X} & \mathrm{X} & \mathrm{X} & \mathrm{X} & \mathrm{X} & \mathrm{X} & \mathrm{X} \\ 0.33 & 0.26 & 0.49 & 0.40 & 0.48 & 0.44 & 0.61 & 0.59 \\ 528 & 528 & 528 & 528 & 528 & 528 & 528 & 528\end{array}$

R-squared

528

528

528

Notes: Faculty population weighting is such that all academic departments receive a weight equal to the number of tenure-track faculty in that department and 2004/05 academic year, i.e., the first year of my data panel. Robust standard errors in parentheses are clustered at the major level. Significance levels: ** 5 percent level, * 10 percent level. 


\section{Appendix A}

\section{Supplementary Figures and Tables for Chapter 1}

Appendix Figure A.1. Replication of Figure 1.1, Including Non-Tenure-Track Teaching Faculty.
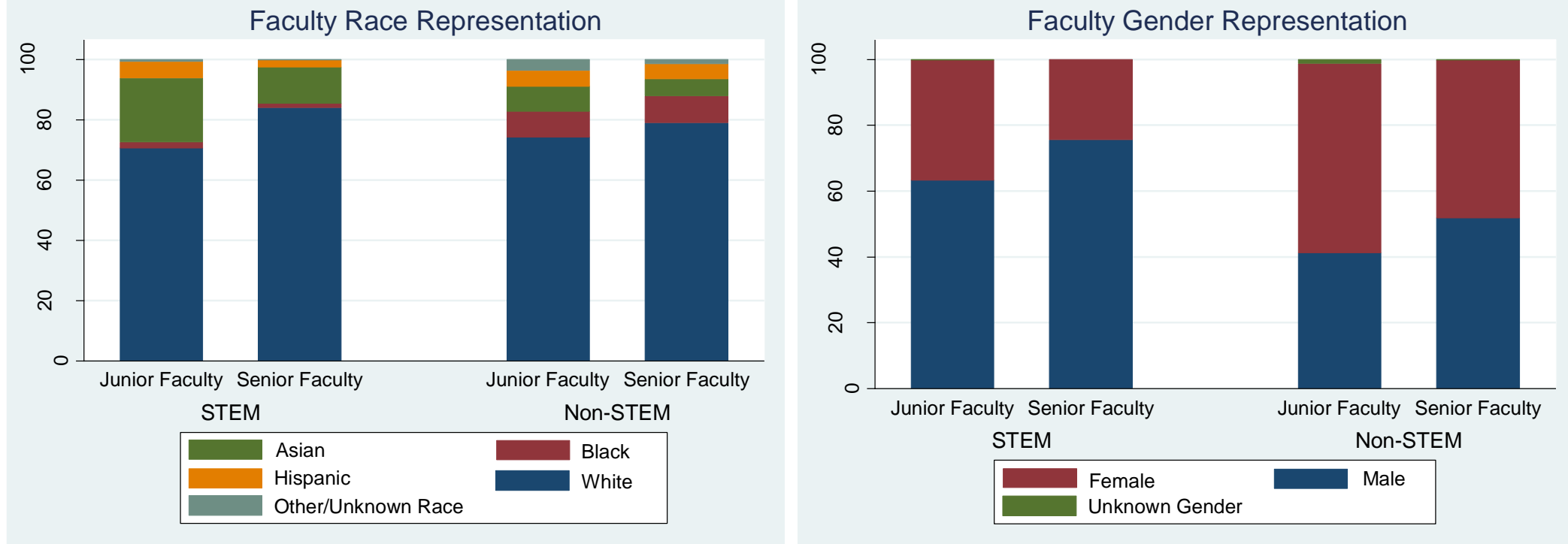

Note: Assistant professors and lecturers are considered junior faculty; associate/full professors and senior lecturers are considered senior faculty. 
Appendix Table A.1. Sample of Universities and Departments.

\begin{tabular}{|c|c|c|c|c|c|c|}
\hline & Biology & Chemistry & Economics & $\begin{array}{c}\text { Education } \\
\text { (Leadership/ } \\
\text { Policy) }\end{array}$ & English & Sociology \\
\hline University of California-Berkeley & & & & $\mathrm{X}$ & $\mathrm{X}$ & $\mathrm{X}$ \\
\hline University of California-Los Angeles & & $\mathrm{X}$ & $\mathrm{X}$ & $\mathrm{X}$ & & \\
\hline University of Virginia & & & $\mathrm{X}$ & $\mathrm{X}$ & $\mathrm{X}$ & \\
\hline University of Michigan-Ann Arbor & & & $\mathrm{X}$ & $\mathrm{X}$ & & $\mathrm{X}$ \\
\hline University of North Carolina-Chapel Hill & & $\mathrm{X}$ & $\mathrm{X}$ & & & $\mathrm{X}$ \\
\hline College of William \& Mary & & $\mathrm{X}$ & $\mathrm{X}$ & & $\mathrm{X}$ & \\
\hline Georgia Institute of Technology & $\mathrm{X}$ & & $\mathrm{X}$ & & & $\mathrm{X}$ \\
\hline University of California-Santa Barbara & $\mathrm{X}$ & & & & $\mathrm{X}$ & $\mathrm{X}$ \\
\hline University of California-Irvine & $\mathrm{X}$ & $\mathrm{X}$ & $\mathrm{X}$ & & & \\
\hline University of California-San Diego & $\mathrm{X}$ & & & & $\mathrm{X}$ & $\mathrm{X}$ \\
\hline University of Illinois-Urbana-Champaign & $\mathrm{X}$ & & & & $\mathrm{X}$ & $\mathrm{X}$ \\
\hline University of Wisconsin-Madison & & $\mathrm{X}$ & & $\mathrm{X}$ & & $\mathrm{X}$ \\
\hline University of Florida & $\mathrm{X}$ & & $\mathrm{X}$ & & $\mathrm{X}$ & \\
\hline Ohio State University-Columbus & & & $\mathrm{X}$ & $\mathrm{X}$ & $\mathrm{X}$ & \\
\hline University of Texas-Austin & & $\mathrm{X}$ & & $\mathrm{X}$ & & $\mathrm{X}$ \\
\hline University of Washington & $\mathrm{X}$ & & $\mathrm{X}$ & $\mathrm{X}$ & & \\
\hline University of Connecticut & $\mathrm{X}$ & $\mathrm{X}$ & $\mathrm{X}$ & & & \\
\hline University of Maryland-College Park & $\mathrm{X}$ & $\mathrm{X}$ & & & & $\mathrm{X}$ \\
\hline Clemson University & $\mathrm{X}$ & & & $\mathrm{X}$ & & $\mathrm{X}$ \\
\hline Purdue University-West Lafayette & $\mathrm{X}$ & & $\mathrm{X}$ & $\mathrm{X}$ & & \\
\hline University of Georgia & & $\mathrm{X}$ & & $\mathrm{X}$ & $\mathrm{X}$ & \\
\hline University of Minnesota-Twin Cities & $\mathrm{X}$ & & $\mathrm{X}$ & $\mathrm{X}$ & & \\
\hline Texas A\&M University-College Station & & $\mathrm{X}$ & & $\mathrm{X}$ & $\mathrm{X}$ & \\
\hline Virginia Tech & $\mathrm{X}$ & & & $\mathrm{X}$ & $\mathrm{X}$ & \\
\hline Rutgers University-New Brunswick & $\mathrm{X}$ & & & $\mathrm{X}$ & & $\mathrm{X}$ \\
\hline Indiana University-Bloomington & & & $\mathrm{X}$ & $\mathrm{X}$ & $\mathrm{X}$ & \\
\hline Michigan State University & $\mathrm{X}$ & $\mathrm{X}$ & $\mathrm{X}$ & & & \\
\hline University of Massachusetts-Amherst & $\mathrm{X}$ & & $\mathrm{X}$ & & $\mathrm{X}$ & \\
\hline Miami University-Oxford & $\mathrm{X}$ & & $\mathrm{X}$ & & & $\mathrm{X}$ \\
\hline University of Iowa & & $\mathrm{X}$ & $\mathrm{X}$ & & $\mathrm{X}$ & \\
\hline Binghamton University-SUNY & $\mathrm{X}$ & $\mathrm{X}$ & $\mathrm{X}$ & & & \\
\hline North Carolina State University-Raleigh & $\mathrm{X}$ & & $\mathrm{X}$ & & $\mathrm{X}$ & \\
\hline Stony Brook University-SUNY & $\mathrm{X}$ & & & & $\mathrm{X}$ & $\mathrm{X}$ \\
\hline University of Vermont & $\mathrm{X}$ & & $\mathrm{X}$ & & & $\mathrm{X}$ \\
\hline Florida State University & & & & $\mathrm{X}$ & $\mathrm{X}$ & $\mathrm{X}$ \\
\hline University at Buffalo-SUNY & & $\mathrm{X}$ & & $\mathrm{X}$ & $\mathrm{X}$ & \\
\hline University of Missouri & & $\mathrm{X}$ & & $\mathrm{X}$ & $\mathrm{X}$ & \\
\hline University of Nebraska-Lincoln & $\mathrm{X}$ & $\mathrm{X}$ & & & & $\mathrm{X}$ \\
\hline University of Oregon & & & $\mathrm{X}$ & $\mathrm{X}$ & $\mathrm{X}$ & \\
\hline Iowa State University & $\mathrm{X}$ & $\mathrm{X}$ & & & & $\mathrm{X}$ \\
\hline Total Departments & 23 & 17 & 22 & 20 & 20 & 18 \\
\hline
\end{tabular}

Notes: Our sampling design is such that we would expect to collect data from 20 departments in each field.

The small deviations from the expected number by field are the result of sampling variability. 
Appendix Table A.2. Descriptive Statistics for Our Sample, by Field.

\begin{tabular}{|c|c|c|c|c|c|c|}
\hline Wage (Dollars) & $\begin{array}{c}\text { Biology } \\
\text { Mean (St Dev) } \\
118,355.02 \\
(46,549.79)\end{array}$ & $\begin{array}{c}\text { Chemistry } \\
\text { Mean (St Dev) } \\
131,966.04 \\
(57,511.42)\end{array}$ & $\begin{array}{c}\text { Economics } \\
\text { Mean }(\text { St Dev }) \\
160,316.64 \\
(64,907.21)\end{array}$ & $\begin{array}{c}\text { Ed Leadership/Policy } \\
\text { Mean (St Dev) } \\
105,100.80 \\
(46,864.48)\end{array}$ & $\begin{array}{c}\text { English } \\
\text { Mean (St Dev) } \\
97,623.86 \\
(35,458.17)\end{array}$ & $\begin{array}{c}\text { Sociology } \\
\text { Mean (St Dev) }\end{array}$ \\
\hline Asian & $0.13(0.34)$ & $0.14(0.35)$ & $0.21(0.41)$ & $0.08(0.28)$ & $0.06(0.23)$ & $0.08(0.28)$ \\
\hline Black & $0.01(0.08)$ & $0.01(0.12)$ & $0.03(0.17)$ & $0.15(0.36)$ & $0.09(0.28)$ & $0.09(0.29)$ \\
\hline Hispanic & $0.03(0.17)$ & $0.02(0.16)$ & $0.05(0.22)$ & $0.08(0.27)$ & $0.04(0.20)$ & $0.06(0.24)$ \\
\hline White & $0.83(0.37)$ & $0.82(0.39)$ & $0.71(0.45)$ & $0.69(0.46)$ & $0.80(0.40)$ & $0.77(0.42)$ \\
\hline Race Other/Unknown & $0.00(0.03)$ & - & $0.00(0.04)$ & - & $0.01(0.09)$ & $0.00(0.05)$ \\
\hline Female & $0.31(0.46)$ & $0.18(0.39)$ & $0.20(0.40)$ & $0.53(0.50)$ & $0.49(0.50)$ & $0.47(0.50)$ \\
\hline Male & $0.69(0.46)$ & $0.82(0.39)$ & $0.80(0.40)$ & $0.47(0.50)$ & $0.51(0.50)$ & $0.53(0.50)$ \\
\hline Gender Unknown & - & - & - & - & $0.00(0.03)$ & - \\
\hline Assistant Professor & $0.21(0.41)$ & $0.19(0.39)$ & $0.30(0.46)$ & $0.22(0.42)$ & $0.13(0.34)$ & $0.17(0.38)$ \\
\hline Associate Professor & $0.25(0.43)$ & $0.17(0.38)$ & $0.23(0.42)$ & $0.36(0.48)$ & $0.41(0.49)$ & $0.29(0.45)$ \\
\hline Professor & $0.54(0.50)$ & $0.64(0.48)$ & $0.47(0.50)$ & $0.42(0.49)$ & $0.46(0.50)$ & $0.54(0.50)$ \\
\hline PhD Schl U.S. 1-10 & $0.16(0.37)$ & $0.27(0.44)$ & $0.34(0.47)$ & $0.18(0.38)$ & $0.25(0.43)$ & $0.28(0.45)$ \\
\hline PhD Schl U.S. 11-50 & $0.30(0.46)$ & $0.32(0.47)$ & $0.36(0.48)$ & $0.33(0.47)$ & $0.32(0.47)$ & $0.43(0.50)$ \\
\hline PhD Schl U.S. 50+ & $0.29(0.45)$ & $0.24(0.43)$ & $0.21(0.41)$ & $0.42(0.49)$ & $0.19(0.40)$ & $0.24(0.43)$ \\
\hline PhD Schl Outside U.S. & $0.17(0.38)$ & $0.16(0.37)$ & $0.09(0.28)$ & $0.05(0.22)$ & $0.05(0.22)$ & $0.04(0.20)$ \\
\hline PhD Schl Missing & $0.08(0.27)$ & $0.02(0.13)$ & $0.00(0.04)$ & $0.02(0.16)$ & $0.13(0.33)$ & $0.01(0.10)$ \\
\hline No PhD (English only) & - & - & - & - & $0.06(0.24)$ & - \\
\hline Experience & $23.98(11.29)$ & $25.07(13.13)$ & $19.61(13.61)$ & $18.05(11.21)$ & $18.44(11.37)$ & $21.18(12.16)$ \\
\hline Experience Source: CV/Website & $0.72(0.45)$ & $0.90(0.31)$ & $0.97(0.17)$ & $0.78(0.41)$ & $0.58(0.49)$ & $0.92(0.27)$ \\
\hline $\begin{array}{l}\text { Experience Source: Website (Pubs } \\
\text { Based) }\end{array}$ & $0.00(0.04)$ & $0.00(0.04)$ & $0.01(0.07)$ & $0.04(0.18)$ & $0.05(0.22)$ & $0.01(0.08)$ \\
\hline $\begin{array}{l}\text { Experience Source: Scopus@ } \\
\text { Publications }\end{array}$ & $0.27(0.45)$ & $0.10(0.30)$ & $0.02(0.15)$ & $0.15(0.36)$ & $0.30(0.46)$ & $0.07(0.26)$ \\
\hline $\begin{array}{l}\text { Experience Unavailable from Any } \\
\text { Source }\end{array}$ & $0.00(0.05)$ & - & $0.00(0.06)$ & $0.03(0.18)$ & $0.07(0.26)$ & $0.00(0.05)$ \\
\hline Scopus® Publications & $65.68(70.43)$ & $128.03(142.32)$ & $21.66(23.59)$ & $14.87(12.39)$ & $6.12(7.74)$ & $21.90(27.60)$ \\
\hline Scopus ${ }^{\circledR}$ Citations & $3277.55(4,815.76)$ & $5264.11(7766.70)$ & $470.88(884.45)$ & $204.81(350.35)$ & $14.46(29.62)$ & $580.57(1,035.40)$ \\
\hline H-index & $23.68(14.92)$ & $30.81(18.28)$ & $7.84(6.57)$ & $5.37(4.21)$ & 1.47 (1.39) & $8.47(7.32)$ \\
\hline Scopus@ Missing & $0.01(0.08)$ & $0.01(0.08)$ & $0.10(0.30)$ & $0.12(0.32)$ & $0.17(0.37)$ & $0.04(0.19)$ \\
\hline $\mathrm{N}$ & 1,325 & 569 & 554 & 284 & 888 & 427 \\
\hline
\end{tabular}

Notes: This table breaks out the descriptive statistics shown in Table 1.1 by field. The notes to Table 1.1 apply. 
Appendix Table A.3. Output from a Regression of an Indicator for Missing Wage Data on Observable Faculty Characteristics.

Coefficient (Standard Error)

\begin{tabular}{|c|c|}
\hline Asian & $0.018(0.013)$ \\
\hline Black & $-0.014(0.014)$ \\
\hline Hispanic & $0.026(0.022)$ \\
\hline Race Other/Unknown & $0.099(0.080)$ \\
\hline Female & $0.002(0.006)$ \\
\hline Gender Unknown & $-0.153(0.096)$ \\
\hline Assistant Professor & $0.101 * *(0.019)$ \\
\hline Associate Professor & $-0.019 * *(0.007)$ \\
\hline Chemistry & $-0.015(0.012)$ \\
\hline Economics & $-0.001(0.013)$ \\
\hline Education(Leadership/Policy) & $-0.004(0.022)$ \\
\hline English & $-0.039 * *(0.015)$ \\
\hline Sociology & $-0.022(0.015)$ \\
\hline PhD School U.S. 11-50 & $-0.006(0.009)$ \\
\hline PhD School U.S. 50+ & $0.016(0.013)$ \\
\hline PhD School Outside U.S. & $0.003(0.019)$ \\
\hline PhD School Missing & $0.027(0.023)$ \\
\hline No PhD (English only) & $-0.000(0.035)$ \\
\hline Experience & $-0.002 * *(0.001)$ \\
\hline Experience Source: Website Publication & $0.004(0.037)$ \\
\hline Experience Source: Scopus $\odot$ Publication & $-0.003(0.011)$ \\
\hline Experience Missing & $-0.066(0.061)$ \\
\hline Standardized Scopus@ Publications & $0.007(0.004)$ \\
\hline Standardized Scopus@ Citations & $0.011(0.010)$ \\
\hline Standardized h-index & $-0.010(0.007)$ \\
\hline Scopus $@$ Missing & $0.106 * *(0.0332)$ \\
\hline Constant & $0.079 * *(0.026)$ \\
\hline R-squared & 0.075 \\
\hline $\mathrm{N}$ & 4,047 \\
\hline
\end{tabular}

Notes: The regression is estimated as linear probability model. The dependent variable is equal to one if a wage record for the faculty member is unavailable in public-employee wage reports, and zero otherwise. 94 percent of faculty have a wage record.

$* * / *$ Indicates statistical significance at the $5 / 10$ percent level. 
Appendix Table A.4. Replication of Table 1.5, Including Non-Tenure-Track Teaching Faculty.

\begin{tabular}{|c|c|c|c|c|c|c|}
\hline & (1) & (2) & (3) & (4) & (5) & (6) \\
\hline Asian & $\begin{array}{l}-\$ 3,140.43 \\
(3,034.81)\end{array}$ & $\begin{array}{c}-\$ 6,518.36^{* *} \\
(2,443.04)\end{array}$ & $\begin{array}{c}-\$ 11,023.62^{* *} \\
(2,282.11)\end{array}$ & $\begin{array}{c}-\$ 11,730.66^{* *} \\
(2,402.31)\end{array}$ & $\begin{array}{c}-\$ 399.97 \\
(1,851.87)\end{array}$ & $\begin{array}{c}\$ 39.92 \\
(1,539.01)\end{array}$ \\
\hline Black & $\begin{array}{c}-\$ 11,218.53^{* *} \\
(4,428.12)\end{array}$ & $\begin{array}{c}-\$ 10,104.65^{* *} \\
(4,472.75)\end{array}$ & $\begin{array}{l}-\$ 6,264.19 \\
(4,414.31)\end{array}$ & $\begin{array}{l}-\$ 6,444.50 \\
(4,388.72)\end{array}$ & $\begin{array}{c}-\$ 79.64 \\
(3,488.85)\end{array}$ & $\begin{array}{l}\$ 5,499.76 \\
(3,411.24)\end{array}$ \\
\hline Hispanic & $\begin{array}{c}-\$ 8,757.98 * * \\
(3,356.70)\end{array}$ & $\begin{array}{c}-\$ 14,755.74 * * \\
(2,790.62)\end{array}$ & $\begin{array}{c}-\$ 13,290.58^{* *} \\
(2,632.95)\end{array}$ & $\begin{array}{c}-\$ 13,902.20 * * \\
(2,653.46)\end{array}$ & $\begin{array}{l}-\$ 2,753.21 \\
(2,411.22)\end{array}$ & $\begin{array}{l}\$ 2,592.10 \\
(2,323.19)\end{array}$ \\
\hline Race Other/Unknown & $\begin{array}{c}-\$ 48,528.04^{* *} \\
\quad(6,390.82)\end{array}$ & $\begin{array}{c}-\$ 33,867.05^{* *} * \\
(5,308.00)\end{array}$ & $\begin{array}{c}-\$ 27,789.05^{* *} \\
\quad(5,545.50)\end{array}$ & $\begin{array}{c}-\$ 20,090.72 * * \\
(4,865.07)\end{array}$ & $\begin{array}{c}-\$ 10,344.59 * \\
(5,151.55)\end{array}$ & $\begin{array}{c}-\$ 6,160.47^{*} \\
(3,492.24)\end{array}$ \\
\hline Female & $\begin{array}{c}-\$ 25,936.62 * * \\
(1,959.78)\end{array}$ & $\begin{array}{c}-\$ 22,471.21 * * \\
(2,004.27)\end{array}$ & $\begin{array}{c}-\$ 17,573.94 * * \\
(1,749.40)\end{array}$ & $\begin{array}{c}-\$ 16,875.78^{* *} \\
(1,754.72)\end{array}$ & $\begin{array}{c}-\$ 9,261.33 * * \\
(1,485.55)\end{array}$ & $\begin{array}{c}\$ 5,309.09 * * \\
(1,035.97)\end{array}$ \\
\hline Gender Unknown & $\begin{array}{c}-\$ 28,469.03^{* *} \\
(13,373.70)\end{array}$ & $\begin{array}{c}-\$ 31,545.04 * * \\
(12,319.82)\end{array}$ & $\begin{array}{c}-\$ 24,638.23 * \\
(13,261.19)\end{array}$ & $\begin{array}{l}-\$ 16,726.52 \\
(12,967.98)\end{array}$ & $\begin{array}{l}-\$ 1,303.18 \\
(12,435.44)\end{array}$ & $\begin{array}{c}-\$ 1,991.95 \\
(12,696.10)\end{array}$ \\
\hline University Fixed Effects & & $X$ & $X$ & $X$ & $X$ & $X$ \\
\hline Field Fixed Effects & & & $X$ & $X$ & $X$ & $X$ \\
\hline PhD School Rank & & & & $\mathrm{X}$ & $\mathrm{X}$ & $\mathrm{X}$ \\
\hline Experience & & & & & $\mathrm{X}$ & $\mathrm{X}$ \\
\hline Research Productivity & & & & & & $\mathrm{X}$ \\
\hline R-Squared & 0.07 & 0.18 & 0.23 & 0.25 & 0.41 & 0.56 \\
\hline $\mathrm{N}$ & 4,246 & 4,246 & 4,246 & 4,246 & 4,246 & 4,246 \\
\hline
\end{tabular}

Notes: The omitted groups are white and male faculty. Standard errors clustered at the university level are reported in parentheses.

$* * / *$ Indicates statistical significance at the $5 / 10$ percent level. 
Appendix Table A.5. Extensions of Wage Regressions from Table 1.5 that (A) Include Faculty Rank as Independent Variable Vector (Assistant, Associate, Full), (B) Include All Three Scopus@ Measures of Research Productivity Simultaneously and (C) Include a Vector of Experience Bins in Place of the Linear Experience Control.

\begin{tabular}{lccc} 
Asian & $-\$ 689.01$ & $-\$ 1,458.42$ & $-\$ 1,612.35$ \\
Black & $(1,709.55)$ & $(1,800.27)$ & $(1,768.50)$ \\
& $\$ 4,878.69^{*}$ & $\$ 2,858.40$ & $\$ 3,455.24$ \\
Hispanic & $(2,889.15)$ & $(3,043.29)$ & $(3,130.66)$ \\
& $\$ 2,531.86$ & $\$ 1,039.01$ & $\$ 1,797.82$ \\
Race Other/Unknown & $(2,465.00)$ & $(2,112.08)$ & $(2,234.17)$ \\
& $-\$ 4,396.28$ & $-\$ 3,398.29$ & $-\$ 4,670.84$ \\
& $(4,887.75)$ & $(5,245.30)$ & $(4,993.18)$ \\
Female & & & \\
& $\$ 3,277.08^{* *}$ & $-\$ 3,960.32 * *$ & $-\$ 4,586.14 * *$ \\
Gender Unknown & $(943.63)$ & $(1,119.44)$ & $(1,078.62)$ \\
& $\$ 16,209.67 * *$ & $\$ 8,210.85$ & $\$ 8,478.57$ \\
University Fixed Effects & $(7,217.20)$ & $(7,378.30)$ & $(7,237.76)$ \\
Field Fixed Effects & & & $\mathrm{X}$ \\
PhD School Rank & $\mathrm{X}$ & $\mathrm{X}$ & $\mathrm{X}$ \\
Experience & $\mathrm{X}$ & $\mathrm{X}$ & $\mathrm{X}$ \\
Research Productivity Standard (h- & $\mathrm{X}$ & $\mathrm{X}$ & $\mathrm{X}$ \\
index) & $\mathrm{X}$ & & \\
Faculty Rank & & & \\
(Assistant/Associate/Full) & $\mathrm{X}$ & & \\
Research Productivity: All Three & & & \\
Measures & & & \\
Non-Linear Experience & & & \\
R-Squared & & & \\
N & & & \\
\hline
\end{tabular}

Notes: The omitted groups are white and male faculty. In column (3), in place of the linear experience control we divide faculty into four groups by experience - 1-10, 11-20, 21-30, and 30+ years - and include indicator variables in the model to identify each teacher's group (30+ is omitted). Standard errors clustered at the university level are reported in parentheses.

$* * / *$ Indicates statistical significance at the $5 / 10$ percent level. 
Appendix Table A.6. Full Output from the Primary Wage Regression Shown in the Last Column of Table 1.5.

\begin{tabular}{lc}
\hline & Coefficient (Standard Error) \\
Asian & $-1,409.96(1,798.85)$ \\
Black & $3,316.14(3,218.97)$ \\
Hispanic & $1,201.72(2,148.95)$ \\
Race Other/Unknown & $-3,001.76(5,063.69)$ \\
& \\
Female & $-4,279.70^{* *}(1,091.66)$ \\
Gender Unknown & $7,231.95(7,242.97)$ \\
Chemistry & \\
Economics & $9,868.14 * *(4,662.92)$ \\
Education Leadership/Policy & $41,177.82^{* *}(5,447.62)$ \\
English & $-10,258.61 * *(3,193.99)$ \\
Sociology & $-12,090.63^{* *}(2,850.55)$ \\
& $-1,820.23(2,650.49)$ \\
PhD School U.S. 11-50 & \\
PhD School U.S. 50+ & $-281.08(1,283.90)$ \\
PhD School Outside U.S. & $222.35(1,948.18)$ \\
PhD School Missing & $-1,457.45(2,239.74)$ \\
No PhD (English only) & $-3,074.25(2,987.91)$ \\
& $14,772.79 * *(4,508.25)$ \\
Experience & \\
Experience Website Publication & $1,148.03 * *(96.37)$ \\
Experience Scopus@ Publication & $1,511.62(5,625.05)$ \\
Experience Missing & $2,732.45(2,638.47)$ \\
Standardized h-index & $17,681.64 * *(6,089.77)$ \\
Chemistry*std h-index & \\
Economics*std h-index & $23,013.41^{* *}(1,708.73)$ \\
Education*std h-index & $2,220.97(3,414.55)$ \\
English*std h-index & $12,457.81 * *(3,690.89)$ \\
Sociology*std h-index & $-16,693.72 * *(3,617.47)$ \\
Scopus@ Missing & $-16,222.21 * *(2,136.70)$ \\
Constant & $-3,960.16(3,000.53)$ \\
& $-13,595.12 * *(3,191.82)$ \\
R-squared & \\
N & $93,092.53^{* *}(2,700.78)$ \\
\hline
\end{tabular}

Notes: The omitted groups are whites, men, biologists, and faculty from top-10 PhD institutions. Standard errors clustered at the university level are reported in parentheses.

$* * / *$ Indicates statistical significance at the 5/10 percent level. 


\section{Appendix B}

\section{Correction Document for Chapter 1}

Here we correct a substantive reporting error in our published manuscript, Representation and Salary Gaps by Race/Ethnicity and Gender at Selective Public Universities (Educational Researcher 46(7), 343-354). We became aware of the error during external correspondence about the article after publication.

The issue is that some of the descriptive statistics reported in the published version of Table 1.4 (p. 347) are incorrect. The purpose of Table 1.4 is to compare racial/ethnic and gender shares among assistant professors in our data to racial/ethnic and gender shares among new PhDs from top-50 universities, by field. The latter data are taken from the Survey of Earned Doctorates (SED).

The errors are primarily concentrated in the reported gender shares among assistant professors in our data (the numbers in brackets in the table). All 12 field-specific, gendershare values are incorrect. The published values from the SED data are correct. Figure 1.1 also reports similar gender-share information about assistant professors based on our data, in aggregated form. The published values in Figure 1.1 are also correct. The error only applies to the gender-share numbers reported in Table 1.4 for assistant professors in our data.

The correct numbers are shown in the corrected version of Table 1.4 below. The substantive importance of the correction is as follows: the inaccurate numbers in the published article imply that the representation of women in STEM fields among assistant professors is similar to the representation of women in STEM fields among recent $\mathrm{PhD}$ 
completers in the SED sample; however, the corrected numbers make clear that women are underrepresented as assistant professors in STEM fields relative to their representation in $\mathrm{PhD}$ production. The gender representation numbers in non-STEM fields are also incorrect in the published article, but the true values are similar to the erroneously reported values and there is no substantive implication of the correction.

We also offer a brief explanation of what happened for interested readers. The error occurred during our first round of revisions with the paper (i.e., the originally submitted manuscript had the correct numbers in Table 1.4 throughout). The original version of Table 1.4 compared the assistant professor shares in our data to analogous shares from the SED, but did not restrict the university sample. A referee suggested a more elite sample of $\mathrm{PhD}$ granting institutions might be more appropriate, given the universities we sampled to obtain our faculty data are selective. This was a good suggestion. Over the course of responding to the referee, and in our own efforts to be thorough, ultimately obtained data on $\mathrm{PhDs}$ awarded by field from selective universities using two sources: IPEDS and the SED. Ultimately the numbers from each source were similar and we elected to keep the SED as the comparison dataset in our paper. But when we were comparing the SED and IPEDS data we used spreadsheets of the same structure as Table 1.4 for the comparisons. An unfortunate copy-and-paste error led to the problem $\mathrm{n}$ the published version of Table 1.4: the published numbers for the gender shares compare $\mathrm{PhD}$ production by field between IPEDS and the SED, rather than between the SED and our data, which was the obvious intent.

When we became aware of this error, we decided it would be prudent to go back through all of our results and analysis to make sure there are no more errors. We did not 
find any other substantive errors, but we did find two small errors that we also correct with this document. First, in that same table (Table 1.4), there is a typo for the share of white junior faculty in sociology. The published article wrongly indicates that 61.5 percent of junior faculty in sociology are white, but the correct number is 68.5 percent. We cannot attribute this error to anything other than a pure typo. This typo is corrected in the updated version of Table 1.4 below. The second error is in Table 1, where a mistake in handling imputed values among individuals with missing experience led us to report a value of average experience in our data of 21.24 , when a more accurate number is 21.67 . This issue is inconsequential to the regression output that forms the basis of our wage decompositions, but the mishandling of imputed values did affect the reported descriptive statistic. We did not find any other errors in our thorough review of the published results (although the imputation error with experience also affects the field-by-field descriptive statistics in Appendix Table A.2, which was not published in Educational Researcher but is available on our websites and has been corrected).

We convey our deepest apologies for our errors. We recognize they are totally unacceptable and take full responsibility. We appreciate the editors of Educational Researcher allowing us to publish this correction. 
Appendix Table B.1. Table 1.4 CORRECTED, Comparison of Race/Ethnicity and Gender Representation by Field in PhD Production Data from the Survey of Earned Doctorates at Top-50 Universities, and Among Assistant Professors in Our Data (Percentages).

Biology $\quad$ Chemistry $\quad$ Economics $\quad$ Education $\quad$ English $\quad$ Sociology

\section{Racial/Ethnic}

(Leadership/Policy)

\section{Shares}

$\begin{array}{lcccccc}\text { Asian } & 13.7[20.3] & 9.8[19.4] & 16.8[34.2] & 10.3[17.5] & 5.3[12.8] & 12.2[6.9] \\ \text { Black } & 3.6[0.4] & 2.5[0.9] & 2.7[2.4] & 15.5[15.9] & 1.8[8.6] & 3.9[13.7] \\ \text { Hispanic } & 6.2[3.6] & 6.8[6.5] & 5.0[11.0] & 7.2[4.8] & 8.5[4.3] & 8.3[11.0] \\ \text { White } & 70.6[75.8] & 74.7[73.2] & 70.0[52.4] & 58.8[61.9] & 78.9[74.4] & 71.7[68.5] \\ \text { Other/Unknown } & 5.9[0.0] & 6.2[0.0] & 5.5[0.0] & 8.2[0.0] & 5.5[0.0] & 3.9[0.0]\end{array}$

\section{Gender Shares}

Female

Male

Unknown

$\begin{array}{ccc}\mathbf{5 3 . 7}[40.6] & \mathbf{3 8 . 3}[26.9] & \mathbf{2 9 . 9}[\mathbf{2 5 . 0}] \\ \mathbf{4 6 . 1}[\mathbf{5 9 . 4}] & \mathbf{6 1 . 6}[\mathbf{7 3 . 2}] & \mathbf{6 9 . 9}[\mathbf{7 5 . 0}] \\ 0.2[0.0] & 0.1[0.0] & 0.2[0.0]\end{array}$

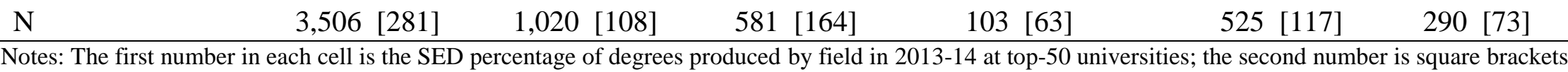

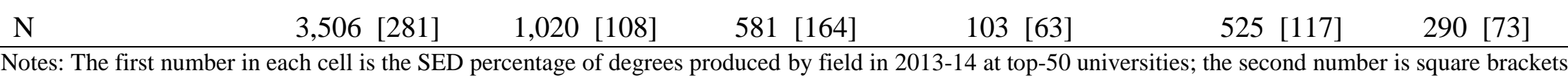

63.1 $[60.3]$

$36.9[39.7]$

$0.0[0.0]$
$5.5[0.0]$

$3.9[0.0]$

\footnotetext{
the percentage of assistant professors in that field in our data from 2015-16. The SED data are restricted to doctorate recipients who graduated from universities on the U.S. News \& World Report "Best Colleges 2016" list of top-50 universities, inclusive of private universities. Bolded entries indicate cells where the published number reported for our data (in brackets) has been corrected.
} 


\section{Appendix C}

\section{Supplementary Tables for Chapter 2}

Appendix Table C.1. Validation Tests, Splitting Non-Resident Enrollment Share into Out-of-State and Foreign Enrollment Share. Male Asian Black Hispanic Other Races

ACT Math

ACT Math
ACT English $\quad$ ACT English HS. Pctile.

Out-of-State Enrollment Share

0.0011

$-0.0001 \quad 0.0006$

$-0.0000$

0.0001

$-0.0072$

0.0001

$-0.0045$

0.0001

$-0.0208$

0.0007

$\begin{array}{llll}(0.0007) & (0.0001) \quad(0.0004) \quad(0.0001)\end{array}$

(0.0002)

(0.0083)

(0.0001)

(0.0101)

(0.0001)

(0.0407)

(0.0006)

Foreign Enrollment Share

0.0001

0.0007

0.0007

$-0.0001$

$-0.0013 * *$

$-0.0299$

$-0.0002$

$-0.0376$

$-0.0002$

$-0.1231$

$-0.0005$

(0.0013)

(0.0005)

$(0.0017) \quad(0.0005)$

(0.0006)

(0.0282)

(0.0005)

(0.0321)

(0.0005)

(0.1096)

(0.0013)

Overall P-value

0.94

Major Fixed Effects

Year Fixed Effects

R-squared

$\mathrm{N}$

$\begin{array}{cc}\mathrm{X} & \mathrm{X} \\ \mathrm{X} & \mathrm{X} \\ 0.20 & 0.01 \\ 40,638 & 40,638\end{array}$

$\begin{array}{cc}X & X \\ X & X\end{array}$

$\mathrm{X}$
$\mathrm{X}$

$\mathrm{X}$
$\mathrm{X}$
0.14
40,638

X

$\mathrm{X}$

$\mathrm{X}$
$\mathrm{X}$
0.08
40,638

$\mathrm{X}$
$\mathrm{X}$
0.01

X

X

Notes: This table displays estimates from validation tests of endogenous student sorting. Female and white are the omitted groups. Robust standard errors in parentheses are clustered at the major level. Significance levels: ** 5 percent level, * 10 percent level. 
Appendix Table C.2. Full Output from the First-Stage

Regression of the IV Model.

\begin{tabular}{lc}
\hline & Coefficient (Standard \\
& Error) \\
Predicted In-State Enrollment & $-5.727^{* *}(1.782)$ \\
Predicted Out-of-State Enrollment & $-3.606^{* *}(0.779)$ \\
Predicted Foreign Enrollment & $-3.391(25.388)$ \\
Male & $0.021(0.053)$ \\
Black & $0.166(0.111)$ \\
Asian & $-0.121(0.091)$ \\
Hispanic & $0.301(0.216)$ \\
Other Races & $-0.119(0.112)$ \\
& \\
ACT Math & $-0.007(0.009)$ \\
ACT Math Missing Indicator & $-0.302(0.960)$ \\
ACT English & $-0.010(0.009)$ \\
ACT English Missing Indicator & $0.278(0.961)$ \\
High School Percentile Rank & $-0.002(0.002)$ \\
High School Percentile Rank Missing Indicator & $0.094(0.061)$ \\
& \\
Constant & $77.300^{* *}(18.018)$ \\
Major Fixed Effects & \\
Year Fixed Effects & $\mathrm{X}$ \\
F-statistic & $\mathrm{X}$ \\
R-Squared & 13.23 \\
N & 0.91 \\
\hline
\end{tabular}

Notes: Robust standard errors in parentheses are clustered at the major level. Significance levels: $* * 5$ percent level, * 10 percent level. 
Appendix Table C.3. Comparison of Number and Annual Salary of Faculty between Top and Bottom Quartile Majors of Out-of-State Enrollment Growth.

\begin{tabular}{|c|c|c|c|c|c|c|c|c|}
\hline \multirow[b]{2}{*}{ Year } & \multicolumn{2}{|c|}{$\begin{array}{c}\text { Average Number of Tenure- } \\
\text { Track Faculty }\end{array}$} & \multicolumn{2}{|c|}{$\begin{array}{c}\text { Average Number of Teaching } \\
\text { Faculty }\end{array}$} & \multicolumn{2}{|c|}{$\begin{array}{c}\text { Average Salary of Tenure-Track } \\
\text { Faculty }\end{array}$} & \multicolumn{2}{|c|}{$\begin{array}{c}\text { Average Salary of Teaching } \\
\text { Faculty }\end{array}$} \\
\hline & Top Quartile Majors & $\begin{array}{l}\text { Bottom } \\
\text { Quartile } \\
\text { Majors }\end{array}$ & Top Quartile Majors & $\begin{array}{l}\text { Bottom } \\
\text { Quartile } \\
\text { Majors }\end{array}$ & Top Quartile Majors & $\begin{array}{l}\text { Bottom } \\
\text { Quartile } \\
\text { Majors }\end{array}$ & Top Quartile Majors & $\begin{array}{l}\text { Bottom } \\
\text { Quartile } \\
\text { Majors }\end{array}$ \\
\hline 2004 & 15.88 & 16.60 & 0.50 & 0.07 & 71421.96 & 78363.48 & 7912.36 & 3118.33 \\
\hline 2005 & 16.31 & 16.47 & 0.50 & 0.27 & 73579.52 & 80650.68 & 20835.04 & 12202.27 \\
\hline 2006 & 16.38 & 16.27 & 0.50 & 0.33 & 75145.45 & 82831.83 & 22050.30 & 15915.20 \\
\hline 2007 & 16.69 & 16.69 & 2.44 & 0.69 & 76764.34 & 87053.77 & 22381.50 & 16511.49 \\
\hline 2008 & 16.38 & 16.63 & 3.25 & 1.88 & 82314.09 & 92105.11 & 22009.24 & 33125.92 \\
\hline 2009 & 16.13 & 16.81 & 3.31 & 2.25 & 82551.22 & 92249.22 & 25923.98 & 33541.68 \\
\hline 2010 & 16.88 & 16.69 & 3.88 & 2.63 & 81424.96 & 91833.96 & 30042.68 & 40380.43 \\
\hline 2011 & 16.63 & 17.38 & 4.50 & 2.94 & 86524.39 & 95731.51 & 35574.30 & 42801.54 \\
\hline 2012 & 16.94 & 17.75 & 5.56 & 3.31 & 90301.09 & 100125.20 & 37734.71 & 47445.38 \\
\hline 2013 & 16.75 & 17.75 & 6.19 & 3.56 & 92526.06 & 100467.00 & 37704.91 & 48020.75 \\
\hline 2014 & 16.81 & 18.31 & 5.88 & 3.88 & 96450.16 & 102813.00 & 35129.68 & 52393.53 \\
\hline
\end{tabular}

Notes: Both top and bottom quartile of out-of-state enrollment growth distribution consists of 13 majors. Only full-time tenure-track and teaching faculty are included. Faculty salary is represented by annual salary in dollars. Data source is University of Missouri System Annual Salary Report from 2004 to 2014. 
Appendix Table C.4. Full Output from Panel A in Table 2.3.

Enrolled in the Same Major at MU Enrolled at MU

Enrolled at Any System Campus

Cum. Credit Hrs.

Cum. GPA

Non-Resident Enrollment Share

Male

Black

Asian

Hispanic

Other Races

ACT Math

ACT Math Missing Indicator

ACT English

ACT English Missing Indicator

H.S. Percentile Rank

H.S. Percentile Rank Missing Indicator

Constant

Major Fixed Effects

Year Fixed Effects

$\mathrm{R}$-squared

$\mathrm{N}$

\section{$-0.0008(0.0016)$}

$0.0431 * *(0.0156)$

$0.0024(0.0251)$

$0.0394(0.0304)$

$-0.0320 * *(0.0117)$

$-0.0062(0.0125)$

$0.0062 * *(0.0019)$

$-0.1560 * *(0.0738)$

0.0007 (0.0013)

$0.1230 *(0.0684)$

$0.0021 * *(0.0007)$

$0.0230 * *(0.0093)$

$0.1812 *(0.1067)$
0.0004 (0.0004)

$-0.0227 * *(0.0074)$

$-0.0623^{* *}(0.0127)$

$-0.0098(0.0178)$

$-0.0168(0.0168)$

$-0.0430 * *(0.0131)$

$0.0080 * *(0.0008)$

0.0891 (0.0913)

$0.0031 * *(0.0008)$

$-0.1478 *(0.0857)$

$0.0040 * *(0.0002)$

$0.0333 * *(0.0095)$

$0.2246 * *(0.0250)$
$0.0001(0.0003)$

$-0.0194 * *(0.0051)$

$-0.0510 * *(0.0119)$

$-0.0020(0.0148)$

$-0.0051(0.0137)$

$-0.0378 * *(0.0107)$

$0.0041 * *(0.0007)$

0.1193 (0.0918)

$0.0013 * *(0.0005)$

$-0.1866 * *$ (0.0913)

$0.0026^{* *}(0.0002)$

$0.0160 * *(0.0059)$
$0.0228(0.0280)$

$-3.9971 * *(0.3447)$

$-8.1222 * *(0.5253)$

$-0.6953(0.8856)$

$-2.0100 * *(0.6318)$

$-3.0618 * *(0.6595)$

$0.8484 * *(0.0578)$

$-2.9422(3.2948)$

$0.4220 * *(0.0385)$

-2.3706 (3.5072)

$0.4135 * *(0.0174)$

$-1.2514 *(0.6640)$
$0.0006(0.0007)$

$-0.1547 * *(0.0175)$

$-0.2949 * *(0.0178)$

$-0.0529 * *(0.0168)$

$-0.0612 * *(0.0226)$

$-0.0921 * *(0.0202)$

$0.0301 * *(0.0019)$

$0.0980(0.1805)$

$0.0214 * *(0.0009)$

-0.1538 (0.1973)

$0.0143 * *(0.0005)$

0.0294 (0.0217)

Notes: Robust standard errors in parentheses are clustered at the major level. Significance levels: ** 5 percent level, * 10 percent level. 
Appendix Table C.5. Estimates of the Effects of Non-Resident Enrollment Growth on Third-Year Outcomes for In-State Students, Using 2008-2014 Subsample.

\begin{tabular}{|c|c|c|c|c|c|}
\hline & $\begin{array}{c}\text { Enrolled in } \\
\text { the Same } \\
\text { Major at } \\
\text { MU }\end{array}$ & $\begin{array}{l}\text { Enrolled at } \\
\text { MU }\end{array}$ & $\begin{array}{c}\text { Enrolled at } \\
\text { Any System } \\
\text { Campus }\end{array}$ & $\begin{array}{c}\text { Cum. Credit } \\
\text { Hrs. }\end{array}$ & Cum. GPA \\
\hline \multicolumn{6}{|l|}{$\begin{array}{l}\text { Panel A. Continuous Treatment Differences-in- } \\
\text { Differences Model }\end{array}$} \\
\hline Non-Resident Enrollment Share & $\begin{array}{c}-0.0027 * \\
(0.0015)\end{array}$ & $\begin{array}{c}0.0001 \\
(0.0005)\end{array}$ & $\begin{array}{c}0.0005 \\
(0.0004)\end{array}$ & $\begin{array}{c}0.0155 \\
(0.0360)\end{array}$ & $\begin{array}{c}0.0010 \\
(0.0011)\end{array}$ \\
\hline R-squared & 0.15 & 0.07 & 0.04 & 0.21 & 0.28 \\
\hline $\mathrm{N}$ & 26,368 & 26,368 & 26,368 & 26,368 & 26,368 \\
\hline \multicolumn{6}{|l|}{ Panel B. IV Model } \\
\hline Non-Resident Enrollment Share & $\begin{array}{l}-0.0050 \\
(0.0164)\end{array}$ & $\begin{array}{c}0.0008 \\
(0.0019)\end{array}$ & $\begin{array}{c}0.0016 \\
(0.0013)\end{array}$ & $\begin{array}{l}-0.0633 \\
(0.0716)\end{array}$ & $\begin{array}{c}0.0004 \\
(0.0052)\end{array}$ \\
\hline R-squared & 0.15 & 0.06 & 0.04 & 0.21 & 0.28 \\
\hline $\mathrm{N}$ & 26,368 & 26,368 & 26,368 & 26,368 & 26,368 \\
\hline Major Fixed Effects & $\mathrm{X}$ & $\mathrm{X}$ & $\mathrm{X}$ & $\mathrm{X}$ & $\mathrm{X}$ \\
\hline Year Fixed Effects & $X$ & $X$ & $X$ & $X$ & $X$ \\
\hline Student Characteristics & $X$ & $\mathrm{X}$ & $X$ & $\mathrm{X}$ & $\mathrm{X}$ \\
\hline
\end{tabular}

Notes: Panel B replicates the results from Panel B in Table 2.3. Major fixed effects, year fixed effects and student characteristics are included in the continuous treatment differences-in-differences model and the IV model. The coefficients for student characteristics are excluded for brevity. Robust standard errors in parentheses are clustered at the major level. Significance levels: ** 5 percent level, $* 10$ percent level. 
Appendix Table C.6. Continuous Treatment Differences-in-Differences Model Estimates of the Effects of Non-

Resident Enrollment Growth on 6-Year Graduation Outcomes for In-State Students, Using 2004-2010 Subsample.

\begin{tabular}{|c|c|c|c|}
\hline $\begin{array}{l}\text { Graduated in } \\
\text { the Same }\end{array}$ & Graduated at MU & $\begin{array}{l}\text { Graduated at Any } \\
\text { System Campus }\end{array}$ & Cum. Credit Hrs. \\
\hline
\end{tabular}

Major at MU

Non-Resident Enrollment Share

$\begin{array}{ccccc}0.0015 & 0.0006 & 0.0001 & 0.1728 & -0.0016 \\ (0.0012) & (0.0007) & (0.0007) & (0.1053) & (0.0015)\end{array}$

$\begin{array}{lccccc}\text { Major Fixed Effects } & \text { X } & \text { X } & \text { X } & \text { X } & \text { X } \\ \text { Year Fixed Effects } & \text { X } & \text { X } & \text { X } & \text { X } & \text { X } \\ \text { Student Characteristics } & \text { X } & \text { X } & 0.10 & 0.27 & 0.17 \\ \text { R-squared } & 0.18 & 0.10 & 26,140 & 26,140 & 26,140 \\ \text { N } & 26,140 & 26,140 & \end{array}$

Notes: The coefficients for student characteristics are excluded for brevity. Robust standard errors in parentheses are clustered at the major level. Significance levels: ** 5 percent level, * 10 percent level. 


\section{Appendix D}

\section{Supplementary Figures and Tables for Chapter 3}

Appendix Figure D.1. Relationships between the Annual Growths in Bachelor's Degrees and Faculty Size, with Faculty Population Weighting.
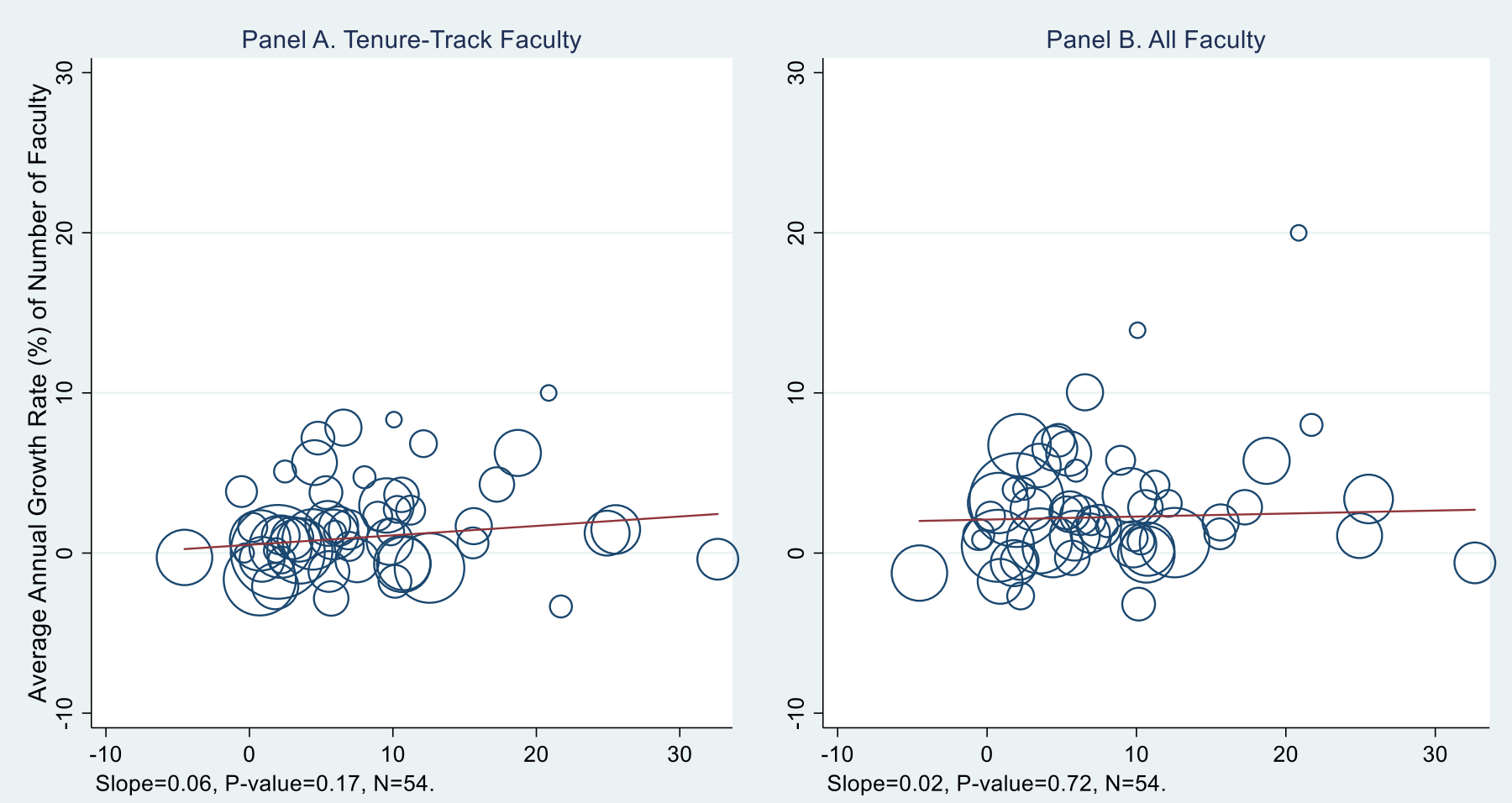

Notes: Faculty population weighting is such that all academic departments receive a weight equal to the number of tenure-track faculty in that department and 2004/05 academic year, i.e., the first year of my data panel. 
Appendix Figure D.2. Relationships between the Annual Growths in Bachelor's Degrees and Total Salaries of Faculty, with Faculty Population Weighting.
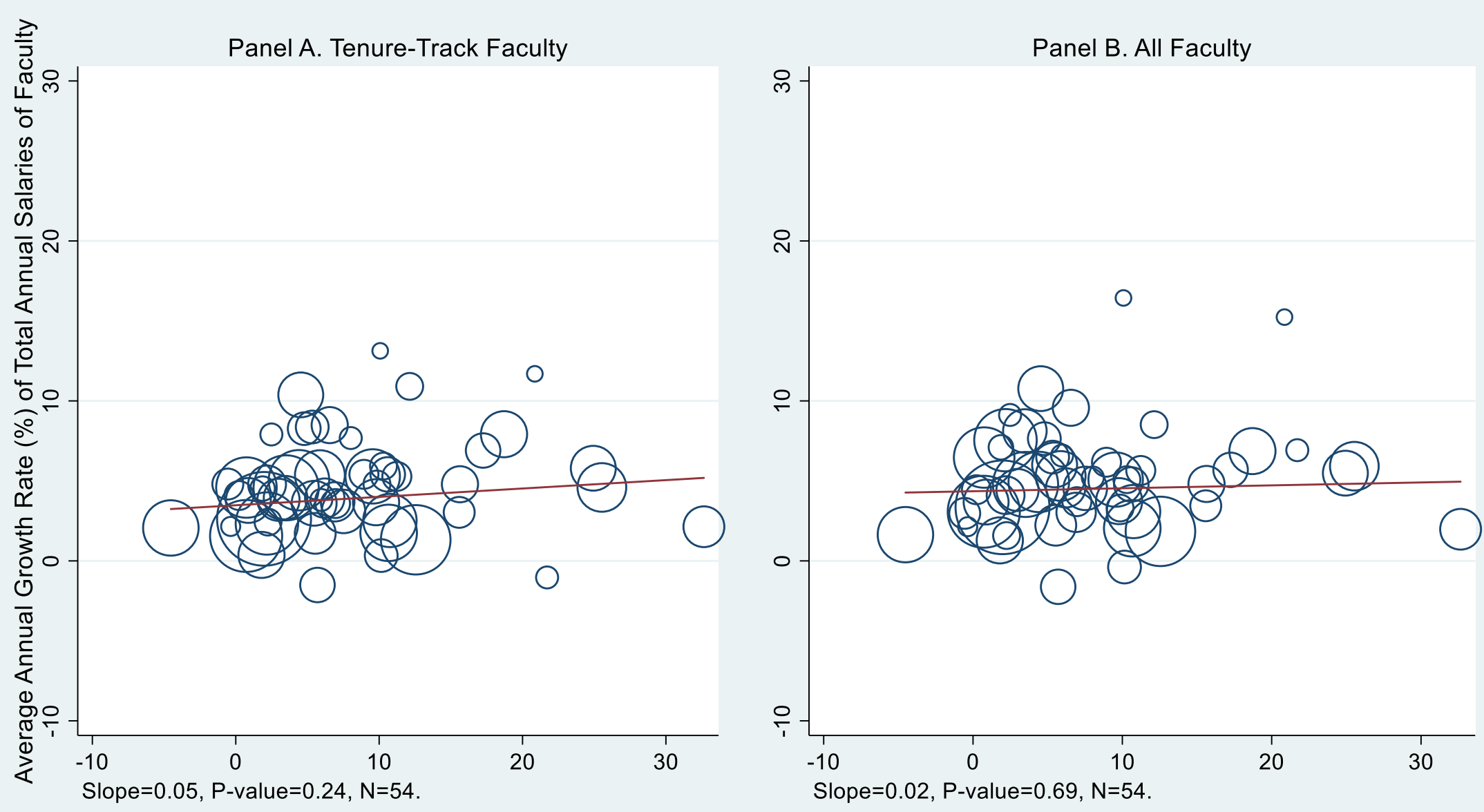

Average Annual Growth Rate (\%) of Number of Degrees Conferred

Notes: Faculty population weighting is such that all academic departments receive a weight equal to the number of tenure-track faculty in that department and 2004/05 academic year, i.e., the first year of my data panel. 
Appendix Figure D.3. Relationships between the Annual Growths in Freshman Enrollment and Faculty Size, Unweighted Data.
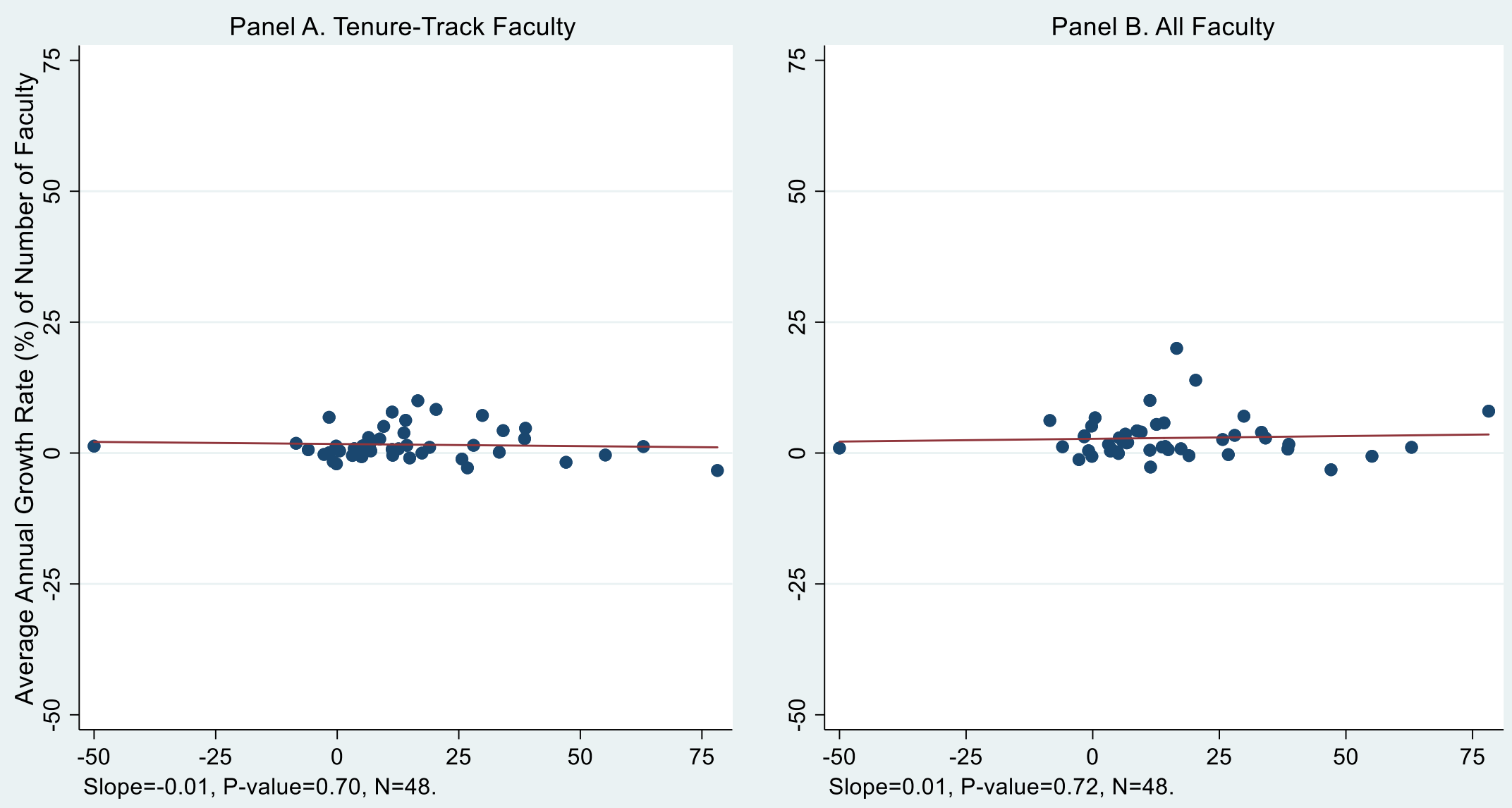

Average Annual Growth Rate (\%) of Number of Freshmen 
Appendix Figure D.4. Relationships between the Annual Growths in Freshman Enrollment and Total Salaries of Faculty, Unweighted Data.
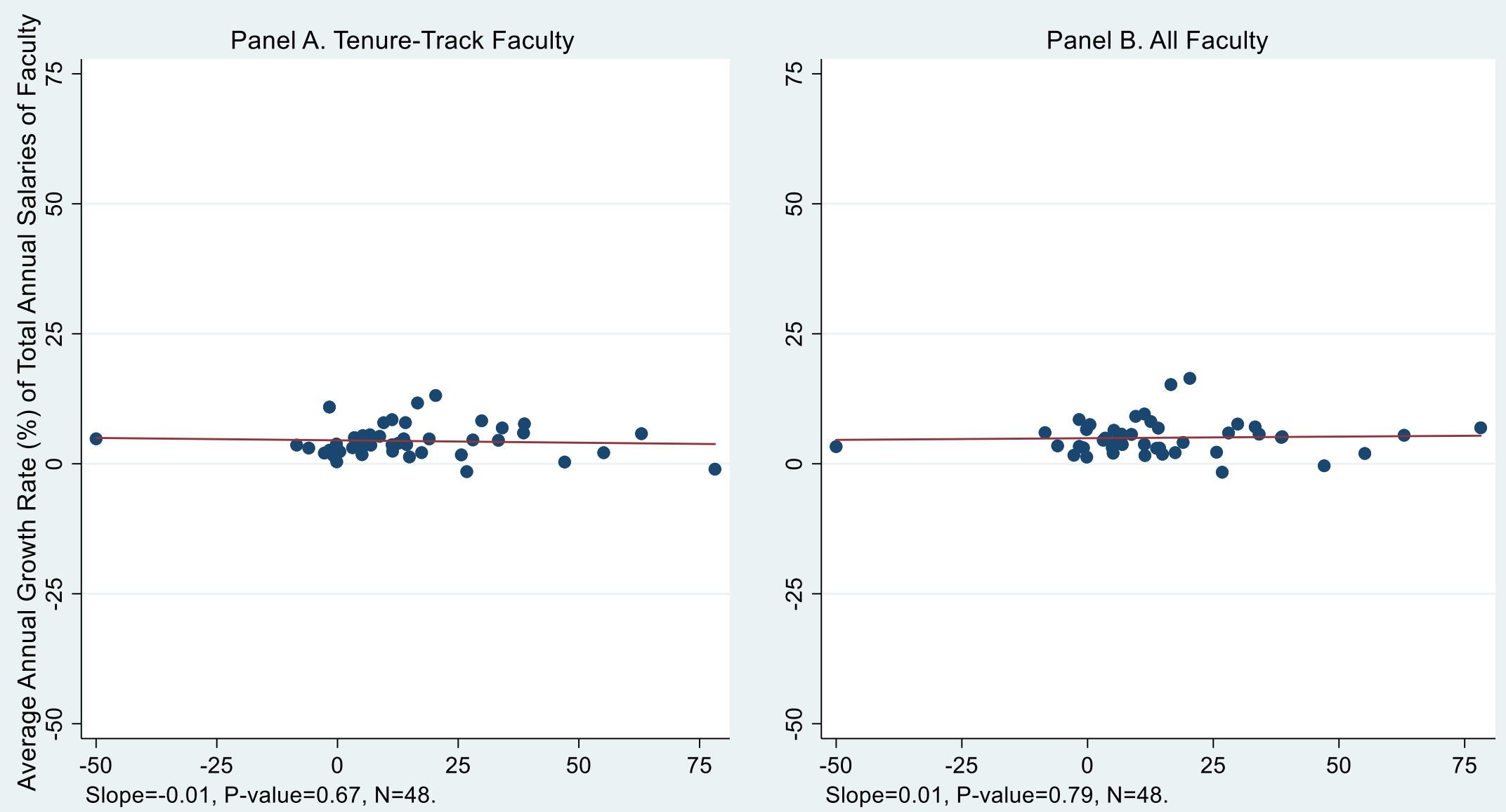

Average Annual Growth Rate (\%) of Number of Freshmen 
Appendix Figure D.5. Relationships between the Cumulative Growths in Freshman Enrollment and Faculty Size between Two Periods, with Faculty Population Weighting.
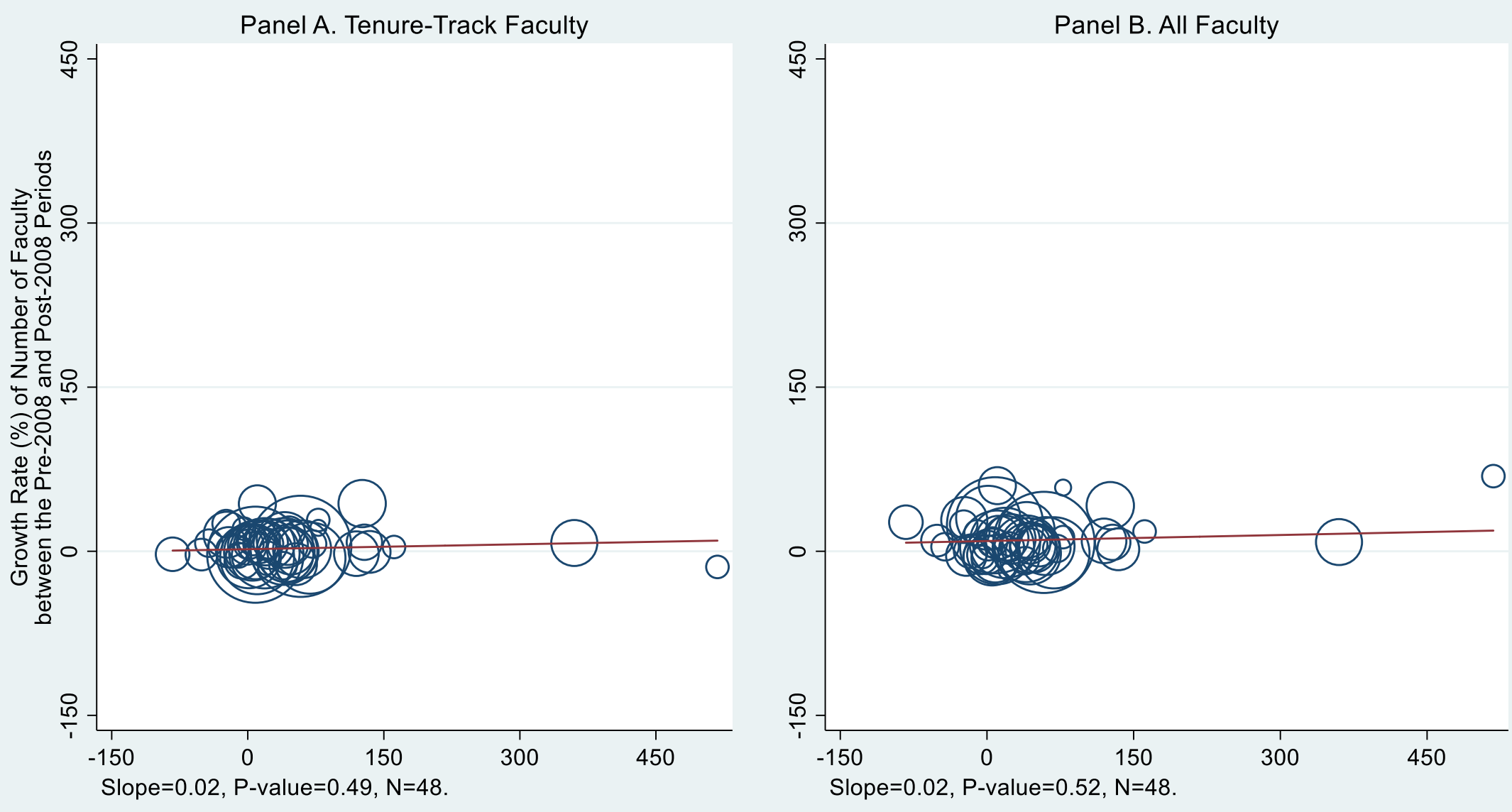

Growth Rate (\%) of Number of Freshmen between the Pre-2008 and Post-2008 Periods

Notes: Faculty population weighting is such that all academic departments receive a weight equal to the number of tenure-track faculty in that department and 2004/05 academic year, i.e., the first year of my data panel. 
Appendix Figure D.6. Relationships between the Cumulative Growths in Freshman Enrollment and Total Salaries of Faculty between Two Periods, with Faculty Population Weighting.
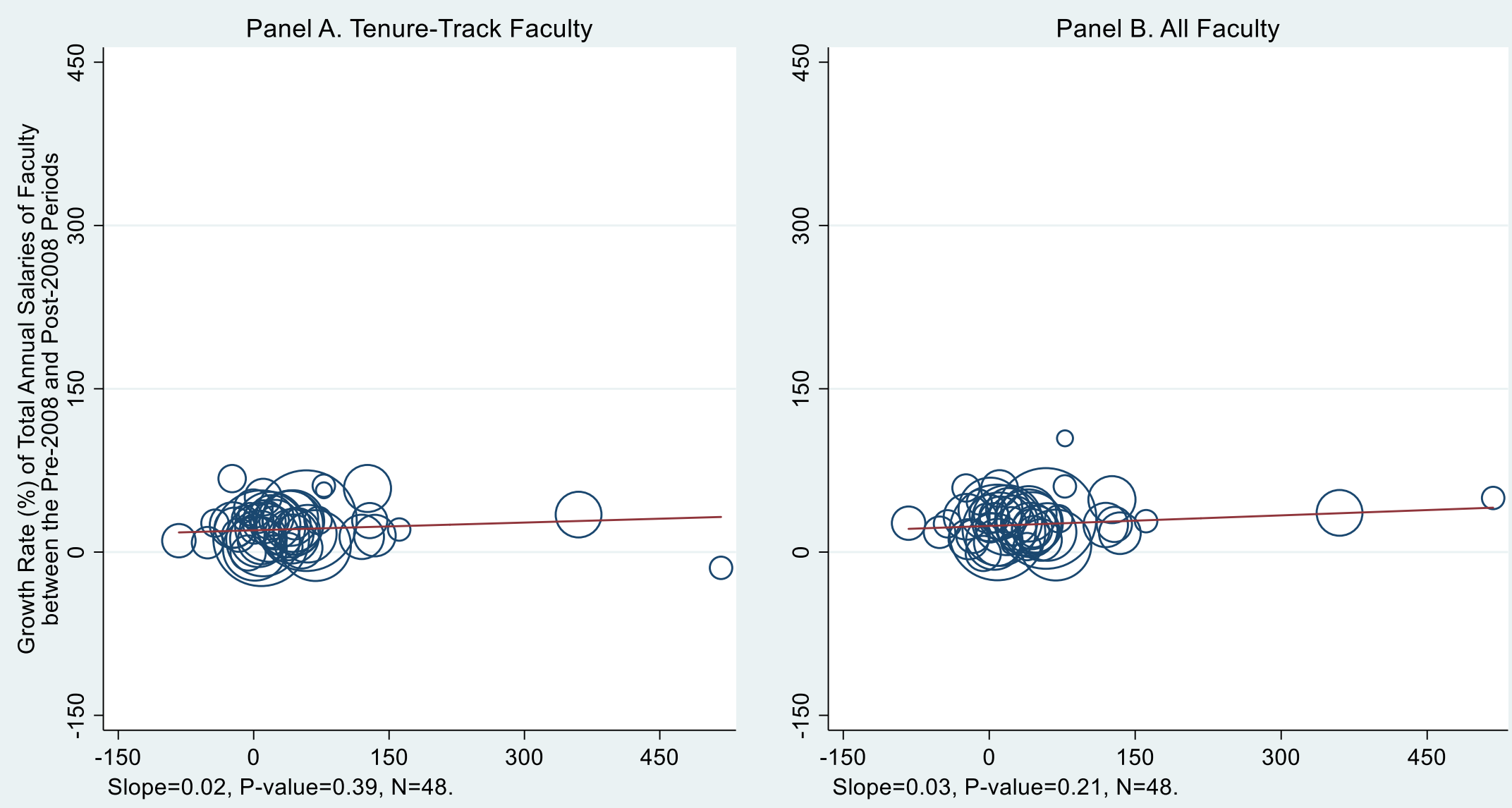

Growth Rate (\%) of Number of Freshman between the Pre-2008 and Post-2008 Periods

Notes: Faculty population weighting is such that all academic departments receive a weight equal to the number of tenure-track faculty in that department and 2004/05 academic year, i.e., the first year of my data panel. 
Appendix Table D.1. Summary Statistics for Regression Analyses.

\begin{tabular}{lc}
\hline Variable & Mean (SD) \\
Panel A. & \\
Number of Freshmen & $96.42(209.21)$ \\
Number of Tenure-Track Faculty & $18.24(16.77)$ \\
Number of All Faculty & $28.21(27.79)$ \\
Total Annual Salaries of Tenure-Track Faculty (Million Dollars) & $1.62(1.70)$ \\
Total Annual Salaries of All Faculty (Million Dollars) & $2.11(2.26)$ \\
N & 528 \\
\hline Panel B. & $14.32(20.46)$ \\
Average Annual Growth Rate of Freshman Enrollment (Percentage) & $1.62(2.95)$ \\
Average Annual Growth Rate of Tenure-Track Faculty (Percentage) & $2.88(4.03)$ \\
Average Annual Growth Rate of All Faculty (Percentage) & $4.38(2.99)$ \\
Average Annual Growth Rate of Tenure-Track Faculty Salaries (Percentage) & $5.00(3.30)$ \\
Average Annual Growth Rate of All Faculty Salaries (Percentage) & \\
N & 48 \\
\hline
\end{tabular}


Appendix Table D.2. Output from Regressions of Faculty Resources on Number of Bachelor's Degrees Conferred.

\begin{tabular}{|c|c|c|c|c|c|c|c|}
\hline \multirow[b]{2}{*}{ Number of Degrees Conferred } & $\begin{array}{l}\text { Number of Tenure- } \\
\text { Track Faculty }\end{array}$ & \multicolumn{2}{|c|}{$\begin{array}{l}\text { Number of All } \\
\text { Faculty }\end{array}$} & \multicolumn{2}{|c|}{$\begin{array}{c}\text { Total Annual Salaries of } \\
\text { Tenure-Track Faculty }\end{array}$} & \multicolumn{2}{|c|}{$\begin{array}{c}\text { Total Annual Salaries of } \\
\text { All Faculty }\end{array}$} \\
\hline & $0.05 * *$ & $0.13 * *$ & $0.12 * *$ & $5620.09 * *$ & $5159.63 * *$ & $10224.16^{* *}$ & $9118.88 * *$ \\
\hline & $(0.02)$ & $(0.03)$ & $(0.04)$ & (1189.25) & (1739.99) & (1853.50) & (1952.56) \\
\hline
\end{tabular}

\begin{tabular}{|c|c|c|c|c|c|c|c|c|}
\hline Faculty Population Weights & & $\mathrm{X}$ & & $X$ & & $\mathrm{X}$ & & $\mathrm{X}$ \\
\hline Year Fixed Effects & $\mathrm{X}$ & $X$ & $\mathrm{X}$ & $X$ & $\mathrm{X}$ & $X$ & $\mathrm{X}$ & $\mathrm{X}$ \\
\hline R-squared & 0.27 & 0.20 & 0.47 & 0.40 & 0.41 & 0.34 & 0.56 & 0.52 \\
\hline $\mathrm{N}$ & 594 & 594 & 594 & 594 & 594 & 594 & 594 & 594 \\
\hline
\end{tabular}

Notes: Faculty population weighting is such that all academic departments receive a weight equal to the number of tenure-track faculty in that department and 2004/05 academic year, i.e., the first year of my data panel. Robust standard errors in parentheses are clustered at the major level. Significance levels: ** 5 percent level, * 10 percent level. 


\section{BIBLIOGRAPHY}

Abraham, Katharine G. and Melissa A. Clark. 2006. Financial Aid and Students' College Decisions Evidence from The District of Columbia Tuition Assistance Grant Program.

Journal of Human Resources, 41(3), 578-610.

Anderson, Nick and Danielle Douglas-Gabriel. 2016. Nation's Prominent Public Universities Are Shifting to Out-of-State Students. The Washington Post. Retrieved on 08.30.2017 from URL:

https://www.washingtonpost.com/local/education/nations-prominent-public-universitiesare-shifting-to-out-of-state-students/2016/01/30/07575790-beaf-11e5-bcda62a36b394160_story.html?utm_term=.bf2210e44c11.

Anelli, Massimo, Kevin Y. Shih and Kevin M. Williams. 2017. Foreign Peer Effects and STEM Major Choice. Working Paper.

Arcidiacono, Peter and Cory Koedel. 2014. Race and College Success: Evidence from Missouri. American Economic Journal: Applied Economics, 6(3), 20-57.

Bayard, Kimberly, Judith Hellerstein, David Neumark and Kenneth Troske. 1999. New Evidence on Sex Segregation and Sex Differences in Wages from Matched EmployeeEmployer Data. NBER Working Paper No. 7003.

Bellows, Kate. 2017. Out-of-State Admissions, Financial Aid under Debate at General Assembly. The Cavalier Daily. Retrieved on 08.30.2017 from URL:

http://www.cavalierdaily.com/article/2017/01/out-of-state-admissions-financial-aidunder-debate-at-general-assembly.

Bettinger, Eric P. and Bridget Terry Long. 2005. Do Faculty Serve as Role Models? The Impact of Instructor Gender on Female Students. American Economic Review P\&P 95(2), 152-157.

Betts, Julian R., and Darlene Morrell. 1999. The Determinants of Undergraduate Grade Point Average: The Relative Importance of Family Background, High School Resources, and Peer Group Effects. Journal of Human Resources, 34(2), 268-293.

Betts, Julian R., and Robert W. Fairlie. 2003. Does Immigration Induce 'Native Flight' from Public Schools into Private Schools? Journal of Public Economics, 87(5), 9871012.

Betts, Julian. 1998. Educational Crowding out: Do Immigrants Affect the Educational Attainment of American Minorities? in Help of Hindrance? The Economic Implications of Immigration for African-Americans, 253-281. New York: Russell Sage Foundation. 
Bird, Kelli and Sarah Turner. 2014. College in the States: Foreign Student Demand and Higher Education Supply in the US. EdPolicyWorks Working Paper Series No. 23, University of Virginia.

Bollinger, Christopher R., Barry T. Hirsh, Charles M. Hokayem and James P. Ziliak. 2014. Trouble in the Tails? Earnings Non-Response and Response Bias Across the Distribution. Working Paper.

Borjas, George J. 2007. Do Foreign Students Crowd Out Native Students from Graduate Programs? in Science and the University. Madison, WI: University of Wisconsin Press.

Bound, John, and Sarah Turner. 2007. Cohort Crowding: How Resources Affect Collegiate Attainment. Journal of public Economics, 91(5), 877-899.

Bound, John, Breno Braga, Gaurav Khanna, and Sarah Turner. 2016. A Passage to America: University Funding and International Students. NBER Working Paper No. w22981.

Bound, John, Michael F. Lovenheim and Sarah Turner. 2010. Why Have College Completion Rates Declined? An Analysis of Changing Student Preparation and Collegiate Resources. American Economic Journal: Applied Economics, 2(3), 129-157.

Bound, John, Sarah Turner and Patrick Walsh. 2009. Internationalization of U.S. Doctorate Education, in Science and Engineering Careers in the United States: An Analysis of Markets and Employment. Chicago, IL: Chicago University Press. Burd, Stephen. 2015. The Out-of-State Student Arms Race. New America. Retrieved on 08.30.2017 from URL: https://www.newamerica.org/education-policy/policy-papers/outof-state-student-arms-race/.

Butcher, Kristin F., Patrick J. McEwan, and Akila Weerapana. 2014. The Effects of an Anti-Grade-Inflation Policy at Wellesley College. Journal of Economic Perspectives 28(3), 189-204.

Calcagno, Juan Carlos, Thomas Bailey, Davis Jenkins, Gregory Kienzi and Timothy Leinbach. 2008. Community College Student Success: What Institutional Characteristics Make a Difference? Economics of Education Review, 27(6), 632-645.

Card, David and Alan B. Krueger. 1996. School Resources and Student Outcomes: An Overview of the Literature and New Evidence from North and South Carolina. Journal of Economics Perspectives, 10(4), 31-50.

Card, David, and John DiNardo. 2000. Do Immigrant Inflows Lead to Native Outflows? American Economic Review, 90(2), 360-367.

Card, David. 2001. Immigrant Inflows, Native Outflows, and the Local Labor Market Impacts of Higher Immigration. Journal of Labor Economics, 19(1), 22-64. 
Carnevale, Anthony P., Megan L. Fasules, Andrea Porter and Jennifer Landis-Santos. 2016. African Americans: College Majors and Earnings. Policy Report. Center on Education and the Workforce: Georgetown University.

Carrell, Scott E., Marianne E. Page, and James E. West. 2010. Sex and science: How professor gender perpetuates the gender gap. The Quarterly Journal of Economics, 125(3), $1101-1144$.

Ceci, Stephen J., Donna K. Ginther, Shulamit Kahn, and Wendy M. Williams. 2014. Women in Academic Science: A Changing Landscape. Psychological Science in the Public Interest 15(3), 75-141.

Cherng, Hua-Yu Sebastian and Peter F. Halpin. 2016. The Importance of Minority Teachers: Student Perceptions of Minority Versus White Teachers. Educational Researcher 45(7), 407-420.

Cohodes, Sarah R and Joshua S. Goodman. 2014. Merit Aid, College Quality, and College Completion: Massachusetts' Adams Scholarship as an In-Kind Subsidy. American Economic Journal: Applied Economics, 6(4), 251-285.

Cooke, Thomas J., and Paul Boyle. 2011. The Migration of High School Graduates to College. Educational Evaluation and Policy Analysis, 33(2), 202-213.

Coudriet, Cater. 2016. Should U.S. Public Colleges Accept More International Students, Or Not? Forbes. Retrieved on 08.30.2017 from URL: https://www.forbes.com/sites/cartercoudriet/2016/11/11/should-u-s-public-collegesaccept-more-international-students-or-not/\#20aa2dc61ce4.

Cullen, Julie Berry, Brian A. Jacob and Steven Levitt. 2006. The Effect of School Choice on Participants: Evidence from Randomized Lotteries. Econometrica, 74(5), 1191-1230.

Curs, Bradley R., and Ozan Jaquette. 2017. Crowded Out? The Effect of Nonresident Enrollment on Resident Access to Public Research Universities. Educational Evaluation and Policy Analysis, 39(4), 644-669.

Dee, Thomas S. 2004. Teachers, Race, and Student Achievement in a Randomized Experiment. Review of Economics and Statistics 86(1), 195-2010.

Department of Homeland Security. 2016. STEM Designated Degree Program List. Retrieved on 08.30.2017 from URL: https://www.ice.gov/sites/default/files/documents/Document/2016/stem-list.pdf.

Education Advisory Board. 2014. Optimizing Institutional Budget Models. Retrieved on 02.07.2019 from URL: https://www.eab.com/-/media/EAB/Research-and-

Insights/AAF/Studies/2014/Optimizing-Institutional-Budget-

Models/29224_AABAF_Budget\%20Models_final.pdf. 
Ehrenberg, Ronald G. and Liang Zhang. 2005. Do Tenured and Tenure-Track Faculty Matter? Journal of Human Resources, 40(3), 647-659.

Ellis, Jimmy R., and Seth Gershenson. 2016. LATE for the Meeting: Gender, Peer Advising, and College Success. IZA Discussion Paper No. 9956.

Fairlie, Robert W., Florian Hoffmann, and Philip Oreopoulos. 2014. A Community College Instructor Like Me: Race and Ethnicity Interactions in the Classroom. The American Economic Review, 1049(8), 2567-2591

Figlio, David N, and Umut Ozek. 2017. Unwelcome Guests? The Effects of Refugees on the Educational Outcomes of Incumbent Students. NBER Working Paper No. w23661.

Figlio, David N., Morton O. Schapiro and Kevin B Scoter. 2015. Are Tenure Track Professors Better Teachers? The Review of Economics and Statistics, 97(4), 715-724.

Freeman, Richard B. 1977. The New Job Market for Black Academicians. Industrial and Labor Relations Review 30(2), 161-174.

Garcia-Navarro, Lulu. 2016. For Affirmative Action, Brazil Sets Up Controversial Boards to Determine Race. NPR Parallels. Retrieved on 09.29.2016 from URL:

Gelbach, Jonah B. 2016. When Do Covariates Matter? And Which Ones, and How Much? Journal of Labor Economics 34(2), 509-543.

Gershenson, Seth, Stephen B. Holt and Nicholas Papageorge. 2016. Who Believes in Me? The Effect of Student-Teacher Demographic Match on Teachers' Beliefs. Economics of Education Review 52, 209-224.

Ginther, Donna K. and Kathy J. Hayes. 2003. Gender Differences in Salary and Promotion for Faculty in the Humanities, 1977-95. Journal of Human Resources 38(1), 34-73.

Ginther, Donna K. and Shulamit Kahn (forthcoming). Education and Academic Career Outcomes for Women of Color in Science and Engineering, in Seeking Solutions: Maximizing American Talent by Advancing Women of Color in Academia: A Conference Report. Washington DC: National Academy Press.

Ginther, Donna K., Walter T. Schaffer, Joshua Schnell, Beth Masimore, Faye Liu, Laurel L. Haak, and Raynard Kington. 2010. Diversity in Academic Biomedicine: An Evaluation of Education and Career Outcomes with Implications for Policy. Working Paper.

Glover, Denise, Basmat Parsad and Linda J. Zimbler. 2002. The Gender and Racial/Ethnic Composition of Postsecondary Instructional Faculty and Staff, 1992-1998. United States Department of Education, National Center for Education Statistics. 
Grissom, Jason A., Emily C. Kern and Luis A. Rodriguez. 2015. The "Representative Bureaucracy" in Education: Educator Workforce Diversity, Policy Outputs, and Outcomes for Disadvantaged Students. Educational Researcher 44(3), 185-192.

Grissom, Jason A., Luis A. Rodriguez, and Emily C. Kern. 2017. Teacher and Principal Diversity and the Representation of Students of Color in Gifted Programs: Evidence from National Data. Elementary School Journal 117(3), 396-422.

Groen, Jeffrey A., and Michelle J. White. 2004. In-State versus Out-of-State Students: The Divergence of Interest between Public Universities and State Governments. Journal of Public Economics, 88(9), 1793-1814.

Guarino, Cassandra M. and Victor M. Borden (forthcoming). Faculty Service Loads and Gender: Are Women Taking Care of the Academic Family? Research in Higher Education.

Hanushek, Eric A. 1997. Assessing the Effects of School Resources on Student Performance: An Update. Educational Evaluation and Policy Analysis, 19(2), 141-164.

Hoxby, Caroline M. 1997. How the Changing Market Structure of US Higher Education Explains College Tuition. NBER Working Paper No. w6323. http://www.npr.org/sections/parallels/2016/09/29/495665329/for-affirmative-actionbrazil-sets-up-controversial-boards-to-determine-race.

Huguelet, Austin. 2017. Greitens' Alternative to Raising Tuition Doesn't Fit Missouri Model. St. Louis Post-Dispatch. Retrieved on 08.30.2017 from URL: http://www.stltoday.com/news/local/education/greitens-alternative-to-raising-tuitiondoesn-t-fit-missouri-model/article_4ba8a6cc-e597-5aeb-8b11-c34c0e7558c8.html.

Jacoby, Daniel. 2006. Effects of Part-Time Faculty Employment on Community College Graduation Rates. The Journal of Higher Education, 77(6), 1081-1103.

Jaquette, Ozan, and Bradley R. Curs. 2015. Creating the Out-of-State University: Do Public Universities Increase Nonresident Freshman Enrollment in Response to Declining State Appropriations? Research in Higher Education, 56(6), 535-565.

Jaquette, Ozan, Bradley R. Curs, and Julie R. Posselt. 2016. Tuition Rich, Mission Poor: Nonresident Enrollment Growth and the Socioeconomic and Racial Composition of Public Research Universities. The Journal of Higher Education, 87(5), 635-673.

Kato, Takao and Chad Sparber. 2013. Quotas and Quality: The Effect of H-1B Visa Restrictions on the Pool of Prospective Undergraduate Students from Abroad. Review of Economics and Statistics, 95(1), 109-126.

Koedel, Cory, Jiaxi Li, Matthew G. Springer and Li Tan. 2017. The Impact of Performance Ratings on Job Satisfaction for Public School Teachers. American Educational Research Journal, 54(2), 241-278. 
Koedel, Cory. 2011. Grading Standards in Education Departments at Universities. Education Policy Analysis Archives 19(23), 1-23.

Li, Diyi. 2018. The Effect of Non-Resident Enrollment Growth on In-State College Students. Working Paper.

Light, Audrey and Wayne Strayer. 2000. Determinants of College Completion: School Quality or Student Ability? The Journal of Human Resources, 35(2), 299-332.

Loeb, Susanna, Pamela Morris, Susan Dynarski, Sean Reardon, Daniel McFarland and Sarah Reber. 2017. Descriptive Analysis in Education: A Guide for Researchers. NCEE 2017-4023. National Center for Education Evaluation and Regional Assistance.

Loudenback, Tanza. 2016 International Students Are Now 'Subsidizing' Public American Universities to the Tune of \$9 Billion A Year. Business Insider. Retrieved on 08.30.2017 from URL:

http://www.businessinsider.com/foreign-students-pay-up-to-three-times-as-much-fortuition-at-us-public-colleges-2016-9.

Machin, Stephen and Richard Murphy. 2014. Paying out and Crowding out? The Globalisation of Higher Education. Working Paper.

Menges, Robert J., and William H. Exum. 1983. Barriers to the Progress of Women and Minority Faculty. Journal of Higher Education 54(2), 123-144.

Missouri Department of Higher Education. 2017. Rules of Department of Higher Education, 6 CSR 10-3.010. Retrieved on 08.30.2017 from URL: http://www.sos.mo.gov/cmsimages/adrules/csr/current/6csr/6c10-3.pdf.

Missouri Department of Higher Education. 2018. State of Missouri Performance Funding for Higher Education. Retrieved on 02.07.2019 from URL: https://dhe.mo.gov/documents/performancefunding2018.pdf.

MU International Center. 2016. Open Doors Mizzou: Fast Facts. Retrieved on 08.30.2017 from URL: https://international.missouri.edu/documents/open-doors-mizzou-fastfacts.pdf.

National Science Board. 2014. Science and Engineering Indicators 2014. Arlington, VA: National Science Foundation (NSB 14-01).

National Science Board. 2016. 2016 Science \& Engineering Indicators. Arlington, VA: National Science Foundation.

Nelson, Donna J. and Christopher N. Brammer. 2010. A National Analysis of Minorities in Science and Engineering Faculties at Research Universities, Second Edition. Unpublished Policy Report. 
Olsen, Deborah, Sue A. Maple and Frances K. Stage. 1995. Women and Minority Faculty Job Satisfaction: Professional Role Interests, Professional Satisfactions, and Institutional Fit. Journal of Higher Education 66(3), 267-293.

Peri, Giovanni, Kevin Shih and Chad Sparber. 2015. STEM Workers, H-1B Visas, and Productivity in US Cities. Journal of Labor Economics, 33(3), 225-255.

Perry, Motty and Philip J. Reny. 2016. How to Count Citations if You Must. American Economic Review 106(9), 2722-2741.

Porter, Stephen R. 2007. A Closer Look at Faculty Service: What Affects Participation on Committees? Journal of Higher Education 78(5), 523-41.

Porter, Stephen R., Robert K. Toutkoushian, and John V. Moore III. 2008. Pay Inequities for Recently Hired Faculty, 1988-2004. The Review of Higher Education 31(4), 465-487.

Powell, Farran. 2016. Out-of-State Enrollment Rises at State Flagship Universities. U.S. News \& World Report. Retrieved on 08.30.2017 from URL:

https://www.usnews.com/education/best-colleges/articles/2016-06-13/out-of-stateenrollment-rises-at-state-flagship-universities.

Rizzo, Michael, and Ronald G. Ehrenberg. 2004. Resident and Nonresident Tuition and Enrollment at Flagship State Universities, in College Choices: The Economics of Where to Go, When to Go, and How to Pay for It. Chicago, IL: University of Chicago Press.

Robst, John, Jack Keil and Dean Russo. 1998. The Effect of Gender Composition of Faculty on Student Retention. Economics of Education Review 17(4), 429-439.

Rosenzweig, Mark R. 2006. Global Wage Differences and International Student Flows, in Brookings Trade Forum. Washington DC: Brookings Institution Press.

Scott, Marc, Thomas Bailey and Greg Kienzi. 2006. Relative Success? Determinants of College Graduation Rates in Public and Private Colleges in the U.S. Research in Higher Education, 47(3), 249-279.

Shen, Ying. 2016. The Impacts of the Influx of New Foreign Undergraduate STUDENTS ON U.S. Higher Education. Working Paper.

Shih, Kevin Y. 2015. Do International Students Crowd-Out or Cross-Subsidize Americans in Higher Education? Working Paper.

Shih, Kevin Y. 2016. Labor Market Openness, H-1B Visa Policy, and the Scale of International Student Enrollment in the U.S. Economic Inquiry, 54(1), 121-138. 
Stock, James H and Motohiro Yogo. 2005. Testing for Weak Instruments in Linear IV Regression, in Identification and Inference for Econometric Models. New York, NY: Cambridge University Press.

Toutkoushian, Robert K., and Emily Hoffman. 2002. Alternatives for measuring the unexplained wage gap. In: Toutkoushian R. (ed.), Conducting Salary-Equity Studies: Alternative Approaches to Research. New Directions for Institutional Research No. 115, Jossey-Bass, San Francisco, pp. 71-89.

Toutkoushian, Robert K., Marcia L. Bellas and John V. Moore. 2007. The Interaction Effects of Gender, Race, and Marital Status on Faculty Salaries. The Journal of Higher Education 78(5), 572-601.

University of Missouri System. 2018. Fiscal Year 2018 Budget. Retrieved on 02.07.2019 from URL: https://www.umsystem.edu/media/fa/budget/FY2018_Budget_Book.pdf.

Watanabi, Teresa. 2017. UC Proposes Its First Enrollment Cap - 20\% — on Out-ofState Students. Los Angeles Times. Retrieved on 08.30.2017 from URL: http://www.latimes.com/local/lanow/la-me-ln-uc-limit-nonresident-students-20170306story.html.

Western Interstate Commission for Higher Education. 2016. Knocking at the College Door: Projections of High School Graduates. Retrieved on 08.30.2017 from URL: www.wiche.edu/knocking.

Zhang, Liang. 2009. Does State Funding Affect Graduation Rates at Public Four-Year Colleges and Universities? Educational Policy, 23(5), 714-731. 
Diyi $\mathrm{Li}$ (born November 21, 1988) is a $\mathrm{PhD}$ candidate in Economics at the University of Missouri-Columbia. He wants to be known as a person who loves his family and friends and works hard everyday to be the best he can be.

The son of retired People's Liberation Army officers Daoming Li and Xiangrong Zheng, Diyi Li was born and raised in the greatest city in the world, Beijing, China. His parents guided him to develop a variety of different hobbies at an early age, in particular soccer. To date, his favorite soccer team is Beijing Guoan, also known as The Imperial Guards. Although his parents strongly preferred him to learn playing piano, among other music skills, he was rarely interested as he dreamed to be a professional soccer player. Most importantly, his parents put in great efforts to raise him in the right way, with a whole lot of love, which he began to appreciate as he grew older.

After cruising through the first six grades, he enrolled into one of the best middle schools in the city between 2001 and 2004, i.e., Beijing Sanfan Middle School. Struggling mightily on school work, he started from the bottom in his class and slowly worked his way straight up to... about the middle. More importantly, he made some of his best friends for life in middle school and he also developed a new interest in movies and hip-hop music. He loves Hollywood blockbuster movies such as Star Wars as well as independent movies. After he finally realized he couldn't become a professional soccer player, he started dreaming about being a movie director, which of course never comes true either. Nonetheless, he thoroughly enjoyed his time with so many great movies and also Eminem, though he did not understand his lyrics at all. 
Diyi did not peak in high school, rather he spent three unforgettable years (20042007) with his friends at The Second High School Attached to Beijing Normal University. Some of the knowledge and skills he picked up in high school math courses greatly contributed to his success in his $\mathrm{PhD}$ qualifying and comprehensive exams, which speaks volume for his lack of progress in college.

After performing poorly in his college entrance exams, he enrolled in Renmin University of China, where he majored in Environmental Economics and Administration from fall 2007 to 2011(this is a REAL major). He gained weight and lost his way initially, before he continued to gain more weight but began working hard to prepare for applying for graduate programs in Economics, the academic field that he was told by his high school Chinese teacher that he was going to be good at. He also made a few more friends in college and spent large amount of spare time on further exploring the city of Beijing.

In 2011, Diyi was offered a scholarship to enroll in the Master program of Economics at Baylor University, located in Waco, Texas. The sudden transition from living in Beijing to Waco was difficult at first, especially given that he severely injured his left ankle when playing soccer three weeks prior to departure for the U.S. The injury made him unfit for competitive soccer, yet it opened a door for him to another sport of "football". His favorite football team is undoubtedly the Baylor Bears, and his favorite player is Tomas Edward Patrick Brady Jr., as known as the G.O.A.T. He crossed one item off his bucket list by flying to L.A. to watch his childhood idol Kobe Bryant scoring a lot of points in one game. He also toured various places in the state of Texas and completely fall in love with it. His current ultimate goal of life, after failing the first two, is to buy a piece of land and become a farmer in Texas. He greatly appreciates the opportunity to go to Baylor, as it was the only 
school that offered him at the time and he had a great academic advisor, Dr. Van Pham, great friends, and a great American host family, Bob and Sue Mock during his stay in Waco.

In fall 2013, he enrolled in the $\mathrm{PhD}$ program in Economics at the University of Missouri, after he was convinced this was in the best interest of his future career and that he was rejected by all ten programs he applied initially. During the first two years in the program, Diyi again struggled on school work but he eventually survived both qualifying and comprehensive exams with the help from his friends and classmates. Then he was lucky to become a student of the greatest advisor he could ever ask for, Dr. Cory Koedel, under whose supervision he quickly accumulated valuable research experience and a couple of publications. More importantly, he learned so much from Dr. Koedel from the knowledge of applied microeconomics to professionalism. With his help and support, in fall 2018 Diyi successfully landed a job offer from Mercer, the world's largest human resources consulting firm. He will soon embark on a new journey of his life in New York.

Diyi met the love of his life, Dong Ding, in Columbia, Missouri. After dating four years, they were engaged and married in fall 2018. Together they have a dog, Donut, who is a pure breed beagle. Just like her human dad, Donut loves playing ball and has serious allergy problems. The unconditional and unwavering support from his wife and his promise to his dog of a house with a big backyard are among the most important motivations for Diyi. 